TECHNICAL REPORT STANDARD TITLE PAGE

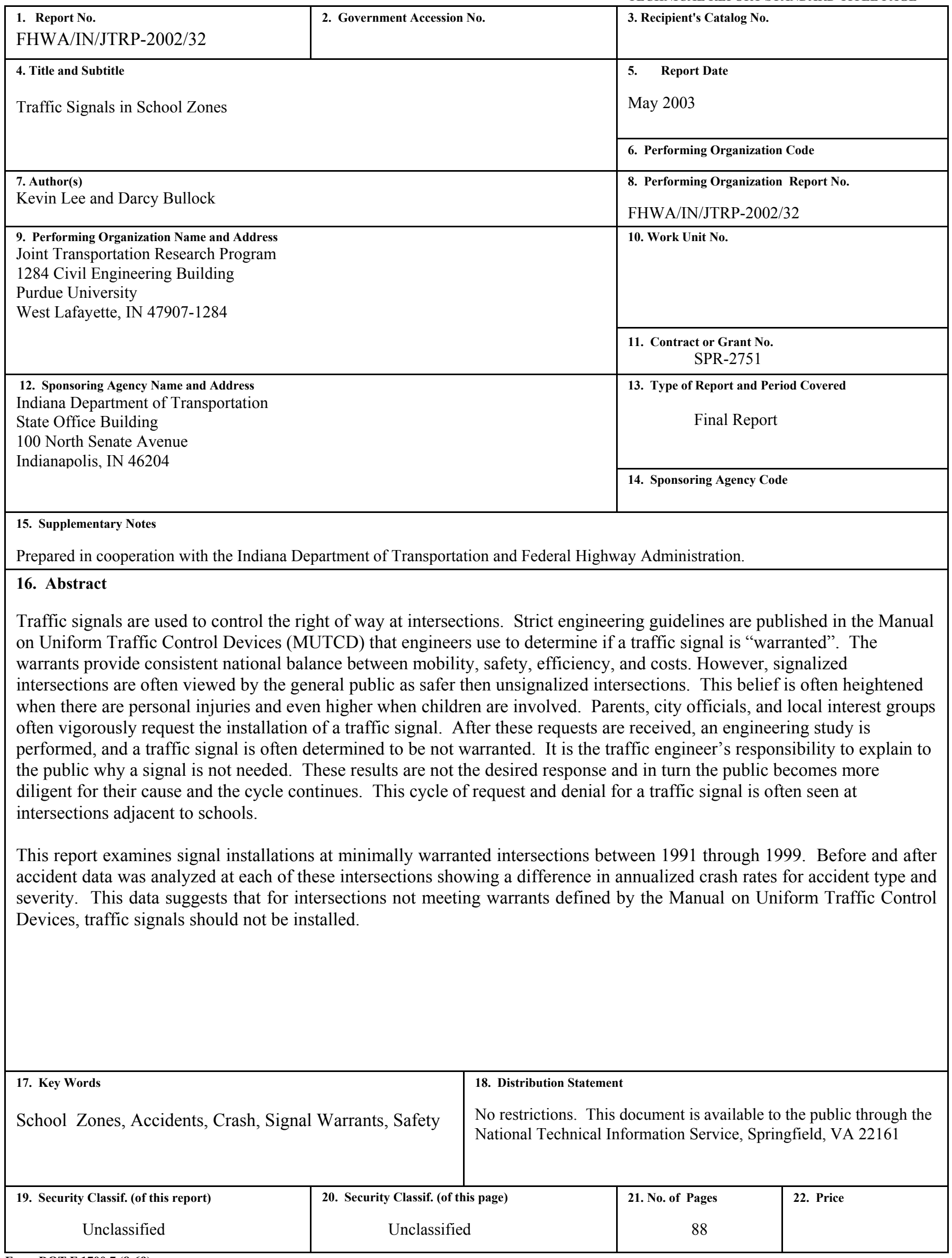

Form DOT F 1700.7 (8-69) 


\section{TECHNICAL Summary}

Technology Transfer and Project Implementation Information

INDOT Research

TRB Subject Code:54-6 Traffic Control Systems

Publication No.: FHWA/IN/JTRP-2002/32, SPR-2751

May 2003

Final Report

\section{Traffic Signals in School Zones}

\section{Introduction}

The Manual of Uniform Traffic Control Devices (http://mutcd.fhwa.dot.gov/) defines engineering guidelines to determine if a traffic signal is warranted. These guidelines are based upon decades of work by national committees that have rigorously evaluated the conditions under which a traffic signal should or should not be installed. The Indiana Department of Transportation, along with virtually all public agencies, follows these procedures defined in that document to determine if a traffic signal should be installed.

The scope of the Joint Transportation Research Program (JTRP) study at Purdue University involved reviewing before and after crash data at signals recently installed adjacent to schools to determine if there were statistically significant changes in crash rates after a traffic signal was installed at a location where the traffic signal warrants were marginally satisfied.

Due to crash database limitations, accident data was only available for the period 1991 to 1999. Signals installed during the period 1992 to 1997 were considered. The construction year was excluded from the study so that any crashes associated with the construction work zone would not bias the data. A maximum of 5 years of before data and 5 years of after data were tabulated for each intersection studied. Data was adjusted to account for changes in average daily traffic and varying number of years of before and after data. INDOT typically only evaluates crash rates within 200 ' of a signalized intersection. However, schools are a special case and school zones are often more than 200' from a signalized intersection. Consequently, this study evaluated crash rates within 200', 500' and 1000' of signalized intersections. Seven signals with 51 years of data were identified as installed adjacent to Indiana schools during the period 1992-1997. The traffic volumes at these intersections were sufficiently low that engineering guidelines (warrants) for signal installation were marginal. To augment this data, twelve additional signals not in school zones, but for which the engineering guidelines (warrants) were marginal, were used to create a second data set. That data set of 19 intersections provided 135 years of data for analysis.

\section{Findings}

Table 1 indicates that for the 7 locations where signals were installed at intersections adjacent to schools that marginally met the warrants, there were no statistically significant reductions in crashes for any of the crash categories. Furthermore, there were statistically significant increases in crash rates for the following crash categories: Rear End, Head On, Off Road, Left Turn, Total, and Property Damage Only.
Table 2 indicates that for the 19 marginally warranted signal installations, there were statistically significant reductions in Right Angle and Right Turn crashes. However, there were also statistically significant increases in crash rates for the following categories: Rear End, Head On, Off Road, Left Turn, Other, and Personal Injury. 


\section{Implementation}

The data summarized in Tables 1 and 2 do not indicate it is beneficial to install traffic signals in school zones when the warrants defined by the Manual on Uniform Traffic Control Devices have not been met. In fact, they suggest that for intersections not meeting the warrants, traffic signals should not be installed. Based upon these findings, it is recommended that the Indiana Department of Transportation continue following nationally prescribed warrants for determining when a traffic signal should be installed.

\section{Contacts}

For more information:

Prof. Darcy Bullock

Principal Investigator

School of Civil Engineering

Purdue University

West Lafayette IN 47907

Phone: (765) 494-2226

Fax: (765) 496-1105

\section{Indiana Department of Transportation}

Division of Research

1205 Montgomery Street

P.O. Box 2279

West Lafayette, IN 47906

Phone: (765) 463-1521

Fax: (765) 497-1665

\section{Purdue University}

Joint Transportation Research Program

School of Civil Engineering

West Lafayette, IN 47907-1284

Phone: (765) 494-9310

Fax: (765) 496-1105 
Table 1: Summary Of Crash Rate Changes After Signals Were Installed At 7 Intersections, Adjacent To Schools, With Marginal Warrants (using 10\% statistical significance levels).

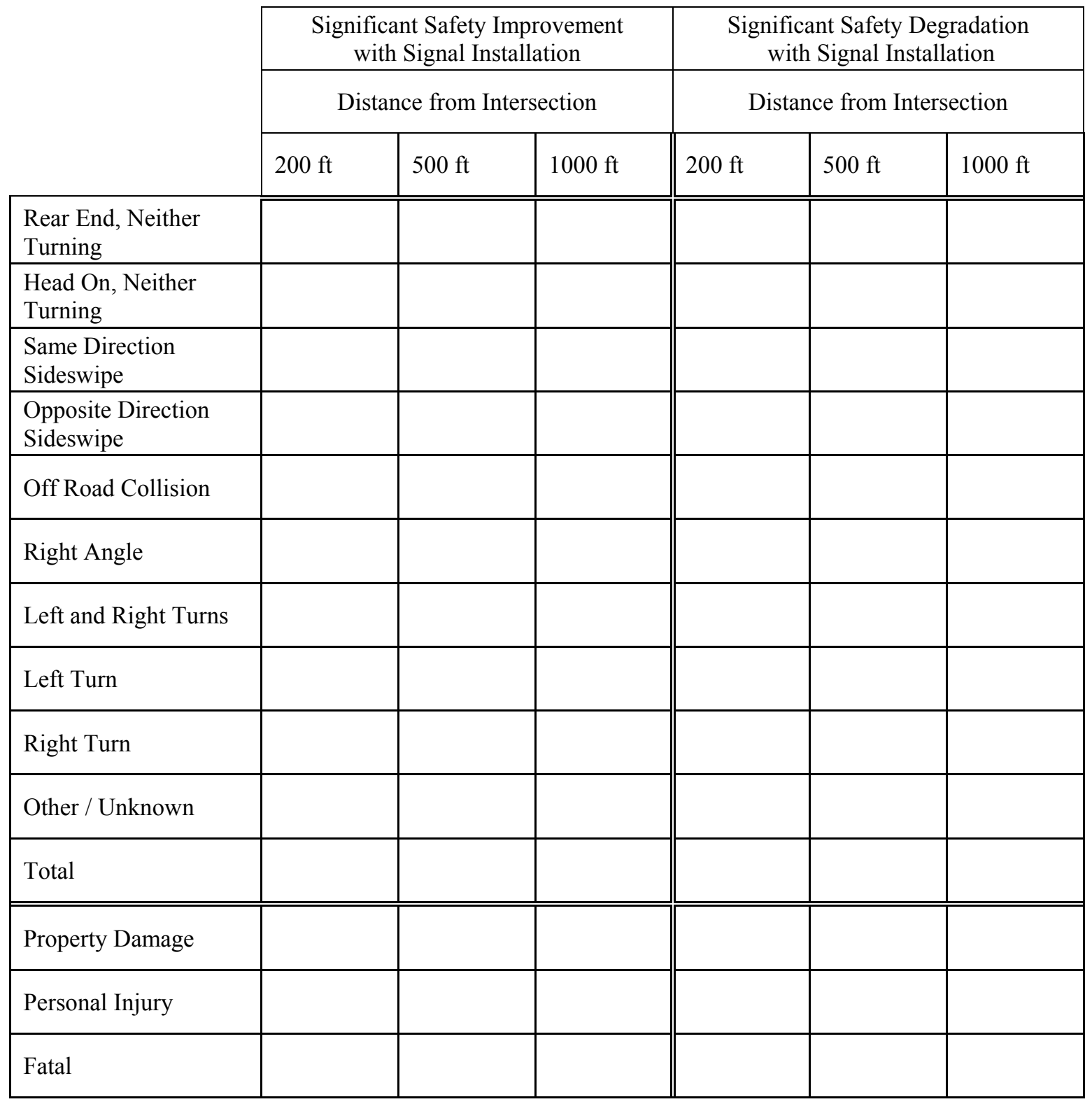


Table 2: Summary Of Crash Rate Changes After Signals Were Installed At 19 Intersections (7 Intersections Were Adjacent To Schools) With Marginal Warrants (using 10\% statistical significance levels).

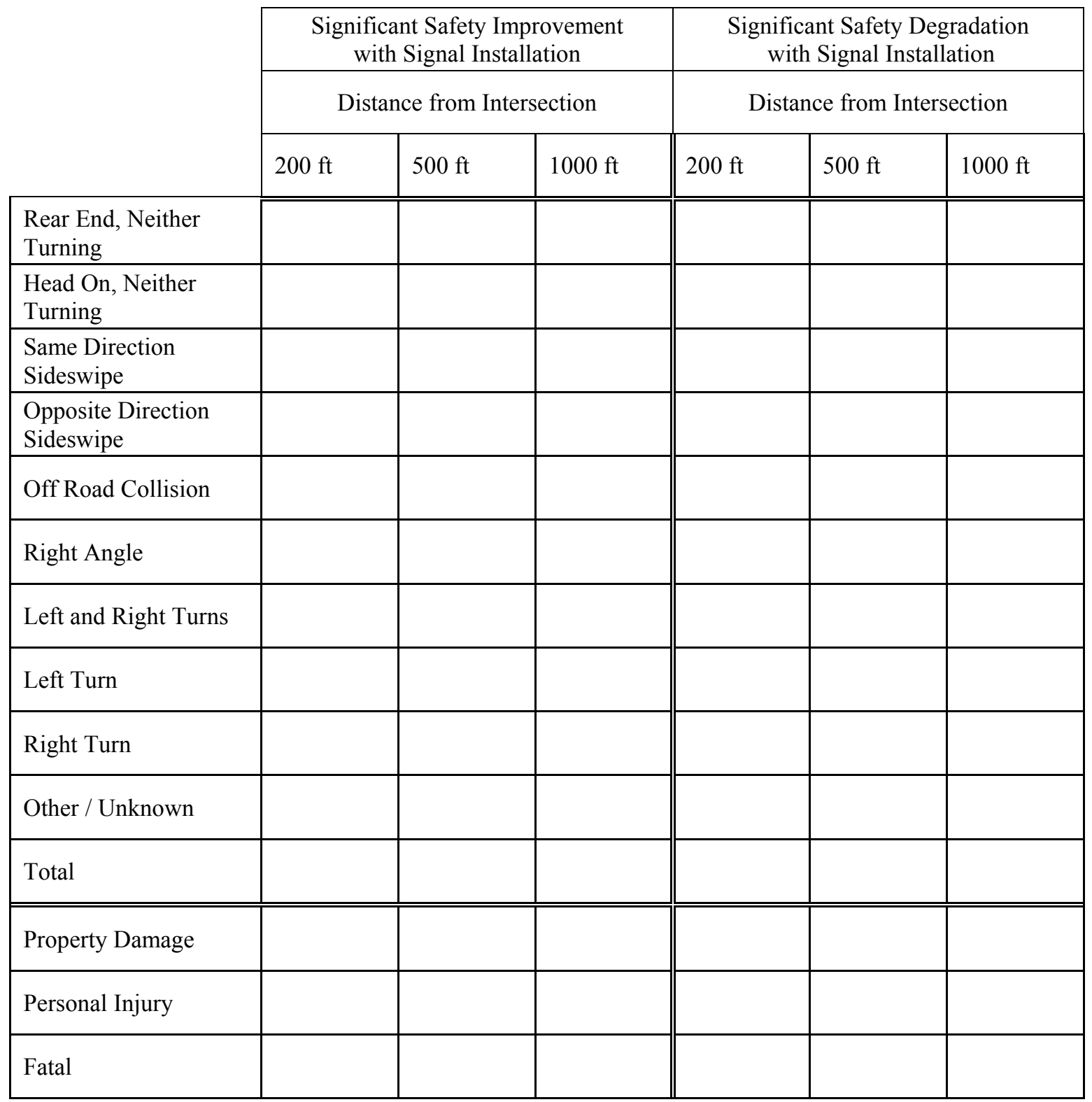


FINAL REPORT

FHWA/INDOT/JTRP-2002/32

\title{
Traffic Signals in School Zones
}

\author{
By \\ Kevin S. Lee \\ Graduate Research Assistant \\ Darcy Bullock \\ Professor of Civil Engineering \\ School of Civil Engineering \\ Purdue University
Joint Transportation Research Program
Project No: C-36-17LLL
File No: 8-4-64
SPR- 2751
Conducted in Cooperation with the
Indiana Department of Transportation
and the
U.S. Department of Transportation
Federal Highway Administration

The contents of this report reflect the views of the authors, who are responsible for the facts and the accuracy of the data presented herein. The contents do not necessarily reflect the official views or policies of the Indiana Department of Transportation or the Federal Highway

Administration at the time of publication. The report does not constitute a standard, specification, or regulation.

Purdue University

West Lafayette, IN 47907

May, 2003 
TABLE OF CONTENTS

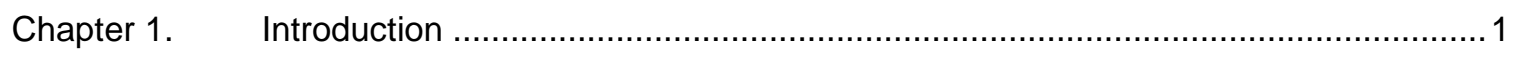

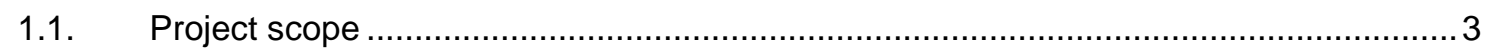

Chapter 2. Background on INDOT Procedure for Approving Signals................................... 5

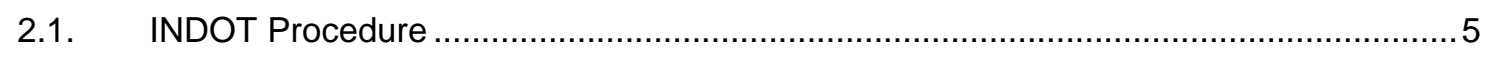

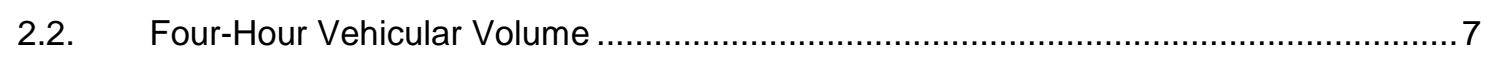

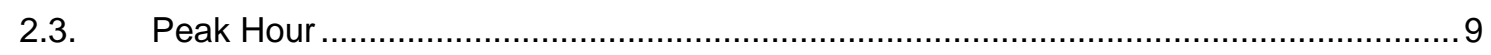

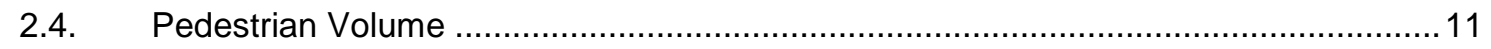

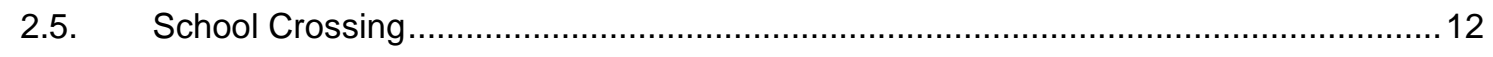

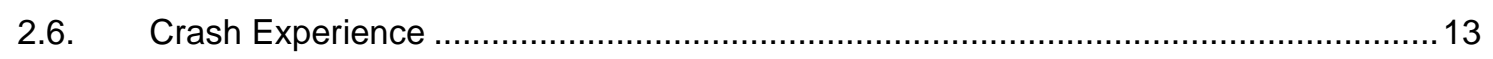

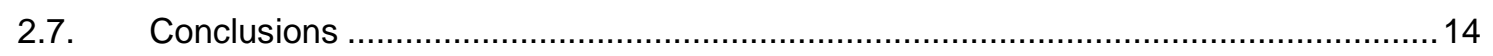

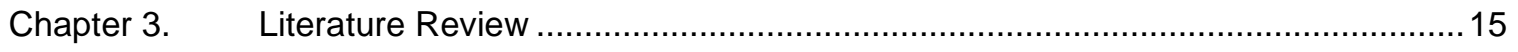

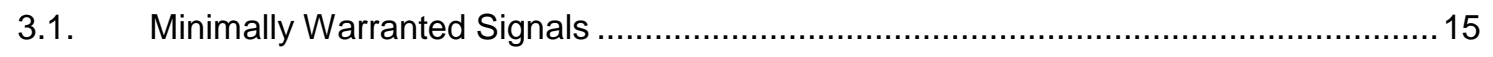

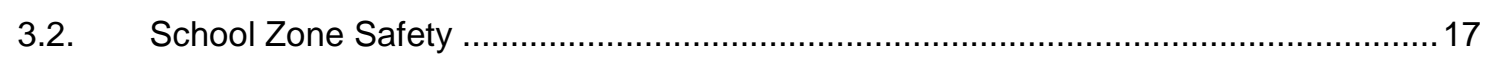

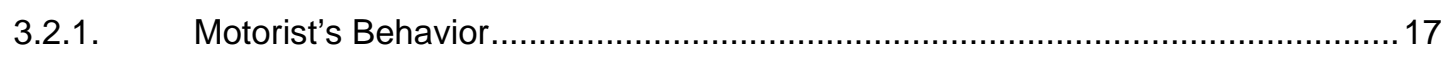

3.2.2. Effectiveness of Traffic Control Devices ...................................................... 18

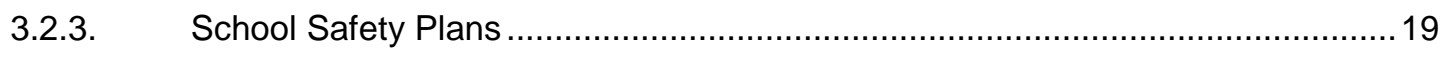

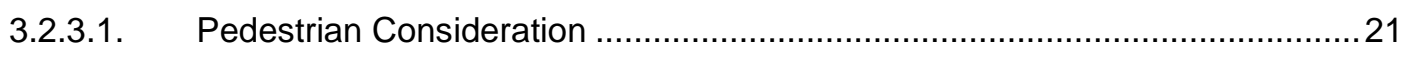

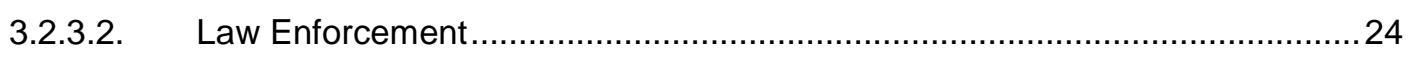

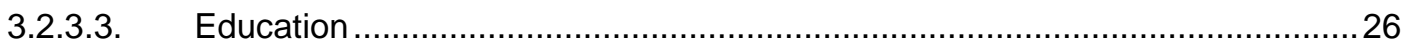

3.2.4. Application to Indiana School Zones.............................................................. 26

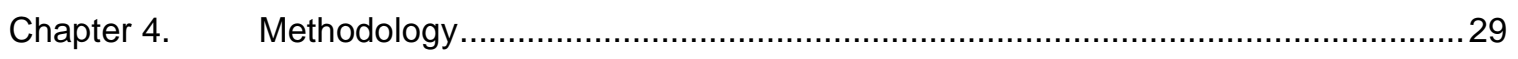

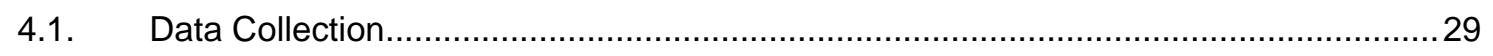

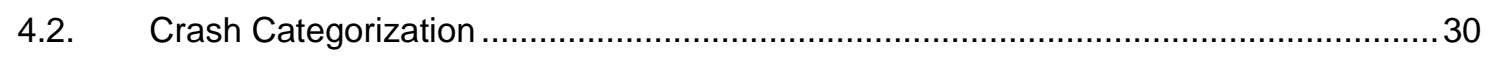

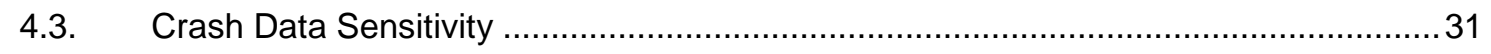

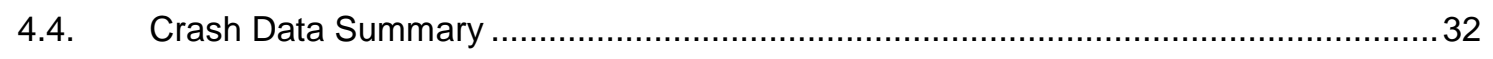

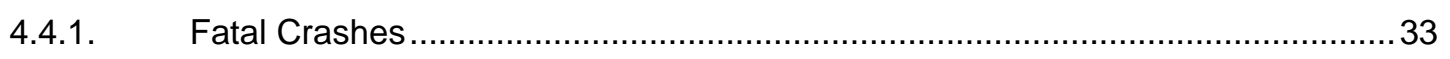

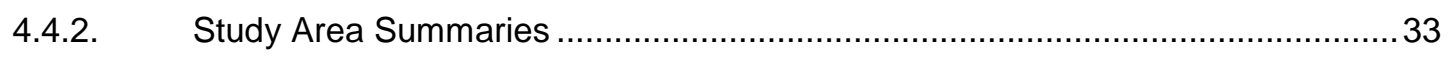

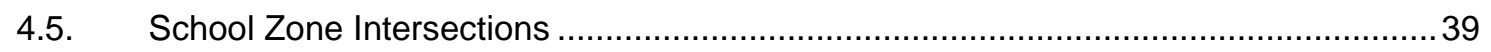




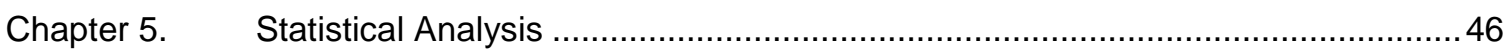

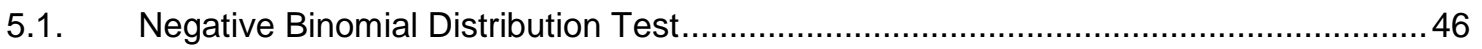

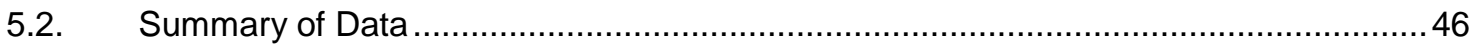

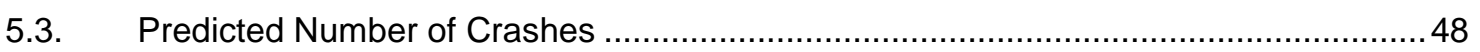

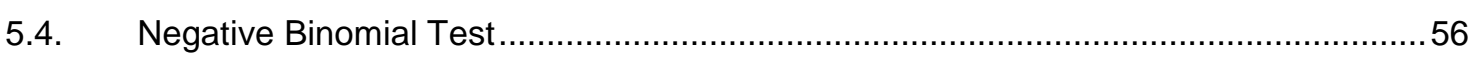

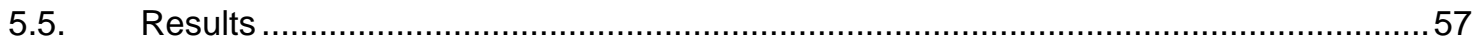

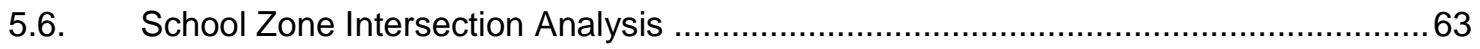

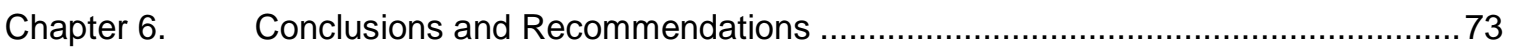

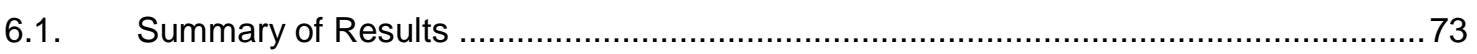

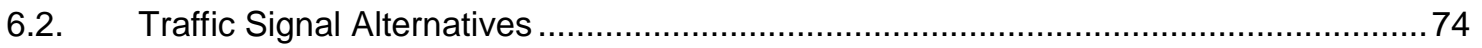

6.2.1. Kankakee Valley High School ...................................................................... 74

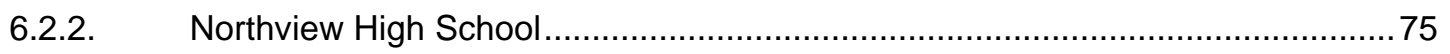

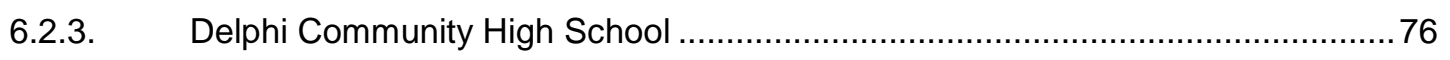

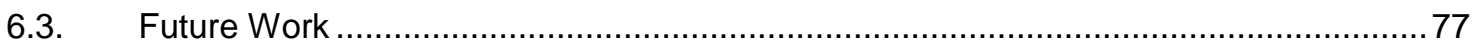

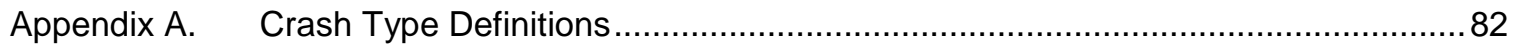




\section{LIST OF TABLES}

Table

Table 1-1: Historical requests for signalization at Kankakee Valley High School in Wheatfield, Indiana.

Table 2-1: Manual on Uniform Traffic Control Devices Traffic Signal Warrants. (Section 4C.01, MUTCD 2001)

Table 2-2: Summary Table of Traffic Volumes at Kankakee Valley High School

Table 2-3: Pedestrian Count at Kankakee Valley High School.

Table 3-1: Responsibilities of Phoenix, Arizona Recommendations Summary Table.

Table 3-2: Recommendations for Indiana City and County School Districts.

Table 4-1: Collected Data Summary Table.

Table 4-2: Summary Table of Crash Types Within 200 feet of the Intersection.

Table 4-3: Summary Table for Severity of Crashes Within 200 feet of the intersection. 35

Table 4-4: Summary Table for Crash Types Within 500 feet of the Intersection. 36

Table 4-5: Summary Table for Severity of Crashes Within 500 feet of the intersection. 37

Table 4-6: Summary Table for Crash Types Within 1000 feet of the Intersection. 38

Table 4-7: Summary Table for Severity of Crashes Within 1000 feet of the intersection. 39

Table 4-8: Summary Table for Crash Types Within 200 feet of the School Zone Intersection. 41

Table 4-9: Summary Table for Severity of Crashes Within 200 feet of the School Zone Intersection.

Table 4-10: Summary Table for Crash Types Within 500 feet of the School Zone Intersection. 43

Table 4-11: Summary Table for Severity of Crashes Within 500 feet of the School Zone Intersection.

Table 4-12: Summary Table for Crash Types Within 1000 feet of the School Zone Intersection. 44

Table 4-13: Summary Table for Severity of Crashes Within 1000 feet of the School Zone Intersection.

Table 5-1: Summary Table of Crash Type Within 500 feet of the Intersection.

Table 5-2: Summary Table of Severity of Crashes Within 500 feet of the Intersection.

Table 5-3: Summary Table of Change in Exposure to Risk.

Table 5-4: Summary Calculations for 'Rear End, Neither Turning', 'Head On, Neither Turning', and 'Same Direction Sideswipe' at a Distance of 500 feet.

Table 5-5: Summary Calculations for 'Opposite Direction Sideswipe', 'Off Road Collision', and 'Right Angle' at a Distance of 500 feet.

Table 5-6: Summary Calculations for 'Left and Right Turns', 'Left Turns', and 'Right Turn' at a Distance of 500 feet.

Table 5-7: Summary Calculations for 'Other / Unknown', and 'Total' at a Distance of 500 feet.

Table 5-8: Summary Calculations for 'Property Damage', 'Personal Injury', and 'Fatal' at a Distance of 500 feet.

Table 5-9: Results Table for Crash Types Within 500 feet of All Intersections.

Table 5-10: Results Table for Severity of Crashes Within 500 feet of All Intersections.

Table 5-11: Summary Statistical Calculations for Crashes Within 500 feet of All Intersections.

Table 5-12: Results Table for Crash Types Within 200 feet of All Intersections.

Table 5-13: Results Table for Severity of Crashes Within 200 feet of All Intersections.

Table 5-14: Results Table for Crash Types Within 1000 feet of All Intersections. 
Table

Table 5-15: Results Table for Severity of Crashes Within 1000 feet of All Intersections.

Table 5-16: Summary Table of Results for Test 1 and Test 2 for Distances 200 feet, 500 feet, and 1000 feet from All Intersections.

Table 5-17: Summary Table of Crash Type Counts at School Zone Intersections Within 500 feet of the Intersection.

Table 5-18: Summary Table of Severity of Crashes at School Zone Intersections Within 500 feet of the Intersection.

Table 5-19: Summary Table of Change in Exposure to Risk for School Zone Intersections. $\quad 66$

Table 5-20: Results Table for Crash Types Within 500 feet of School Zone Intersections. 67

Table 5-21: Results Table for Severity of Crashes Within 500 feet of School Zone Intersections.68

Table 5-22: Results Table for Crash Types Within 200 feet of School Zone Intersections. 69

Table 5-23: Results Table for Severity of Crashes Within 200 feet of School Zone Intersections.69

Table 5-24: Results Table for Crash Types Within 1000 feet of School Zone Intersections. 70

Table 5-25: Results Table for Severity of Crashes Within 1000 feet of School Zone Intersections.

Table 5-26: Summary Table of Results for Test 1 and Test 2 on School Zone Intersection for Distances 200 feet, 500 feet, and 1000 feet from the Intersection. 


\section{LIST OF FIGURES}

$\begin{array}{ll}\text { Figure } & \text { Page }\end{array}$

Figure 2-1: Aerial View of Kankakee Valley High School in Wheatfield, Indiana. .......................... 6

Figure 2-2: Warrant 2, Four-Hour Vehicular Volume Warrant. .................................................. 8

Figure 2-3: Four Hour Vehicular Volume Warrant Analysis for Intersection at Kankakee Valley

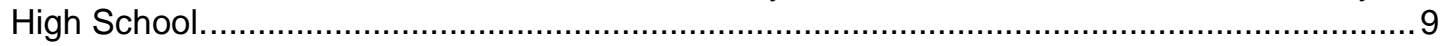

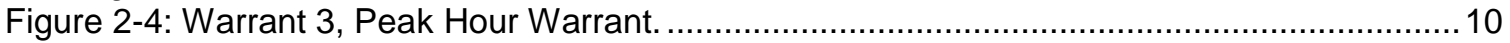

Figure 2-5: Peak Hour Warrant Analysis for Intersection at Kankakee Valley High School.......... 11

Figure 2-6: Example of 'Advanced School Flasher' .................................................................. 13

Figure 3-1: Example of a "Safest Route to School" plan. (Grote 2002) .....................................21

Figure 3-2: Larger waiting areas at intersections. (Grote 2002) ..............................................22

Figure 3-3: Before and After installation of "Stand Back" lines. (Grote 2002) ...............................22

Figure 3-4: Universal pedestrian signals. (Grote 2002) …................................................... 23

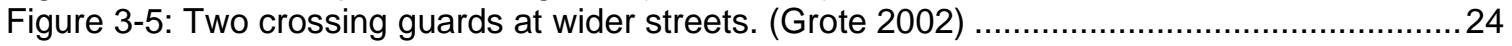

Figure 3-6: Speed Enforcement in School Zones. (Grote 2002) ............................................25

Figure 3-7: Example of School Zone Violation Fines. (Grote 2002) ........................................25

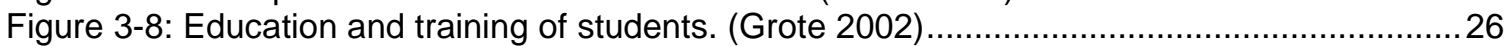

Figure 4-1: Illustration of 200, 5001000 feet data collection radius. ....................................... 32

Figure 6-1: Aerial view of Clay County schools in Brazil, Indiana............................................. 75

Figure 6-2: Aerial view of Delphi Community High School in Delphi, Indiana. ............................. 76

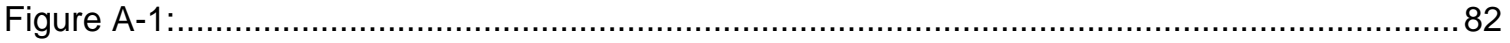

Figure A-2:

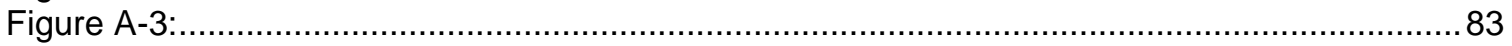

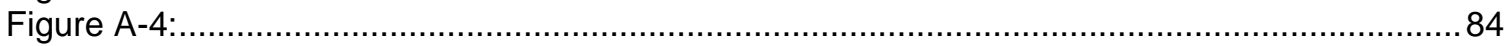

Figure A-5:

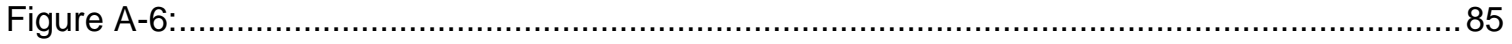

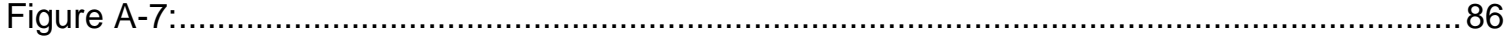

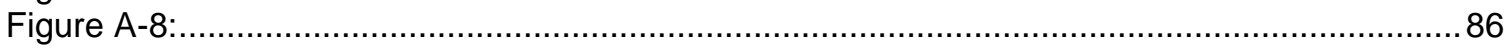

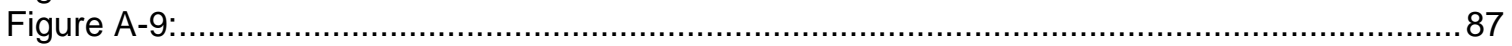

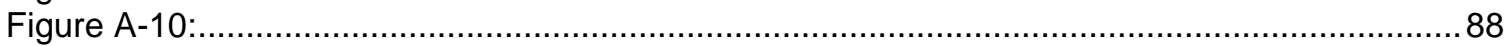




\section{IMPLEMENTATION REPORT}

The data summarized in Table 5-16 and Table 5-26 do not indicate it is beneficial to install traffic signals in school zones when the warrants defined my the Manual on Traffic Control Devices have not been met. In fact, they suggest that for intersections not meeting the warrants, traffic signals should not be installed. Based upon these findings, it is recommended that the Indiana Department of Transportation continue following nationally prescribed warrants for determining when a traffic signal should be installed. 


\section{ACKNOWLEDGMENTS}

The following people assisted in obtaining data and guiding the research: Mike Bowman, INDOT, Dennis Lee, FHWA, Carolyn Coffin, INDOT, Kanwal Kalirai, INDOT, Samy Noureldin, INDOT, Carl Tuttle, INDOT and Professor Darcy Bullock, Purdue University. Professor Andrzej Tarko at Purdue University assisted on the statistical analysis. 


\section{CHAPTER $1 . \quad$ INTRODUCTION}

Traffic signals are used to control the right of way at intersections. Strict engineering guidelines are published in the Manual on Uniform Traffic Control Devices (MUTCD) that engineers use to determine if a traffic signal is "warranted". These guidelines are based upon years of national committee debates. Current warrants for traffic control devices trace their roots to other committee procedures developed for uniform signs, striping, and control devices [MUTCD 48]. The warrants provide consistent national balance between mobility, safety, efficiency, and costs.

However, signalized intersections are often viewed by the general public as safer than unsignalized intersections. This notion is often heightened when there are personal injuries and even higher when children are involved. Parents, city officials, and local interest groups often vigorously request the installation of a traffic signal.

After these requests are received, an engineering study is performed, and a traffic signal is often determined to be not warranted. It is the traffic engineer's responsibility to explain that decision. These results are not the desired response and in turn the public become more diligent for their cause and the cycle continues. This cycle of request and denial for a traffic signal is often seen at intersections adjacent to schools. Table 1-1 shows an example of historical requests for warrant studies at the intersection at Kankakee Valley High School in Wheatfield, Indiana. 
Table 1-1: Historical requests for signalization at Kankakee Valley High School in Wheatfield, Indiana.

\begin{tabular}{|c|c|}
\hline Date & Action \\
\hline March 19, 1992 & Request for traffic control at intersection \\
\hline April 2, 1992 & $\begin{array}{l}\text { Traffic count performed, Flashing Beacon warranted, Approved and } \\
\text { Installed }\end{array}$ \\
\hline January 29,1993 & Letter written by citizen expressing safety concerns at intersection \\
\hline February 8,1993 & Request for reevaluation of traffic study from State Senator Wolf \\
\hline February 15,1993 & $\begin{array}{l}\text { INDOT confirms previous studies, notes prior advise to school to } \\
\text { install Speed Limit sign with flashing beacon at own expense }\end{array}$ \\
\hline May 13,1994 & Student injured in an accident \\
\hline May 17,1994 & Request for signal installation \\
\hline May 24,1994 & Traffic study performed \\
\hline June 7,1994 & Results show no signal warranted \\
\hline June 9,1994 & Recommendation for installation of Advance School Flasher \\
\hline July 7,1994 & Request of signal installation by Senator Wolf \\
\hline July 20,1994 & Request denied by INDOT \\
\hline September 23, 1994 & $\begin{array}{l}\text { Senator Wolf forwards petitions of parents and teachers for } \\
\text { reevaluation of traffic study }\end{array}$ \\
\hline October 5,1994 & $\begin{array}{l}\text { Denial of request, INDOT states signal cannot be installed without } \\
\text { meeting warrants }\end{array}$ \\
\hline October 25,1995 & Request for traffic study for signal installation \\
\hline November 1,1995 & Turn lane suggested, improve right turn lane and sight distance \\
\hline November 28, 1995 & Traffic study performed \\
\hline December 28, 1995 & Results show no signal warranted \\
\hline January 12,1996 & Data confirmed \\
\hline March 11, 1996 & School requests 'Cross Traffic Does Not Stop' sign \\
\hline April 3, 1996 & Signs deemed not appropriate \\
\hline April 24, 1996 & $\begin{array}{l}\text { Signs denied, INDOT suggests reevaluation of the internal traffic } \\
\text { flow }\end{array}$ \\
\hline June 24,1998 & Introduction of project renovations (center lane installation) \\
\hline August 15,1998 & Legal Notice of Improvements issued \\
\hline October 1,1998 & School express concerns for intersection improvements \\
\hline October 7,1998 & $\begin{array}{l}\text { INDOT responds that Turn Lane will decrease conflicts and the } \\
\text { widening will increase sight distance }\end{array}$ \\
\hline October 13,1998 & Senator Wolf expresses concerns on improvements \\
\hline November 2, 1998 & Traffic data and improvement plans are reaffirmed \\
\hline November 25, 1998 & Representative Smith requests information on signal installation \\
\hline December 9, 1998 & Traffic study performed \\
\hline January 8,1999 & Traffic signal found to be not warranted \\
\hline April 24, 2000 & $\begin{array}{l}\text { Displeasure with improvements expressed by school and request } \\
\text { delay construction }\end{array}$ \\
\hline October 7,2000 & Student injured in an accident \\
\hline October 23, 2000 & Strong opinions expressed in local newspaper \\
\hline October 25,2000 & Continued opinions in newspaper \\
\hline
\end{tabular}


School zones often, and understandably, generate spirited public and political involvement due to the strong emotions involved with the safety of the students. Traffic on roadways adjacent to schools is a focus for many safety issues. Traffic issues include high speed traffic, either from rural highways or vehicles not traveling at the posted speed limits, traffic congestion, minor street delays, and insufficient pedestrian precautions. Many of these conditions can increase the likelihood of crashes, especially with higher traffic volumes and speeds. In school zones, high traffic volumes are mainly seen during the morning and afternoon peak hours and last only for a short period of time. Much of this traffic comes from school buses, parents, staff, and students. Concerns for the dangers of severe crashes lead to public to seek solutions that may provide more safety. The perceived solution by the public to this problem is often the installation of a traffic signal.

\section{1. $\quad$ Project scope}

There is a need for a quantitative before and after evaluation of crashes at signals that were installed where the warrants were justified by only a slim margin. This information may be used to determine if Indiana Department of Transportation (INDOT) should consider re-evaluating the procedure used to justify or deny a traffic signal. It is also noted that the 2000 National Manual on Uniform Traffic Control Devices (MUTCD) uses a traffic signal warrant that is met as only a first step in deciding a need to install a new traffic signal.

There is also a need for a development of short video clips documenting other factors affecting safety adjacent to a school, so that INDOT can effectively communicate these issues to the general public.

The national standards for justifying the installation are guidelines that work very well when signals are clearly justified or clearly not justified. It is not clear how well they work for borderline cases. Depending upon what the before/after data shows, the before/after information will either: be used to recommend that INDOT consider re-evaluating the procedures used to deny a traffic signal when criteria are almost met or be used to by INDOT to justify to the public why a signal request was denied. 
With regards to the video clips, areas adjacent to schools often have undesirable circulation patterns and unstructured pedestrian movements that may be the cause of a safety problem. The Texas Department of Transportation (TxDOT) has developed a program called "Precious Cargo" that defines a procedure for school districts to work cooperatively with TXDOT to improve transportation features such as access and pedestrian movements. (TxDOT, 1999) The video clips will provide a mechanism for communicating to the schools, the importance of these alternative considerations. 


\section{CHAPTER 2. BACKGROUND ON INDOT PROCEDURE FOR APPROVING SIGNALS}

\section{1. $\quad$ INDOT Procedure}

The Indiana Department of Transportation follows the National Manual on Uniform Traffic Control Devices (MUTCD) procedure for approving traffic signals. This process begins with an engineering study of the traffic conditions, pedestrian characteristics, and physical characteristics of the location. (Section 4C.01, MUTCD 2000) This study includes a traffic count for a 12 hour period during an average day. Types of vehicles are classified during the peak hours during the count. Also part of the study is a pedestrian volume count during the same period. Information about surrounding facilities, approach speed limits, and intersection geometry are also noted and crash data from crashes during the previous year is collected.

Table 2-1: Manual on Uniform Traffic Control Devices Traffic Signal Warrants. (Section 4C.01, MUTCD 2001)

\begin{tabular}{|c|l|}
\hline \multicolumn{2}{|c|}{$\begin{array}{c}\text { Manual on Uniform Traffic Control Devices } \\
\text { Traffic Signal Warrants }\end{array}$} \\
\hline Warrant 1: & Eight-Hour Vehicular Volume \\
\hline Warrant 2: & Four-Hour Vehicular Volume \\
\hline Warrant 3: & Peak Hour \\
\hline Warrant 4: & Pedestrian Volume \\
\hline Warrant 5: & School Crossing \\
\hline Warrant 6: & Coordinated Signal System \\
\hline Warrant 7: & Crash Experience \\
\hline Warrant 8: & Roadway Network \\
\hline
\end{tabular}

From the engineering study, intersection conditions are evaluated using traffic signal warrants, shown in Table 2-1. The first step in determining if a signal should be installed is to determine if the conditions of the intersection meet the standards of any of the eight warrants and entails the use of engineering judgment during the analysis of the intersection. Often improvements to the 
traffic flow can be made at the intersection without installing a traffic signal. This may include an addition of a turn lane, or improving sight distance.

For this study, five of the eight warrants are explained to further details. These include the 'FourHour Vehicular Volume', 'Peak Hour', 'Pedestrian Volume', 'School Crossing', and 'Crash Experience'. For each of the mentioned warrants, the standard procedure is explained and an example of this process is described. The intersection at Kankakee Valley High School in Wheatfield, Indiana is used as an example for the engineering analysis, shown in Figure 2-1. This intersection is two-way stop controlled with a flashing beacon.

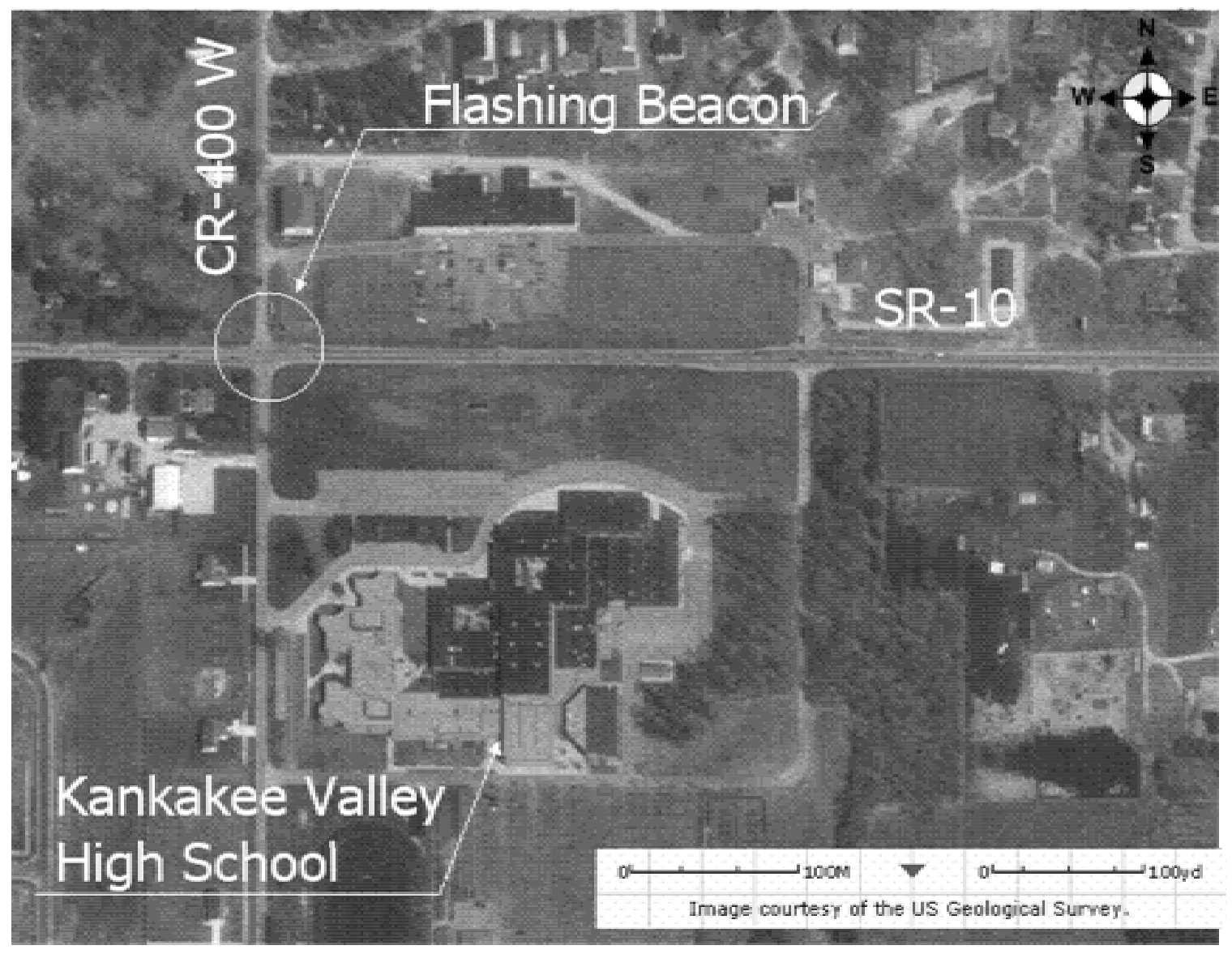

Figure 2-1: Aerial View of Kankakee Valley High School in Wheatfield, Indiana.

Traffic and pedestrian volumes were counted during peak hours during an average day. Only peak hour counts are performed as a result of previous traffic counts reported by INDOT. Results 
of the vehicle and pedestrian volume counts are shown in Table 2-2. The major road, East and West bound, do not have high enough traffic volumes to be considered for an 'Eight-Hour Vehicular Volume' warrant. In such a case, other warrants are considered. Results of the engineering study and warrant analysis for this intersection are described in the following sections.

Table 2-2: Summary Table of Traffic Volumes at Kankakee Valley High School

\begin{tabular}{|c|c|c|c|c|c|c|c|c|c|c|c|c|c|c|c|c|}
\hline & \multicolumn{4}{|c|}{ North Bound } & \multicolumn{4}{|c|}{ East Bound } & \multicolumn{4}{|c|}{ South Bound } & \multicolumn{4}{|c|}{ West Bound } \\
\hline & 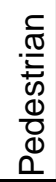 & 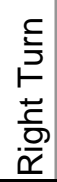 & $\begin{array}{l}\text { 동 } \\
\text { 을 } \\
\text { 른 }\end{array}$ & 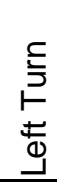 & 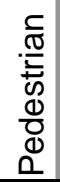 & 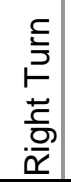 & 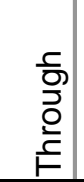 & 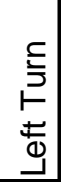 & 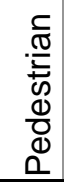 & 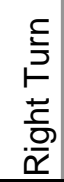 & 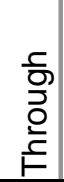 & 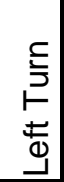 & 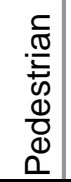 & 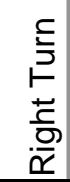 & $\begin{array}{l}\text { 동 } \\
\text { 을 } \\
\text { 을 }\end{array}$ & 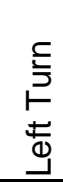 \\
\hline $6: 00-7: 00$ & 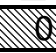 & (1) & 1 & 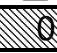 & 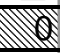 & 1 & me & 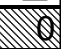 & 1 & (1) & (1) & 1 & 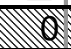 & 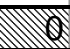 & 1 & 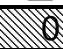 \\
\hline $7: 00-8$ & 0 & 42 & 34 & 5 & 0 & 16 & 189 & 59 & 9 & 24 & 23 & 42 & 1 & 193 & 105 & 24 \\
\hline $8: 0$ & 0 & 37 & 9 & 8 & 0 & 17 & 226 & 20 & 0 & 16 & 8 & 29 & 0 & 27 & 125 & 30 \\
\hline $9: 00$ & 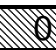 & (1) & 1 & 1 & 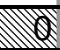 & 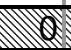 & me & 1 & 2 & 1 & de & 1 & 1 & (1) & (1) & \\
\hline 10:00- & 1 & 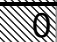 & 18 & 1 & \% & 2 & 1 & 1 & 12 & 1 & 12 & 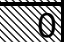 & 1 & 1 & 12 & \\
\hline $11: 00$ & 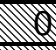 & 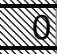 & 1 & 1 & $\alpha$ & 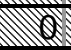 & 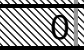 & 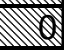 & 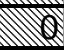 & 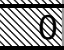 & 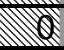 & 1 & 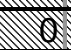 & 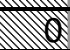 & 2 & 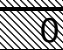 \\
\hline $12: 0$ & 1 & 2 & 1 & 1 & 2 & 1 & 1 & 1 & 1 & 1 & 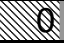 & 1 & 1 & 1 & L & 1 \\
\hline $1: 00-2: 00$ & 1 & 12 & 1 & 1 & 2 & 1 & 1 & 1 & 1 & 1 & $1 \%$ & 11 & 1 & 12 & 12 & 1 \\
\hline $2: 00-3: 00$ & 0 & 36 & 20 & 7 & 1 & 9 & 172 & 24 & 0 & 10 & 21 & 24 & 1 & 42 & 182 & 53 \\
\hline $3: 00-4: 00$ & 0 & 49 & 29 & 8 & 0 & 22 & 260 & 26 & 0 & 41 & 34 & 97 & 40 & 68 & 195 & 66 \\
\hline $4: 00-5: 00$ & 0 & 55 & 39 & 7 & 0 & 14 & 169 & 29 & 0 & 27 & 34 & 41 & 0 & 55 & 198 & 65 \\
\hline $5: 00-6: 00$ & 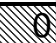 & 1 & 1 & 1 & 2 & 6 & & & 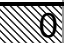 & 1 & 1 & & 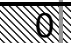 & 1 & & \\
\hline
\end{tabular}

\subsection{Four-Hour Vehicular Volume}

The Four-Hour Vehicular Volume warrant is based on the need of a traffic signal due to the volume of the cross traffic. A signal is warranted if "each of any four hour [traffic volumes] of an average day" (MUTCD, 2000) falls above the corresponding curves in Figure 2-2. As total volumes on the major street increase, the threshold volume on the minor street decrease. 


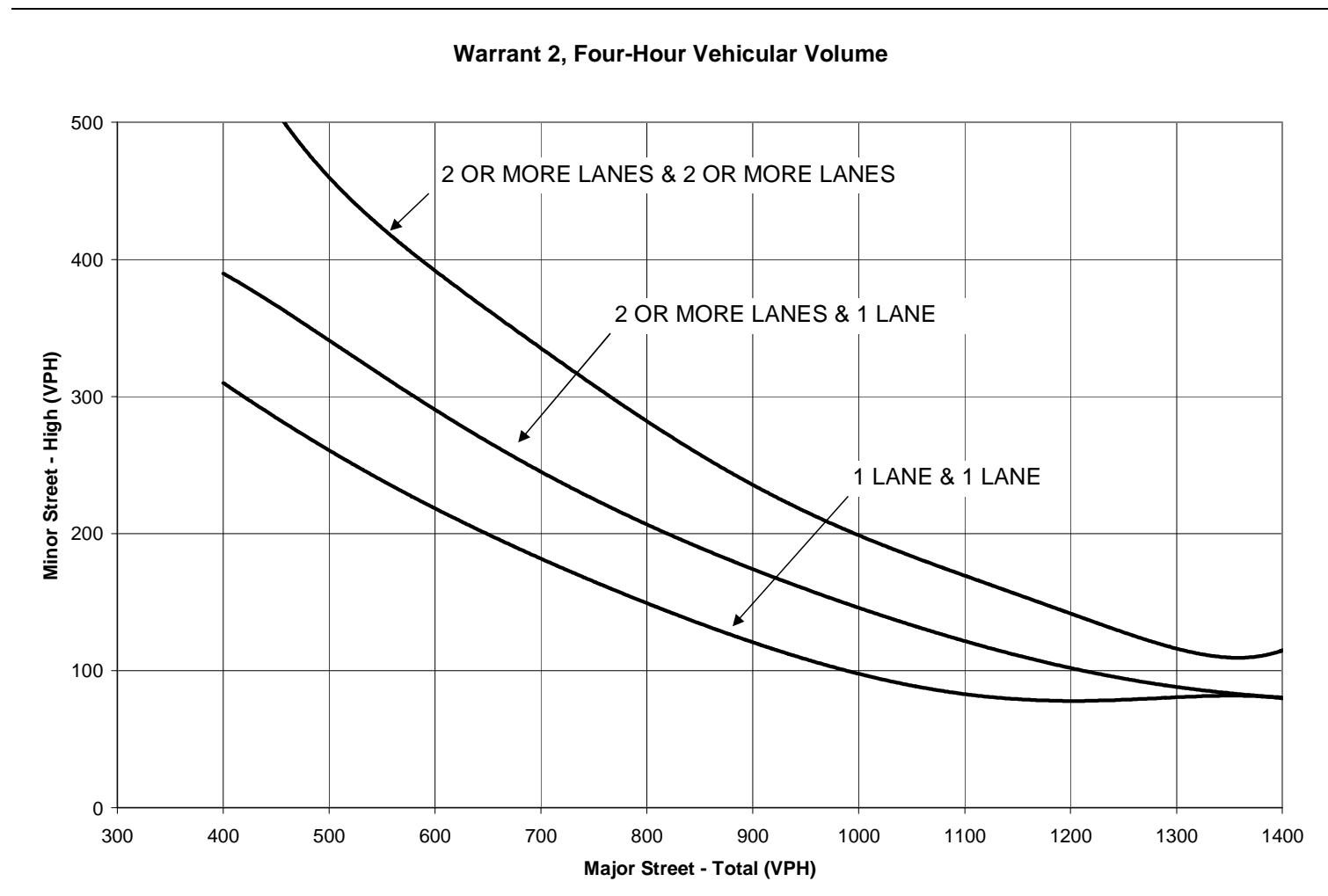

Figure 2-2: Warrant 2, Four-Hour Vehicular Volume Warrant.

For the intersection at Kankakee Valley High School, the collected peak hour data is plotted on Figure 2-2. Vehicular counts show that the maximum volume during the period is 672 vehicles on the major road and 172 vehicles on the minor road. This point is close to the lower limits of the ' 1 Lane \& 1 Lane' threshold, but is still below the necessary volume. The other counted hours are below this point as seen in Figure 2-3. Results show that for this warrant, the intersection is not warranted for a traffic signal. 


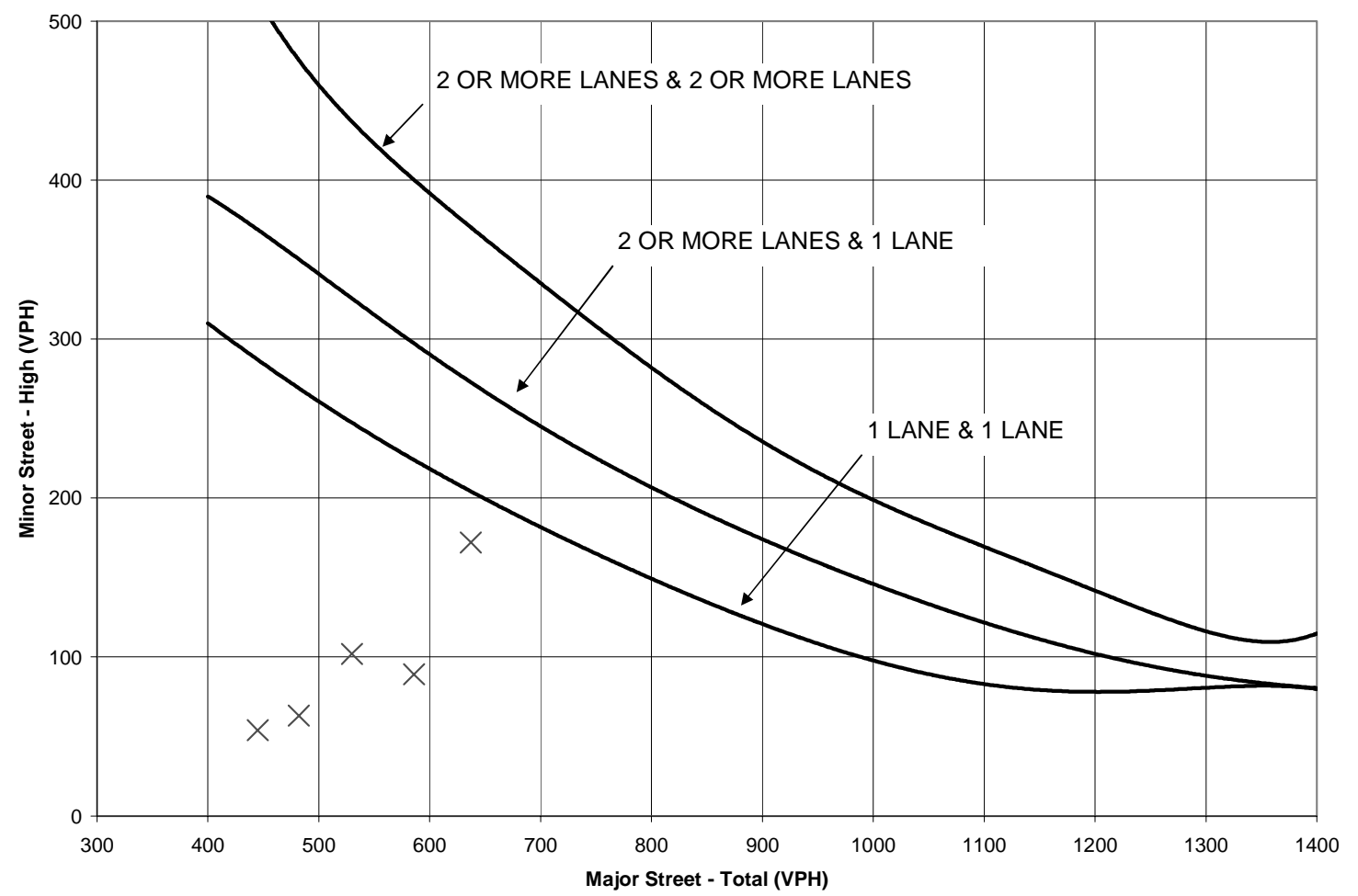

Figure 2-3: Four Hour Vehicular Volume Warrant Analysis for Intersection at Kankakee Valley High School.

\section{3. $\quad$ Peak Hour}

The Peak Hour warrant is used for an intersection where traffic volumes are high during a short period of time. This warrant is used at intersections with factories, commercial centers, or industrial parks. These locations often see a large influx of traffic volumes during peak hours. A traffic signal is considered when either of two criteria is met. The first criterion consists of several conditions where each of them is met. These conditions include the excess of four vehicle-hours time delay for a one-lane approach on the minor street ${ }^{1}$, more than 100 vehicles per hour for the same approach, and the total intersection volume equals or exceeds 800 vehicles per hour with

\footnotetext{
${ }^{1}$ This can be done with the Highway Capacity Manual unsignalized intersection procedure. However, it is rarely the controlling condition.
} 
four approaches. The second criterion consists of plotting corresponding vehicular volumes on a graph, Figure 2-4, similar to the 'Four Hour Vehicular Volume' warrant. Any four consecutive 15minute periods on an average day can be used. A traffic signal is considered when one hour falls above the curve.

Warrant 3, Peak Hour

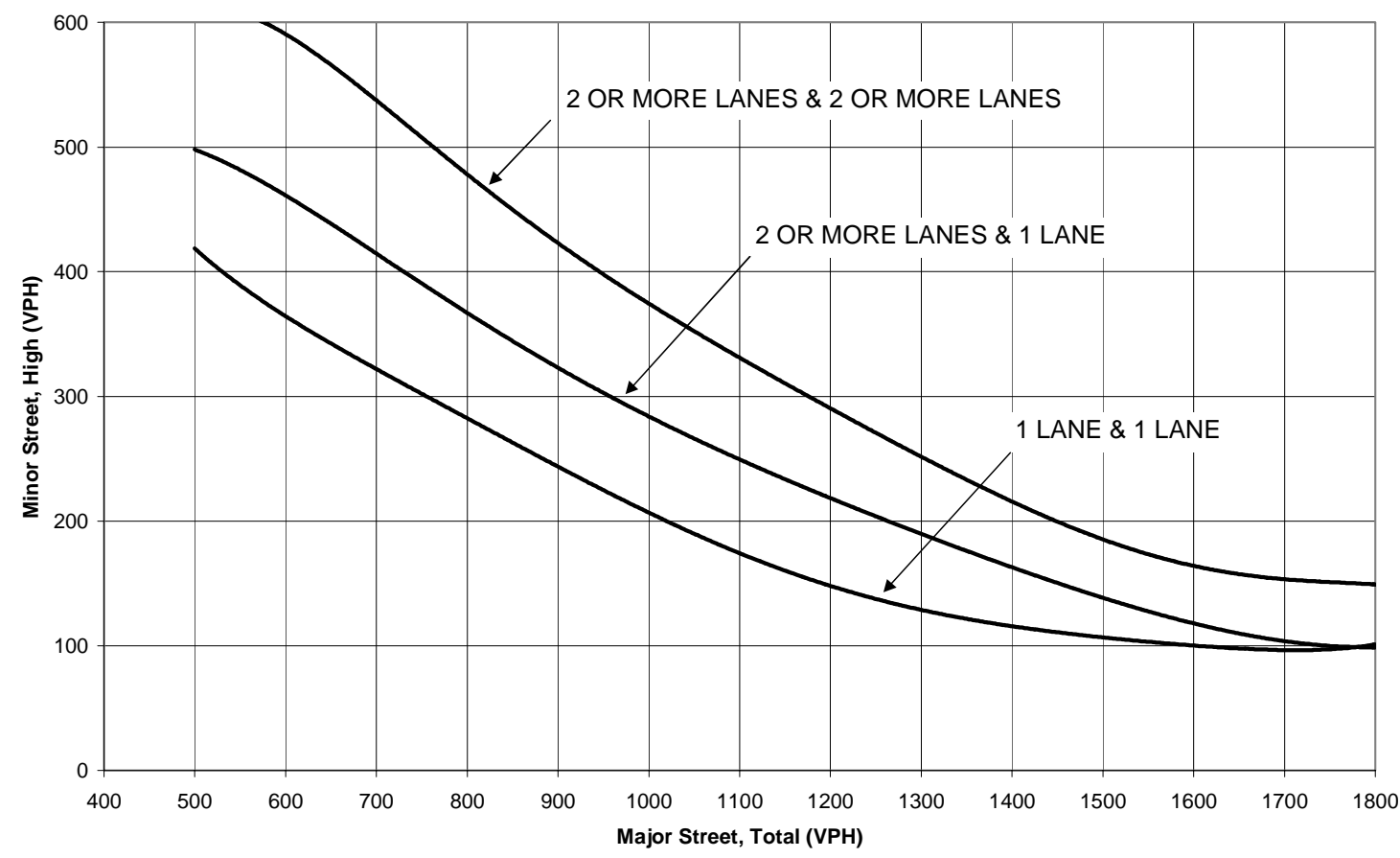

Figure 2-4: Warrant 3, Peak Hour Warrant.

Results from the traffic count in Figure 2-5 show that no four 15 minute periods meet the necessary requirements for consideration of a traffic signal installation. The highest volume period is 638 vehicles on the major road and 176 vehicles on the minor. The intersection volume is at the highest between the time of $3: 00 \mathrm{pm}$ and $4: 30 \mathrm{pm}$. This is the time when the high school is dismissed from class. The exiting volume consists of mainly personal vehicles and a few school buses. 


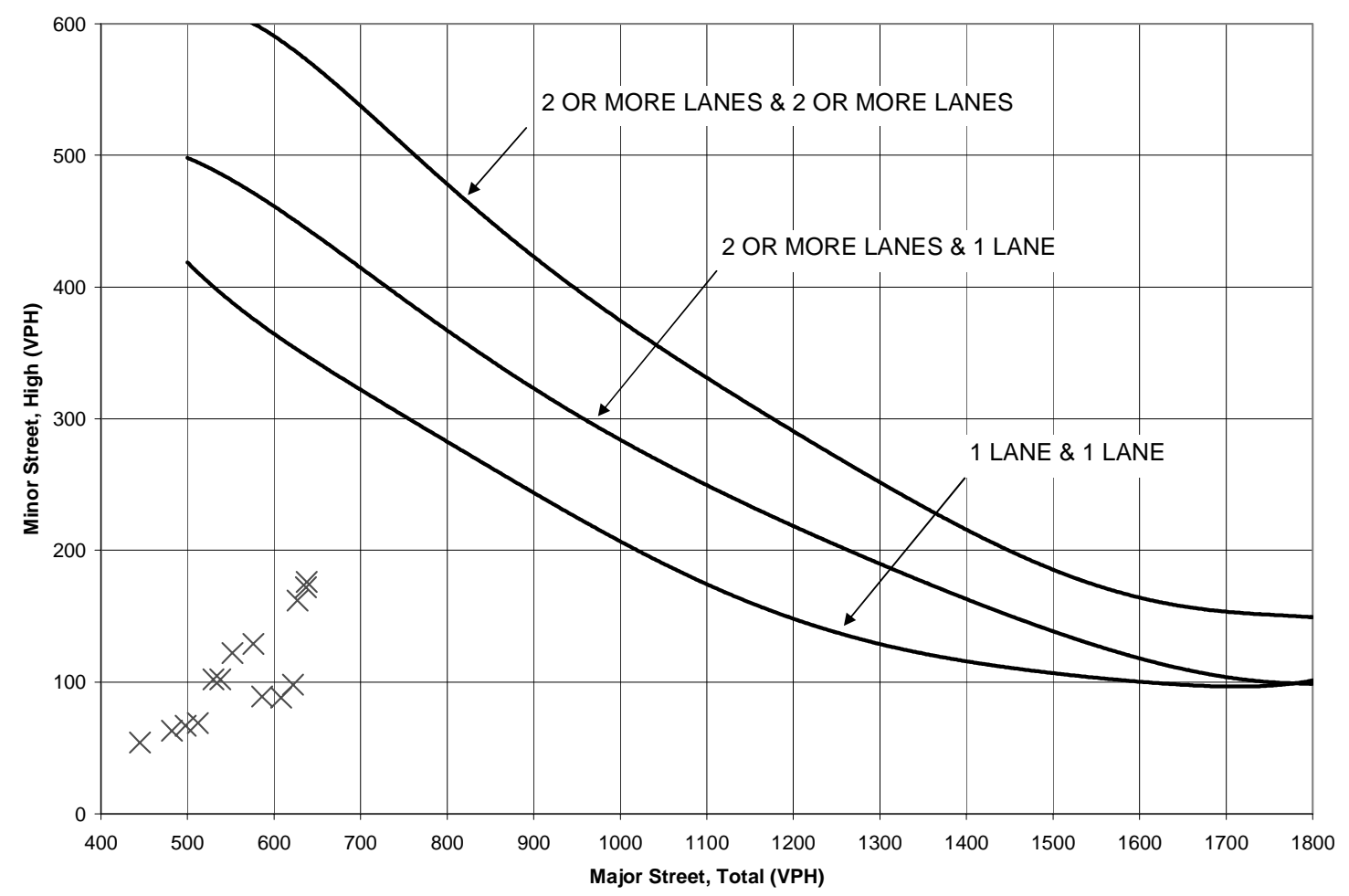

Figure 2-5: Peak Hour Warrant Analysis for Intersection at Kankakee Valley High School.

\section{4. $\quad$ Pedestrian Volume}

The Pedestrian Volume warrant is used for intersections that have high volumes of pedestrian traffic. The warrant is satisfied when the pedestrian volume crossing the major street exceeds 100 pedestrians for each of four hours during an average day and there are less "than 60 gaps per hour in the traffic stream." (Section 4C-10, MUTCD 2000) Both of these criteria must be met for any consideration for signal installation. Gaps are defined as the walking distance divided by the walking speed. The walking distance incorporates the distance from curb to curb or if there is a median, then from curb to median. This warrant is also limited to locations where there is not another traffic control device within 300 feet.

Along with a vehicular traffic count, pedestrians are counted. Observations of the intersection show that there are no crosswalks or a crossing guard at the intersection. Pedestrian counts 
include any person that crosses the street within 1000 feet of the intersection. Results of the count are shown in Table 2-3. There are a total of 52 pedestrians counted during the peak hours of the day. This does not meet the first requirement of the 'Pedestrian Volume' warrant.

Table 2-3: Pedestrian Count at Kankakee Valley High School.

\begin{tabular}{|c|c|c|c|c|}
\hline & North Bound & East Bound & South Bound & West Bound \\
\hline $6: 00-7: 00$ & 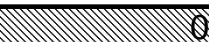 & $\frac{1}{1-\frac{1}{2}}$ & 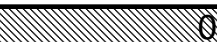 & $1 / \frac{1}{1-1}$ \\
\hline $7: 00-8: 00$ & 0 & 0 & 9 & 1 \\
\hline $8: 00-9: 00$ & $\overline{0}$ & 0 & 0 & 0 \\
\hline 9:00-10:00 & 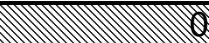 & 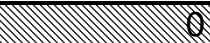 & 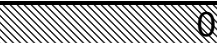 & 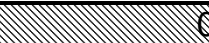 \\
\hline 10:00-11:00 & $\$$ & 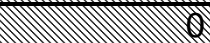 & 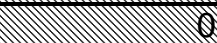 & 0 \\
\hline $11: 00-12: 00$ & 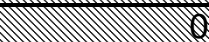 & 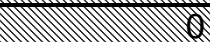 & 1 & 1 \\
\hline 12:00-1:00 & 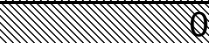 & 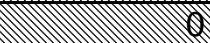 & 1 & 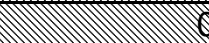 \\
\hline $1: 00-2: 00$ & 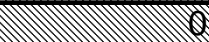 & 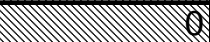 & 1 & 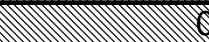 \\
\hline $2: 00-3: 00$ & 0 & 1 & 0 & 1 \\
\hline $3: 00-4: 00$ & 0 & 0 & 0 & 40 \\
\hline $4: 00-5: 00$ & $\overline{0}$ & 0 & $\overline{0}$ & $\overline{0}$ \\
\hline $5: 00-6: 00$ & 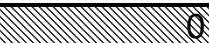 & 2 & 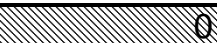 & 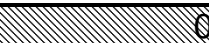 \\
\hline Total & 0 & 1 & 9 & 42 \\
\hline
\end{tabular}

\subsection{School Crossing}

The School Crossing warrant is based on the need for a signal installation where there are children crossing a major street. Prior to the consideration of a signal installation, other means of traffic control are to be used such as warning signs, school speed zones, or crossing guards. After all other options are considered, a signal is warranted if the number of gaps in the traffic flow during a period is less than the number of minutes during the same period when the children are using the crossing.

This warrant is not applicable at Kankakee Valley High School since there are no other means of traffic control installed at the intersection. A flashing beacon was installed in 1992, but other means of traffic control were not installed. INDOT recommends installation of an 'Advance School Flasher' a seen in Figure 2-6 at the schools expense, but the school declined the recommendation. Other safety measures are recommended but not installed at the intersection. This refusal to consider other safety measures does not justify the application of the 'School Crossing' warrant to be applicable to this intersection. 


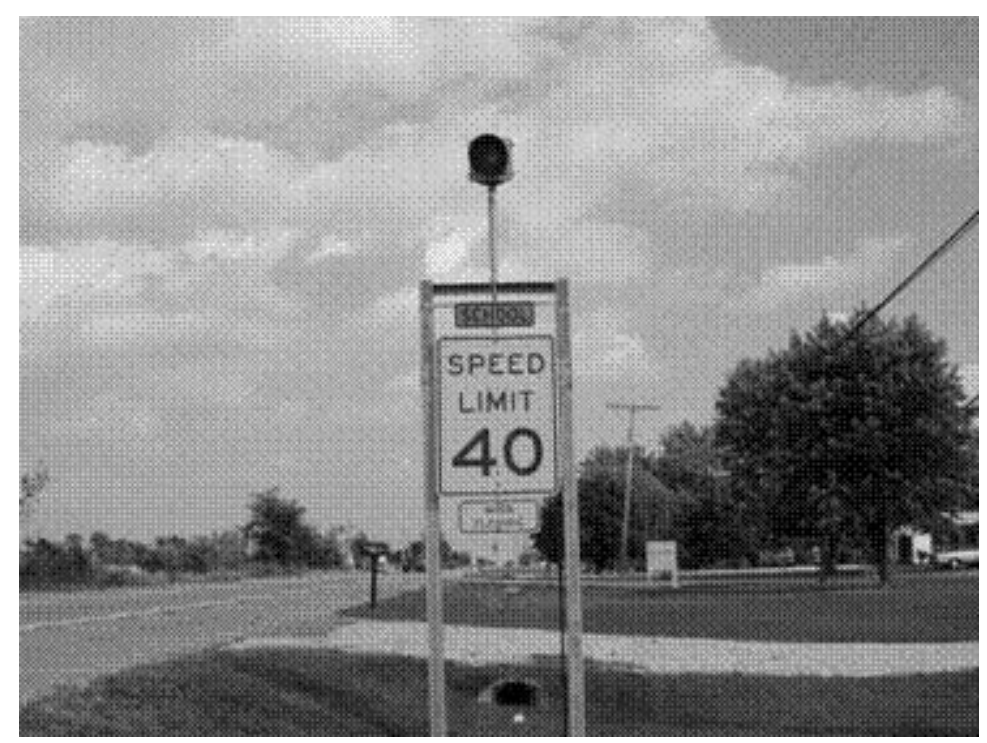

Figure 2-6: Example of 'Advanced School Flasher'

\section{6. $\quad$ Crash Experience}

The Crash Experience warrant is used when a signal is considered based on the frequency and severity of crashes. The signal installation is considered when each of the following criteria are met; if other methods do not reduce the frequency of crashes, five or more crashes during a 12month period, and for each of any eight hours during an average day, the volume meets $80 \%$ of the 'Eight-Hour Volume' warrant requirements or the volume of the 'Pedestrian Volume'.

Of these two criterions, the volume requirements at Kankakee Valley High School were not met for this warrant. A total of 52 pedestrians were counted during the traffic analysis period, which is less than the required 100 pedestrians. Also, the traffic volumes do not meet the $80 \%$ columns of the 'Eight Hour Vehicular Volume' warrant. Failure to meet this criterion does not allow consideration for traffic signal installation. 


\section{7. $\quad$ Conclusions}

This chapter examined different warrants and their procedure used in the consideration of traffic signal installation at lower volume intersections. Traffic counts are not the only source of information for traffic engineers. Intersection geometry, previous crash records, pedestrian movements, and safety precautions need to be examined before any decision is made.

The engineering study and analysis at Kankakee Valley High School describes an example of the many options and considerations needed during the warrant analysis process. Through the analysis, it is noted that a traffic signal installation is not warranted and is not recommended. According to the MUTCD, other safety measures should be considered before a traffic signal is installed. (MUTCD 2000) 


\section{CHAPTER 3. LITERATURE REVIEW}

This chapter discusses previous research on traffic signal warrant analysis, and minimally warranted signals. The chapter also includes a discussion on actions other agencies have taken on school zone safety. This will include the current and future plans for school zone safety developed by the City of Phoenix, Arizona. Finally, the chapter concludes with a summary of previous research findings.

\subsection{Minimally Warranted Signals}

Minimally warranted signals are typically located at intersections with high peak hour volumes and low off peak hour volumes. This is often encountered at factory entrances/exits, sporting facilities, and school entrances/exits. Problems are usually evident when vehicles are exiting the facility. Long delays and queues are created as high volume of traffic attempt to enter a major roadway system. Delays and queues increase if the major road contains high volumes. High volumes have low number of gaps and a higher chance for conflicts. Conflicts are defined as possible collisions or near misses as well as actual crashes. Delays and conflicts are sources for public concern and complaints to the local traffic engineer. Also frequency of crashes and/or severe crashes fuels the public interest for signal installation. Requests for signals are given to the traffic engineer and an engineering study is performed.

Engineering studies are performed at intersections to decide whether or not it fulfills any warrants for signal installation. After the analysis, if the signal is only minimally warranted or not at all, the engineer must use engineering judgment to decide if the signal should be installed. This decision incorporates information on the efficiency of intersection operation and safety. Overall delay and the potential increase of certain types of crashes are also considered. (Williams and Ardekani, 1996) After these factors are evaluated, the engineer decides the need of installing the signal.

It has been shown through simulation and research that signalization at minimally warranted signals will not improve intersection efficiency. (Williams and Ardekani, 1996) The effects of 
signalization at minimally warranted intersections are discussed in previous research by Williams and Ardekani. Their research involves delay and crash data to determine the impacts of traffic signals at minimally warranted intersections.

Williams and Ardekani examined the impacts on efficiency and safety of minimally warranted signals. Efficiency is determined through simulation using field traffic data from a given list of intersections. Twelve different traffic patterns are classified and simulation of these patterns is performed. The traffic patterns are simulated through two-way stop control, all-way stop control, and actuated signalization. Safety is determined from previous crash data at the given intersections. Crash rates for a five-year period are used to determine the frequency of crashes. The intersections are then categorized by speed limit and city population size. The crashes are also separated by type of crashes and severity.

Results from the William and Ardekani study show that at low-speed urban situations, the number of crashes by severity is significantly higher for a signalized intersection compared to an unsignalized intersection. The research further states that similar to urban situations, there is an increase in crash rates in rural low-speed intersections and signalization can decrease the number of crashes. Also, it is found that 'Right Angle' crashes significantly decreased with signalization. Along with the decrease of 'Right Angle' crashes, there is an increase in 'Rear End' crashes.

The results of a decrease in 'Right Angle' crashes and an increase of 'Rear End' crashes are supported by King and Goldblatt. Their study examines intersection crashes at different intersections nationwide. Results show that there is a decrease of 45 percent for 'Right Angle' crashes. The study also discusses the increase of 'Total' crashes of eight percent and an 84 percent increase of 'Rear End' crashes at intersections in Michigan. Intersections in Concord, California "showed a reduction in total crashes" and 'Right Angle' crashes with an increase in 'Rear End' crashes after signal installation. (King and Goldblatt) King and Goldblatt also examine the affects of signalization at an unwarranted intersection. Results show that there is an increase of crash total, volume crash rate and crash disutility. Volume crash rate is defined by the total amount of crashes divided by peak-hour volume divided by 100. Crash disutility is defined as an "index of net economic loss" due to an adjustment of traffic flow patterns.

Through various studies, it can be generalized that there is a decrease in 'Right Angle' crash types and an increase in 'Rear End' and 'Left Turn' crashes after signal installation. Signalization 
at an unwarranted intersection is found to decrease efficiency and increase delay and number of stops.

\subsection{School Zone Safety}

School zones are often a focus of safety concerns since there is an involvement of children. Safety issues in school zones include vehicular travel speeds, student pedestrian movements, and the interaction between the two issues. The following section discusses school zone traffic control devices and the resulting perception of the control devices by motorists. Along with the discussion on traffic control devices, a safety program developed by the City of Phoenix is presented.

\subsubsection{Motorist's Behavior}

There are many studies that analyze the travel speeds through school zones. School zone speed limits can range from 15 miles per hour ( $\mathrm{mph}$ ) to $45 \mathrm{mph}$. Results show that there is a wide range of driver compliance to posted speed limits and travel speeds through school zones. Some studies show that driver compliance can be as low as 20 percent and some $85^{\text {th }}$ percentile speed are more than $20 \mathrm{mph}$ above the posted speed limit. (McCoy and Heimann, 1990) McCoy and Heimann also report that school zone speed limits are not effective in reducing speeds. It is also found that drivers are more likely to comply with a $25 \mathrm{mph}$ speed limit or higher.

In another study, Saibel's "Vehicle Speeds in School Zones", close to half of the vehicles travel under $25 \mathrm{mph}$ in a $20 \mathrm{mph}$ zone. More than 25 percent travel higher than $30 \mathrm{mph}$ and close to 9 percent travel more than $35 \mathrm{mph}$. There is a division in compliance where drivers either follow the posted speed limit or travel much faster. The drivers traveling at the higher speeds pose a risk to other vehicles as well as students walking to and from school. In Saibel's study, four different types of speed limit signs were used to compare driver reaction and travel speeds. The tested signs vary with the type of visibility and time indications. Of the tested signs, the flashing light school zone sign is found to be most effective in lowering the average speed. The flashing light sign gives motorist a visual indication of the school zone and an awareness of a speed change. 
These results are also seen in Rosenbaum's "Speed Control in Rural School Zones". In this study, different sign conditions were used to compare the effectiveness of speed control. Sign conditions vary in signage. The most effective conditions were found to be signs with flashing lights warning of a reduction in speed and upcoming school zone. These conditions were found to decrease travel speed from an average of $55 \mathrm{mph}$ to $35 \mathrm{mph}$. The other sign conditions without flashing lights reduce the average speed to $40 \mathrm{mph}$. It is concluded that the more information that the motorist visualizes; the more likely the motorist will change their behavior.

\subsubsection{Effectiveness of Traffic Control Devices}

The previous research indicates that visual aids lead to driver's awareness and a reduction in speed. This is a direct result from the use of flashing light signs. Aggarwal and Mortensen examine the effectiveness of flashing light signs in "Do Advance School Flashers Reduce Speed". This study discusses the placement and operation of the flashers. Results from the study show that there was a significant reduction in average travel speeds through the tested school zones.

Another study suggests the effectiveness of advance school flashers in Schrader's "Study of Effectiveness of Selected School Zone Traffic Control Devices". In this study, five different traffic control devices were tested to see any reduction in travel speeds. The five devices are postmounted flashing beacons, lavender transverse stripes, span wire-mounted flashing beacons, fiber-optic signs, and painted pavement markings. The use of mounted flashing beacons and fiber optic signs results in a reduction in $85^{\text {th }}$ percentile speeds. Lavender stripes reduce the speeds only for a short period. The span wire-mounted flashing beacon does show immediate reduction, but does have reduction in speeds at the end of the study. Speeds are also reduced with the use of pavement markings. The use of traffic control devices are found to be effective when it is visible to motorists. Drivers are more aware of the speed limit and school zones when there are flashing beacons. (Reiss and Robertson, 1976) 


\subsubsection{School Safety Plans}

Part of increasing school zone safety is the development of a safety plan that can involve all aspects of a school corporation. The following section examines the safety plan of the City of Phoenix in Arizona. The plan is a set of recommendations that would improve safety at schools as listed in Table 3-1. These recommendations can apply to any school and incorporates the help from the city, law enforcement, the school and parents. The shared responsibilities for each of the recommendations show the need of each group to work together. Some recommendations are not applicable to all schools and many are site dependent. 
Table 3-1: Responsibilities of Phoenix, Arizona Recommendations Summary Table.

\begin{tabular}{|c|c|c|c|c|}
\hline Recommendations & 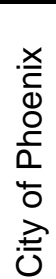 & 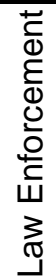 & $\begin{array}{l}\bar{O} \\
\text { D } \\
\overline{0}\end{array}$ & 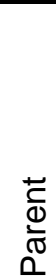 \\
\hline $\begin{array}{l}\text { Two adult crossing guards at wide } \\
\text { streets }\end{array}$ & & & $x$ & \\
\hline $\begin{array}{l}\text { Stronger speed enforcement at } \\
\text { schools }\end{array}$ & $x$ & $x$ & & \\
\hline $\begin{array}{l}\text { Paint SCHOOL pavement stencil } \\
\text { on high-speed approaches }\end{array}$ & $\mathrm{X}$ & & & \\
\hline Larger student waiting areas & $\mathrm{X}$ & & & \\
\hline Student "Stand Back" lines & $\mathrm{X}$ & & & \\
\hline "Safest Route to School" Plans & $\mathrm{X}$ & & $x$ & $\mathrm{x}$ \\
\hline Red-Light cameras at signals & $\mathrm{X}$ & & $x$ & \\
\hline $\begin{array}{l}\text { Zero tolerance at } 15 \mathrm{mph} \text { zones, } 5 \\
\mathrm{mph} \text { tolerance elsewhere }\end{array}$ & $\mathrm{X}$ & $\mathrm{X}$ & & \\
\hline $\begin{array}{l}\text { Brighter vests, and other uniform } \\
\text { pieces }\end{array}$ & & & $x$ & \\
\hline International pedestrian signals & $\mathrm{X}$ & & & \\
\hline More safety training of students & $x$ & & $x$ & $x$ \\
\hline Crossing guard training & & & $x$ & \\
\hline $\begin{array}{l}\text { Prevent future elementary schools } \\
\text { on major streets }\end{array}$ & $\mathrm{X}$ & & $x$ & \\
\hline $\begin{array}{l}\text { Arterial streets as attendance } \\
\text { boundaries }\end{array}$ & & & $x$ & \\
\hline $\begin{array}{l}\text { Arterial streets as bussing } \\
\text { boundaries }\end{array}$ & $X$ & & $x$ & \\
\hline Buffers and/or wider sidewalks & $X$ & & $x$ & \\
\hline $\begin{array}{l}\text { Consider raising fines or adding } \\
\text { points for school zone citations }\end{array}$ & $X$ & $X$ & & \\
\hline
\end{tabular}




\subsubsection{Pedestrian Consideration}

A main focus in the safety plan is the involvement and consideration of pedestrians. Most of the recommendations deal with the increase safety of pedestrians. Increasing pedestrian safety can always start with an organized route to and from the school. This is seen in a "Safest Route to School" program seen in Figure 3-1.

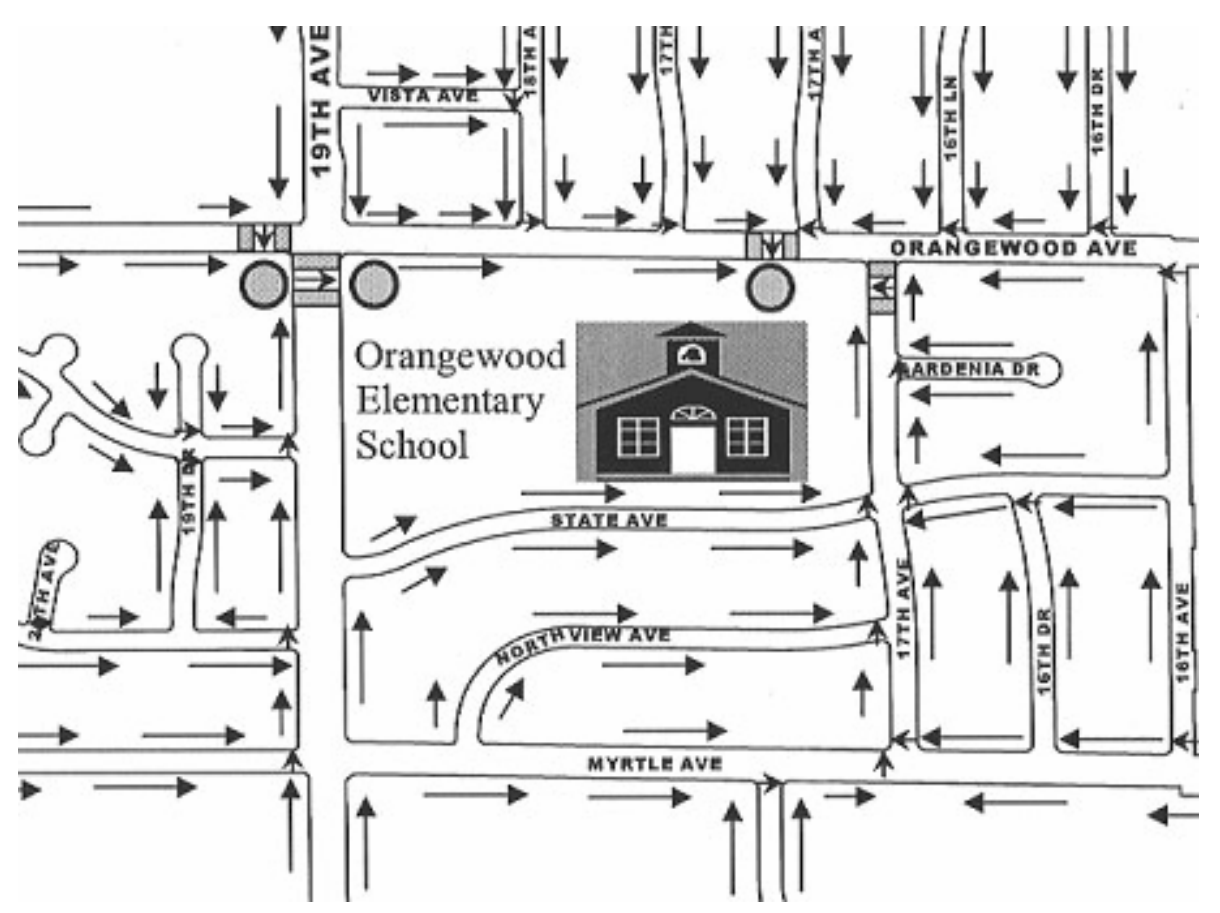

Figure 3-1: Example of a "Safest Route to School" plan. (Grote 2002)

In addition to making a consistent route for the students, the city must accommodate pedestrians on these streets. This includes the development of sidewalks, pedestrian signals, and waiting areas. City engineers and planners need to make it possible for pedestrians to walk beside the streets. Facilities need to be built to allow these pedestrian movements. The recommendations of larger waiting areas, Figure 3-2 and stand back areas, Figure 3-3 allow students and other pedestrians to stay away from moving traffic while waiting to cross the street. Without these additional areas, children are exposed to traffic and may overflow into the street, Figure 3-3a. 


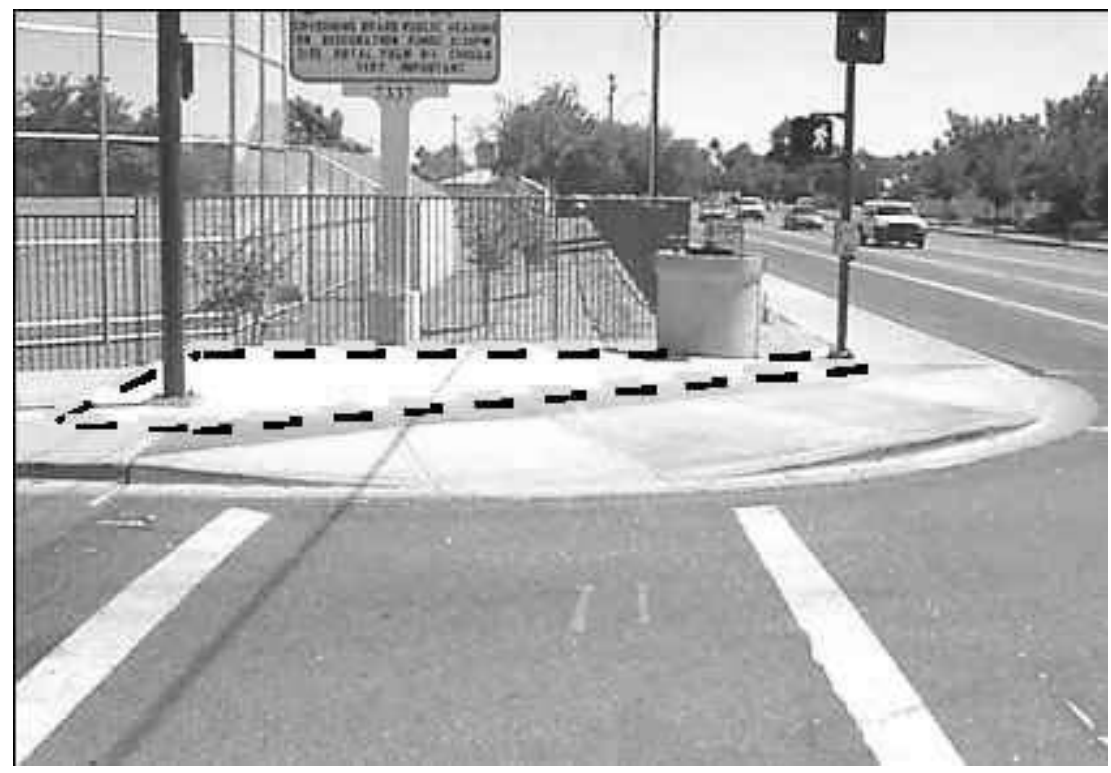

Figure 3-2: Larger waiting areas at intersections. (Grote 2002)

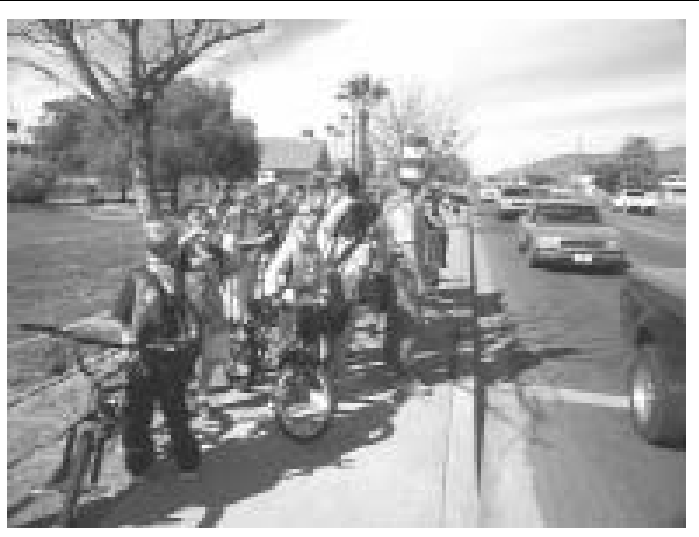

a) Before

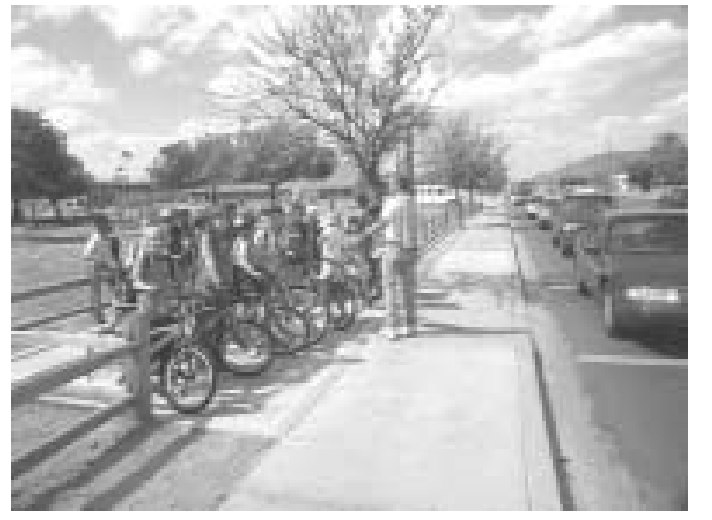

b) After

Figure 3-3: Before and After installation of "Stand Back" lines. (Grote 2002)

Along with creating the facilities for pedestrians, there is a need for adjustments in operations. There are two parts in the adjustment of operations. The first is the signalization at intersections. Universal pedestrian signals, Figure 3-4, and appropriate pedestrian walk times are needed to allow pedestrians to cross the street. Pedestrian walk times need to be adjusted for the pedestrian walking speed. The standard walk times may not be sufficient time for children to walk 
across the intersection. In addition to increasing pedestrian walk and clearance times, pedestrian recall can be utilized to increase safety. Pedestrian recall allows for the 'Pedestrian Walk' indication to be called during each cycle. The second adjustment in operations is the use of crossing guards. Crossing guards help with students crossing the street. Motorists become aware that children are present and as previously discussed, travel speeds decrease. At larger intersections, two crossing guards can be beneficial as seen in Figure 3-5. Crossing guards need to be visible. The use of brighter and more reflective clothes will help in the motorist's recognition of crossing guards.
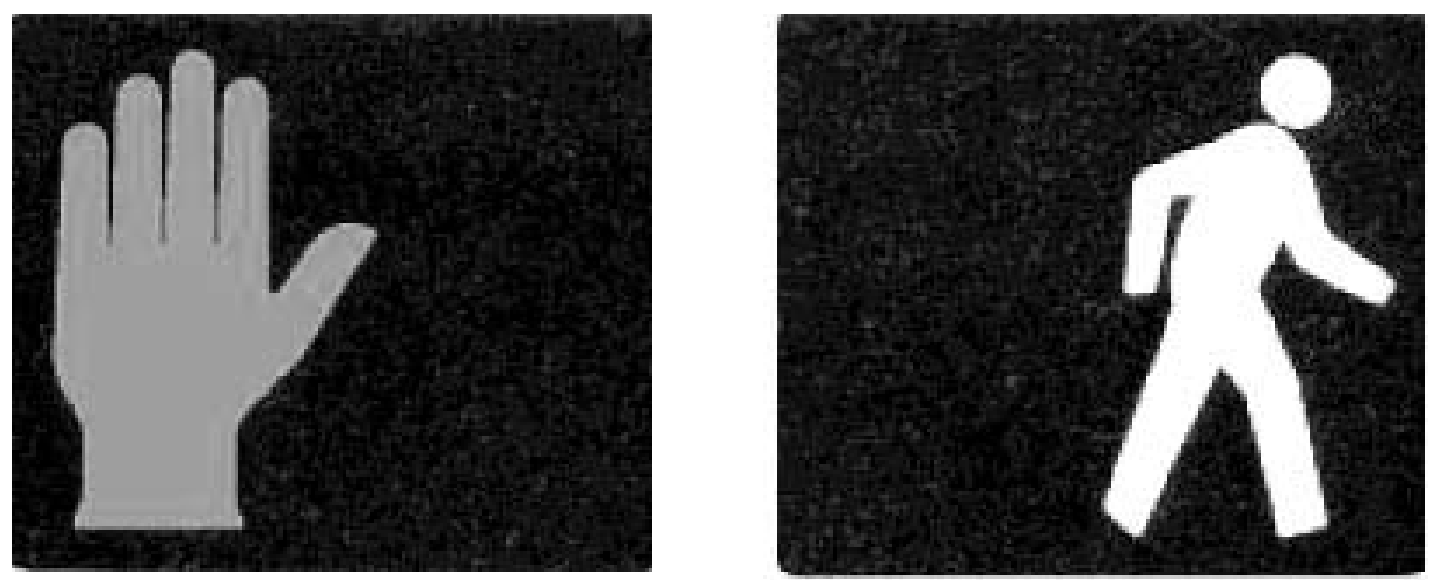

Figure 3-4: Universal pedestrian signals. (Grote 2002) 


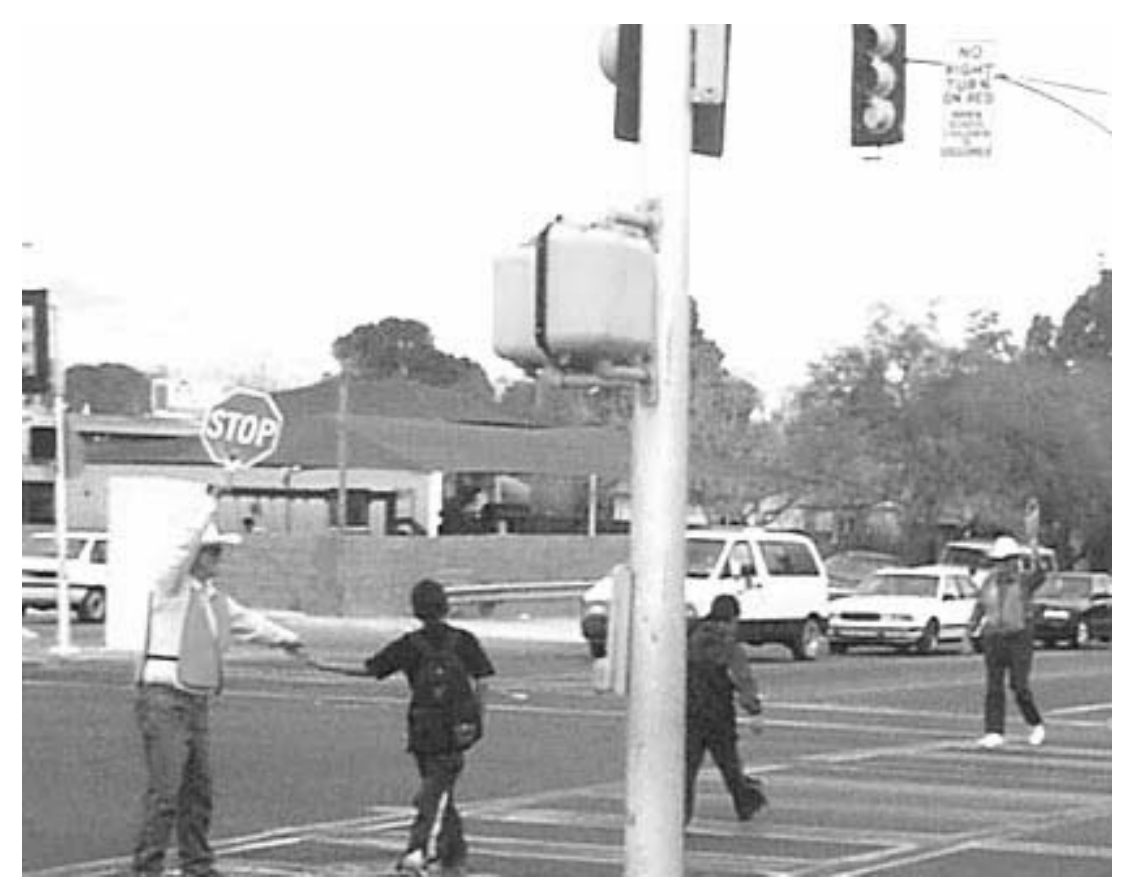

Figure 3-5: Two crossing guards at wider streets. (Grote 2002)

\subsubsection{Law Enforcement}

The following section discusses the use of law enforcement in the increase of safety in school zones. In the previous section, the average travel speed through a school is typically higher than the posted speed limit. An effective method of speed control is having a strong police presence in the school zone as seen in Figure 3-6. Motorists often decrease their speeds to or below the speed limit when there is police present. Another way of deterring high speeds through school zones is the use of increased school zone violation fines as shown in Figure 3-7. A zerotolerance policy can be incorporated along with school zone violation fines. All of these recommendations depend on the cooperation of the city and law enforcement. 


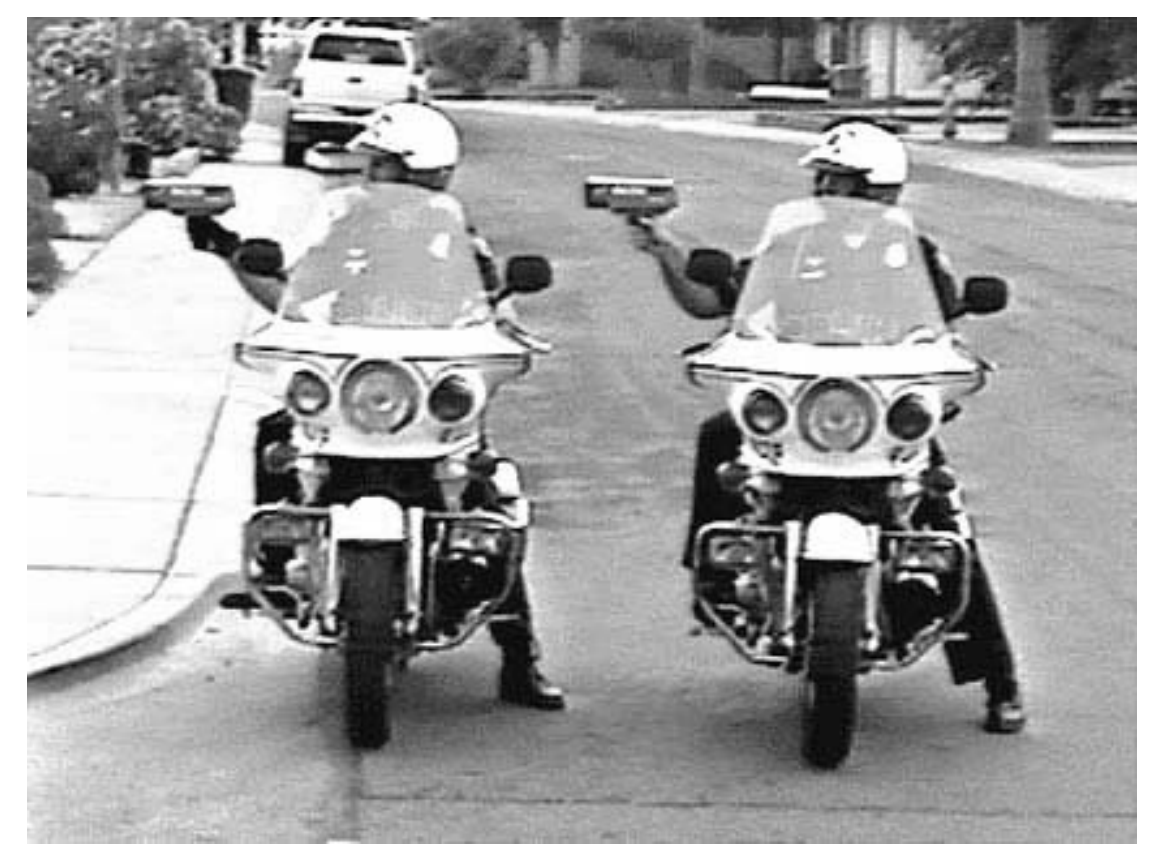

Figure 3-6: Speed Enforcement in School Zones. (Grote 2002)

\section{Existing \\ School Zone Violation Fines}

For speeding or passing in a School Zone

ARS 28-797

Fine: $\$ 110$

Points: 2 


\subsubsection{Education}

Educating everyone involved in school zone safety is a necessary step and process. This begins with the students, shown in Figure 3-8. Parents and teacher begin the learning process by teaching the students basics in safety. Safety training allows students to be aware of the dangers with vehicles and intersections. This process continues to law enforcement officers and city administrators. The people who implement and enforce the safety plan need to understand the goals and mission of the program.

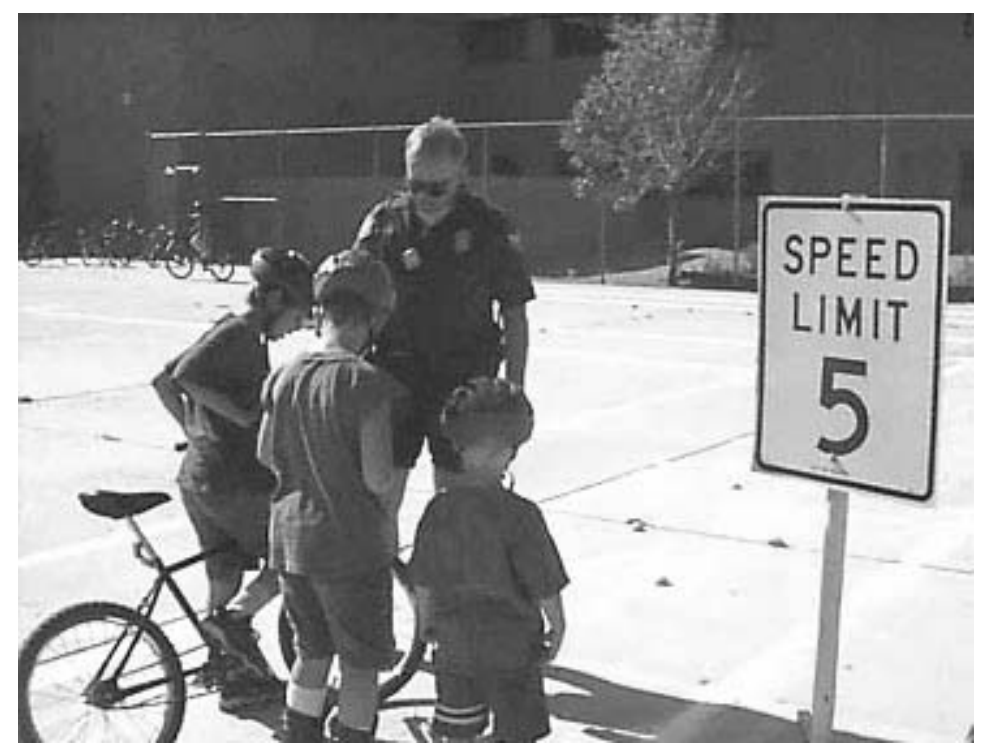

Figure 3-8: Education and training of students. (Grote 2002)

\subsubsection{Application to Indiana School Zones}

The City of Phoenix developed these recommendations to help improve the safety of their local school districts. From the recommendations, the State of Indiana can use these ideas and apply them to the numerous school districts within the state. Indiana school districts can be divided into two categories, city and county. Each of the recommendations will have different impacts to the different districts and application can be adjusted accordingly as noted in Table 3-2. 
Table 3-2: Recommendations for Indiana City and County School Districts.

\begin{tabular}{|c|c|c|}
\hline Recommendations & 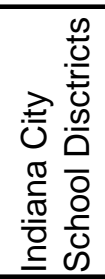 & 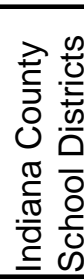 \\
\hline $\begin{array}{l}\text { Two adult crossing guards at wide } \\
\text { streets }\end{array}$ & $x$ & \\
\hline $\begin{array}{l}\text { Stronger speed enforcement at } \\
\text { schools }\end{array}$ & $X$ & $X$ \\
\hline $\begin{array}{l}\text { Paint SCHOOL pavement stencil } \\
\text { on high-speed approaches }\end{array}$ & $X$ & $x$ \\
\hline Larger student waiting areas & $x$ & \\
\hline Student "Stand Back" lines & $\mathrm{x}$ & \\
\hline "Safest Route to School" Plans & $\mathrm{X}$ & \\
\hline Red-Light cameras at signals & $x$ & \\
\hline $\begin{array}{l}\text { Zero tolerance at } 15 \text { mph zones, } 5 \\
\text { mph tolerance elsewhere }\end{array}$ & $X$ & $x$ \\
\hline $\begin{array}{l}\text { Brighter vests, and other uniform } \\
\text { pieces }\end{array}$ & $X$ & $X$ \\
\hline International pedestrian signals & $\mathrm{x}$ & \\
\hline More safety training of students & $X$ & $x$ \\
\hline Crossing guard training & $\mathrm{x}$ & $x$ \\
\hline $\begin{array}{l}\text { Prevent future elementary schools } \\
\text { on major streets }\end{array}$ & $x$ & $X$ \\
\hline $\begin{array}{l}\text { Arterial streets as attendance } \\
\text { boundaries }\end{array}$ & $\mathrm{X}$ & \\
\hline $\begin{array}{l}\text { Arterial streets as bussing } \\
\text { boundaries }\end{array}$ & & \\
\hline Buffers and/or wider sidewalks & $x$ & \\
\hline $\begin{array}{l}\text { Consider raising fines or adding } \\
\text { points for school zone citations }\end{array}$ & $X$ & $X$ \\
\hline
\end{tabular}

Indiana city school districts will be able to use recommendations related to pedestrians due to the higher percentage of students within a walking distance to the schools. The improvements for 
pedestrians will promote a safer walk to school for the students. If students are willing to walk to school, there will be less vehicular traffic going to and from the school. The use of arterial streets as attendance boundaries can help by preventing students from crossing heavy traffic streets and to stay on local streets.

A common problem that both city and county school districts have is traffic speed control. Traffic speeds are often higher than the posted speed limit and is a danger to the students and other vehicles. Law enforcement and traffic control recommendations are used to try to regulate and lower speeds through school zones. Speeds can be lowered through two methods, driver awareness and enforcement. Signs and stencil markings along the road can increase driver awareness and help with lowering travel speeds and increasing caution near schools.

Enforcement around school zones can also help with lowering speeds. Drivers will be aware of the police presence around schools and abide by the speeds limits and other traffic laws.

Another precaution that can be done for city and county school districts is to prevent future schools to be built on major streets. Placing a school near a major road can lead to problems with traffic and safety. During the planning stages, the location of the school can help with increasing safety.

The last applicable recommendation is the safety education and training of students. Making the students aware of the possible dangers around the school and their trip to and from school can help prevent crashes. 


\section{CHAPTER 4. METHODOLOGY}

One of the primary objectives of this research was to conduct a before and after study of crashes at signals that are minimally warranted.

The following data analysis is a process that is comprised of two parts. The first part consists of categorizing and totaling all of the crashes at the identified intersection by crash type and severity. The crashes are also separated by when they occurred, before or after the signal is installed. The second part is an analysis of the before after crash data for each intersection to determine if there are any "statistically significant" changes in safety for different types and severity of crashes. The following section describes the data collection and first part of the analysis process.

\section{1. $\quad$ Data Collection}

In consultation with INDOT, several signals installed during the last seven years where warrants were barely satisfied were identified. Crash data for up to three-five years prior and three-five years after were obtained. From the previous list of intersections, intersections that are adjacent to school zones are identified. Along with the previous list of intersections, groups of intersection adjacent to schools are identified.

Due to limitations of available crash data, the list of intersections was narrowed to nineteen intersections. These intersections had signals installed between the years of 1992 and 1997. The corresponding crash data for these intersections were obtained and is dated from 1991 to 1999. There is a varying amount of crash data for the intersections since the signals at each intersection were installed at different years. This variation ranges between one to five years for each of the before and after cases. The construction year is not included in the total of crashes. This eliminates any crashes due to the variation of circumstances and changing conditions at the intersection. Table 4-1 lists the intersections with the corresponding installation year as well as 
the number of crashes before and after the traffic signal installation. A total of 63 years of before and 72 years of after data are collected along with 146 crashes and 310 crashes respectively.

Table 4-1: Collected Data Summary Table.

\begin{tabular}{|c|c|c|c|c|c|}
\hline Intersection & $\begin{array}{c}\text { Installation } \\
\text { Year }\end{array}$ & Years Before & $\begin{array}{l}\text { Accidents } \\
\text { Before }\end{array}$ & Years After & $\begin{array}{c}\text { Accidents } \\
\text { After }\end{array}$ \\
\hline 1 & 1997 & 5 & 2 & 2 & 1 \\
\hline 2 & 1997 & 5 & 0 & 2 & 7 \\
\hline 3 & 1997 & 5 & 21 & 2 & 7 \\
\hline 4 & 1992 & 1 & 3 & 5 & 20 \\
\hline 5 & 1992 & 1 & 11 & 5 & 54 \\
\hline 6 & 1992 & 1 & 9 & 5 & 33 \\
\hline 7 & 1992 & 1 & 3 & 5 & 10 \\
\hline 8 & 1994 & 3 & 9 & 5 & 28 \\
\hline 9 & 1995 & 4 & 28 & 4 & 29 \\
\hline 10 & 1997 & 5 & 0 & 2 & 7 \\
\hline 11 & 1996 & 5 & 1 & 3 & 0 \\
\hline 12 & 1996 & 5 & 10 & 3 & 8 \\
\hline 13 & 1992 & 1 & 0 & 5 & 9 \\
\hline 14 & 1994 & 3 & 3 & 5 & 25 \\
\hline 15 & 1995 & 4 & 28 & 4 & 33 \\
\hline 16 & 1994 & 3 & 0 & 5 & 1 \\
\hline 17 & 1997 & 5 & 7 & 2 & 12 \\
\hline 18 & 1992 & 1 & 5 & 5 & 24 \\
\hline 19 & 1996 & 5 & 6 & 3 & 2 \\
\hline \multicolumn{2}{|c|}{ Total } & 63 & 146 & 72 & 310 \\
\hline
\end{tabular}

\section{2. $\quad$ Crash Categorization}

The collected crash data was then categorized into crash types and severity of crashes. The types of crashes, explained in Appendix A, are separated into ten groups listed as follows:

- 'Rear End, Neither Turning'

- 'Head On, Neither Turning'

- 'Same Direction Sideswipe'

- 'Opposite Direction Sideswipe' 
- 'Off Road Collision'

- 'Right Angle'

- 'Left and Right Turns'

- 'Left Turn'

- 'Right Turn'

- 'Other/Unknown'

Each crash is also separated by severity;

- 'Property Damage'

- 'Personal Injury'

- 'Fatal'

For each intersection, an aggregate total of each type and severity of crashes was calculated for the before and after years. Along with the crash types and severities, the total crash counts for before and after signal installation are used during analysis.

\section{3. $\quad$ Crash Data Sensitivity}

The study areas for this project were 0-200 feet, 0-500 feet and 0-1000 feet from the intersection. An example of the study areas are seen in Figure 4-1. The study area of 200 feet includes crashes only within 200 feet of the intersection. This area follows INDOT standards for intersection crash studies. The study area of 500 feet allows for the inclusion of crashes from extended queued traffic at intersections and includes crashes within 500 feet from the intersection. Crashes within the study area of 1000 feet allows for the inclusion of any secondary entrances, which are typically seen in school zones. 


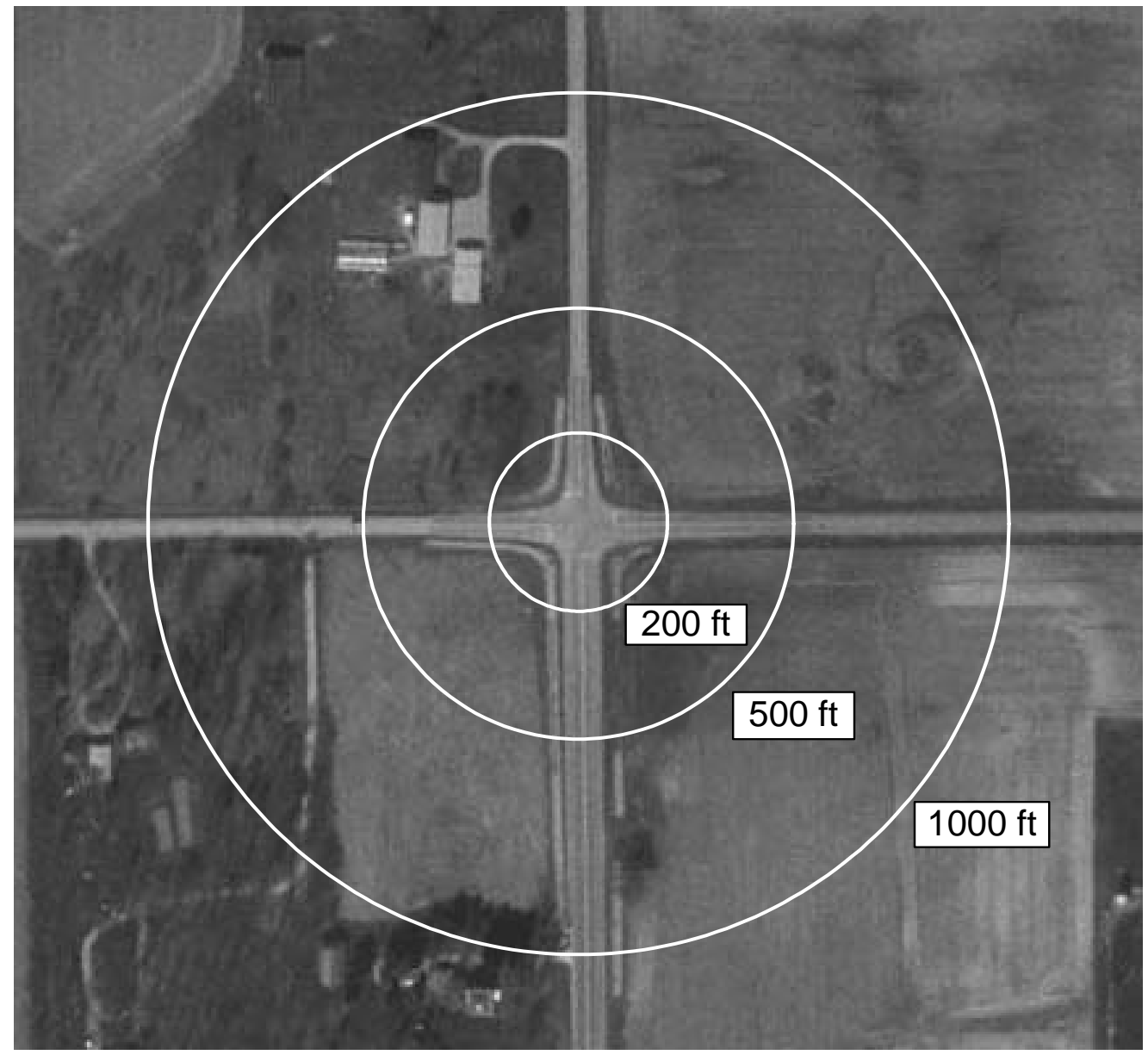

Figure 4-1: Illustration of 200, 5001000 feet data collection radius.

\section{4. $\quad$ Crash Data Summary}

The following tables show crash data summarized for each intersection by type and severity. These summaries are also separated by distances from the intersection. Along with the summarized data tables, two fatalities are denoted in each of the crash type tables. The fatality is depicted as shaded spaces in the tables. 


\subsubsection{Fatal Crashes}

There were two fatalities in the data set. The fatality at Intersection 18 is a 'Right Angle' crash. This crash occurred before the signal installation period on Monday, August 26, 1991 at 5:01 pm. Details of this crash show that the victim of this crash was an under aged unlicensed person driving a moped. The victim enters the intersection without seeing an oncoming vehicle. The oncoming vehicle strikes the moped and the victim is thrown from the moped onto the pavement. The victim later dies at the hospital the following day.

The second fatality occurs at Intersection 19 with a 'Left Turn' crash type. This fatality occurred on Saturday, July 16,1994 at 2:17 pm. This crash consists of a driver failing to yield to the right of way. The driver turns left without watching for oncoming vehicles. The person's view is also obstructed by another vehicle turning left in the opposite direction. The oncoming vehicle, driven by the victim, strikes the turning vehicle causing it to deflect towards the right and hit a stopped vehicle on the minor road.

\subsubsection{Study Area Summaries}

Table 4-2 shows the details of crash types for each intersection within 200 feet. There are a total of 128 crashes before installation and 291 crashes after signal installation. These crashes are further categorized in Table 4-3 by severity. 
Table 4-2: Summary Table of Crash Types Within 200 feet of the Intersection.

\begin{tabular}{|c|c|c|c|c|c|c|c|c|c|c|c|c|c|c|c|c|c|c|c|c|c|c|c|c|c|c|}
\hline \multirow{3}{*}{ 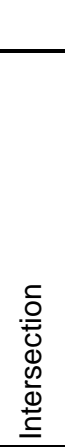 } & & & \multicolumn{24}{|c|}{ Counts by Crash Types } \\
\hline & & 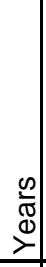 & & 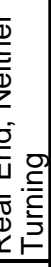 & & 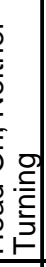 & & $\begin{array}{l}3 \\
3 \\
0 \\
0 \\
0 \\
\frac{1}{0}\end{array}$ & & 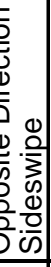 & & & & & 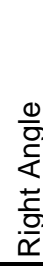 & \multicolumn{3}{|c|}{ 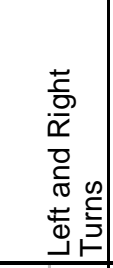 } & \multicolumn{2}{|r|}{ 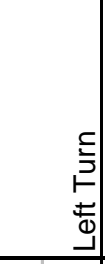 } & & 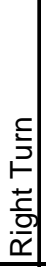 & \multicolumn{2}{|r|}{ 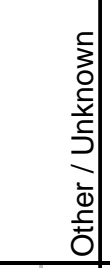 } & \multicolumn{2}{|r|}{$\begin{array}{l}\overline{\widetilde{\pi}} \\
\stackrel{0}{0}\end{array}$} \\
\hline & $\begin{array}{l}\Phi \\
\frac{0}{0} \\
\stackrel{0}{\emptyset} \\
\end{array}$ & $\begin{array}{l}\frac{1}{d} \\
\frac{ \pm}{4} \\
\end{array}$ & $\begin{array}{l}0 \\
\frac{0}{0} \\
\text { D. } \\
\end{array}$ & $\frac{\bar{\Phi}}{\frac{ \pm}{4}}$ & 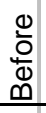 & $\frac{\bar{d}}{\frac{1}{4}}$ & $\begin{array}{l}0 \\
\stackrel{0}{0} \\
\stackrel{0}{0} \\
\square\end{array}$ & 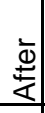 & 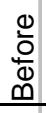 & $\frac{\bar{\Phi}}{\frac{1}{4}}$ & $\begin{array}{l}\frac{0}{\frac{0}{0}} \\
\frac{0}{\Phi} \\
\end{array}$ & & & $\begin{array}{l}\frac{1}{0} \\
\frac{0}{2} \\
\Phi\end{array}$ & $\frac{\bar{d}}{\frac{1}{4}}$ & 空 & & & $\begin{array}{l}\frac{1}{0} \\
\frac{0}{\Phi} \\
\Phi \\
\end{array}$ & $\frac{\bar{d}}{\frac{ \pm}{4}}$ & $\begin{array}{l}0 \\
\frac{0}{0} \\
\Phi \\
D\end{array}$ & 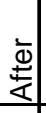 & 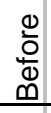 & $\begin{array}{l}\frac{1}{ \pm} \\
\frac{ \pm}{4} \\
\end{array}$ & $\begin{array}{l}0 \\
\frac{0}{0} \\
\stackrel{0}{0} \\
\end{array}$ & $\frac{\bar{\Phi}}{\frac{1}{4}}$ \\
\hline 1 & 5 & 2 & 1 & 0 & 0 & 0 & 0 & 0 & 0 & 0 & 0 & & & 0 & 0 & & & & 0 & 0 & 0 & 0 & 0 & 0 & 1 & 0 \\
\hline 2 & 5 & 2 & 0 & 2 & 0 & 2 & 0 & 0 & 0 & 0 & 0 & & & 0 & 0 & & & 0 & 0 & 0 & 0 & 0 & 0 & 2 & 0 & 6 \\
\hline 3 & 5 & 2 & 6 & 4 & 0 & 0 & 5 & 1 & 0 & 0 & 1 & & & 1 & 1 & & & 4 & 2 & 0 & 1 & 0 & 4 & 1 & 20 & 7 \\
\hline 4 & 1 & 5 & 0 & 11 & 0 & 0 & 0 & 0 & 0 & 1 & 0 & & & 3 & 5 & & & & 0 & 0 & & 0 & 0 & 3 & 3 & 20 \\
\hline 5 & 1 & 5 & 6 & 36 & 0 & 0 & 2 & 1 & 0 & 1 & 0 & & & 1 & 8 & & & 0 & 0 & 0 & 1 & 0 & 1 & 5 & 11 & 51 \\
\hline 6 & 1 & 5 & 4 & 22 & 0 & & 0 & 0 & 0 & 0 & 0 & & & 5 & 3 & & & 0 & 0 & 1 & 0 & 0 & 0 & 4 & 9 & 32 \\
\hline 7 & 1 & 5 & 0 & 1 & 0 & 0 & 0 & 0 & 0 & 0 & 0 & & & 0 & 0 & & & 4 & 0 & 0 & 1 & 0 & 2 & 7 & 3 & 8 \\
\hline 8 & 3 & 5 & 6 & 19 & 0 & 0 & 0 & 2 & 0 & 0 & 0 & & & 1 & 2 & & & & 0 & 3 & 1 & 0 & 1 & 2 & 9 & \\
\hline 9 & 4 & 4 & 6 & 5 & 1 & 1 & 1 & 0 & 0 & 0 & 0 & & & 9 & 9 & & & & 0 & 7 & 2 & 0 & 4 & 3 & 23 & 27 \\
\hline 10 & 5 & 2 & 0 & 3 & 0 & 0 & 0 & 2 & 0 & 0 & 0 & & & 0 & 1 & & & 0 & 0 & 0 & 0 & 0 & 0 & 0 & 0 & 6 \\
\hline 11 & 5 & 3 & 1 & 0 & 0 & 0 & 0 & 0 & 0 & 0 & 0 & & & 0 & 0 & & & & 0 & 0 & 0 & 0 & 0 & 0 & 1 & 0 \\
\hline 12 & 5 & 3 & 1 & 2 & 0 & 0 & 0 & 0 & 0 & 0 & 0 & & & 2 & 3 & & & & 1 & 1 & 0 & 0 & 0 & 0 & 4 & 6 \\
\hline 13 & 1 & 5 & 0 & 2 & 0 & 0 & 0 & 0 & 0 & 0 & 0 & & & 0 & 0 & & & 0 & 0 & 0 & 0 & 0 & 0 & 6 & 0 & 9 \\
\hline 14 & 3 & 5 & 1 & 7 & 0 & 0 & 1 & 2 & 0 & 0 & 0 & & & 0 & 5 & & & 0 & 1 & 8 & 0 & 0 & 0 & 2 & 3 & 25 \\
\hline 15 & 4 & 4 & 7 & 2 & 0 & 2 & 0 & 0 & 2 & 0 & 0 & & & 6 & 2 & & & & 3 & 2 & 0 & 0 & 9 & 23 & 27 & 31 \\
\hline 16 & 3 & 5 & 0 & 0 & 0 & & 0 & 1 & 0 & 0 & 0 & & & 0 & $c$ & & & & 0 & 0 & 0 & 0 & 0 & 0 & 0 & \\
\hline 17 & 5 & 2 & 1 & 4 & 0 & & 0 & 1 & 0 & 0 & 0 & & & 5 & 2 & & & & 0 & 2 & 0 & 0 & 0 & 2 & 6 & \\
\hline 18 & 1 & 5 & 0 & 8 & 0 & 0 & 0 & 1 & 0 & 0 & 0 & & & 2 & 5 & & & 0 & 1 & 3 & 0 & 0 & 0 & 4 & 3 & 21 \\
\hline 19 & 5 & 3 & 0 & 1 & 0 & 0 & 1 & 0 & 0 & 0 & 0 & & & 3 & $c$ & & & 4 & 1 & 0 & 0 & 0 & 0 & 0 & 5 & \\
\hline Total & 63 & 72 & 40 & 129 & 1 & 7 & 10 & 11 & 2 & 2 & 1 & & & 38 & 46 & & & & 9 & 27 & 6 & 0 & 21 & 64 & 128 & 291 \\
\hline
\end{tabular}


Table 4-3: Summary Table for Severity of Crashes Within 200 feet of the intersection.

\begin{tabular}{|c|c|c|c|c|c|c|c|c|}
\hline \multirow{3}{*}{ 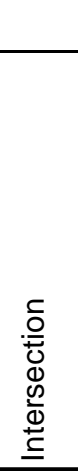 } & & & \multicolumn{6}{|c|}{ Severity of Crashes } \\
\hline & \multicolumn{2}{|r|}{$\begin{array}{l}\stackrel{\infty}{\mathbb{J}} \\
\stackrel{\infty}{ \pm}\end{array}$} & \multicolumn{2}{|c|}{ 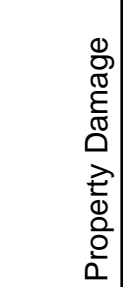 } & \multicolumn{2}{|r|}{ 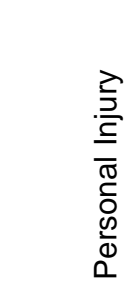 } & \multicolumn{2}{|r|}{ 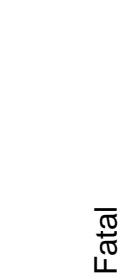 } \\
\hline & $\begin{array}{l}0 \\
\frac{0}{0} \\
\stackrel{0}{0} \\
\varnothing\end{array}$ & 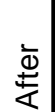 & $\begin{array}{l}\frac{0}{0} \\
\frac{0}{0} \\
\varnothing\end{array}$ & $\underset{\frac{\Phi}{\alpha}}{\frac{\bar{t}}{\alpha}}$ & $\begin{array}{l}\frac{0}{0} \\
\frac{0}{D} \\
\end{array}$ & $\underset{\frac{\Phi}{4}}{\frac{\Phi}{4}}$ & $\frac{\varrho}{\frac{0}{\Phi}}$ & 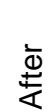 \\
\hline 1 & 5 & 2 & 1 & 0 & 0 & 0 & 0 & 0 \\
\hline 2 & 5 & 2 & 0 & 4 & 0 & 2 & 0 & \\
\hline 3 & 5 & 2 & 17 & 6 & 3 & 1 & 0 & 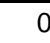 \\
\hline 4 & 1 & 5 & 2 & 19 & 1 & 1 & 0 & \\
\hline 5 & 1 & 5 & 11 & 46 & 0 & 5 & 0 & 0 \\
\hline 6 & 1 & 5 & 9 & 21 & 0 & 11 & 0 & 0 \\
\hline 7 & 1 & 5 & 3 & 6 & 0 & 2 & 0 & 0 \\
\hline 8 & 3 & 5 & 4 & 22 & 5 & 6 & 0 & 0 \\
\hline 9 & 4 & 4 & 18 & 22 & 5 & 5 & 0 & 0 \\
\hline 10 & 5 & 2 & 0 & 4 & 0 & 2 & 0 & 0 \\
\hline 11 & 5 & 3 & 0 & 0 & 1 & $\overline{0}$ & 0 & 0 \\
\hline 12 & 5 & 3 & 2 & 4 & 2 & 2 & 0 & 0 \\
\hline 13 & 1 & 5 & 0 & 6 & 0 & 3 & 0 & 0 \\
\hline 14 & 3 & 5 & 2 & 16 & 1 & 9 & 0 & 0 \\
\hline 15 & 4 & 4 & 18 & 21 & 9 & 10 & 0 & 0 \\
\hline 16 & 3 & 5 & 0 & 1 & 0 & 0 & 0 & 0 \\
\hline 17 & 5 & 2 & 2 & 9 & 4 & 3 & 0 & 0 \\
\hline 18 & 1 & 5 & 2 & 16 & 0 & 5 & 1 & \\
\hline 19 & 5 & 3 & 3 & 1 & $\overline{1}$ & $\overline{0}$ & 1 & 0 \\
\hline Total & 63 & 72 & 94 & 224 & 32 & 67 & 2 & 0 \\
\hline
\end{tabular}

When the study area is expanded to 500 feet, there is an increase in the total data set as seen in Table 4-4 and Table 4-5. There are 11 more crashes before the traffic signal installation and seven more after signal installation. 
Table 4-4: Summary Table for Crash Types Within 500 feet of the Intersection.

\begin{tabular}{|c|c|c|c|c|c|c|c|c|c|c|c|c|c|c|c|c|c|c|c|c|c|c|c|c|c|}
\hline \multirow{3}{*}{ 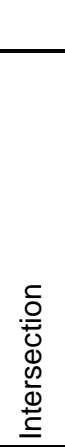 } & & & \multicolumn{23}{|c|}{ Counts by Crash Types } \\
\hline & & $\begin{array}{l}\infty \\
\stackrel{\infty}{\mathbb{d}} \\
\searrow \\
\searrow\end{array}$ & & 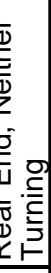 & & 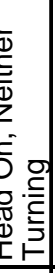 & \multicolumn{2}{|c|}{ 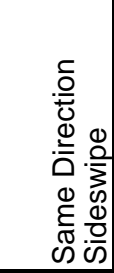 } & \multicolumn{2}{|c|}{ 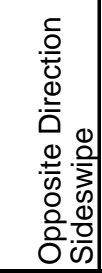 } & \multicolumn{3}{|c|}{ 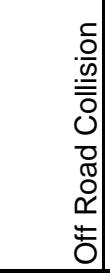 } & \multicolumn{2}{|r|}{ 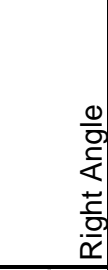 } & \multicolumn{2}{|c|}{ 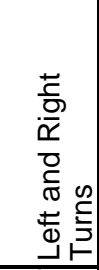 } & \multicolumn{2}{|r|}{ 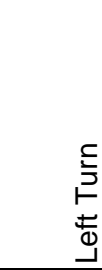 } & \multicolumn{4}{|r|}{ 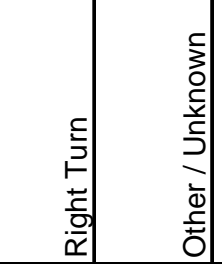 } & \multicolumn{2}{|r|}{$\begin{array}{l}\bar{\pi} \\
\overline{0}\end{array}$} \\
\hline & $\begin{array}{l}\frac{\Phi}{0} \\
\frac{0}{\Phi} \\
\Phi\end{array}$ & $\frac{\bar{d}}{\frac{ \pm}{4}}$ & $\begin{array}{l}\frac{0}{0} \\
\frac{0}{0} \\
\Phi\end{array}$ & $\frac{\bar{\Phi}}{\frac{ \pm}{d}}$ & $\begin{array}{l}0 \\
\frac{0}{0} \\
\stackrel{0}{0} \\
\infty\end{array}$ & $\frac{\bar{d}}{\frac{ \pm}{d}}$ & $\begin{array}{l}0 \\
\stackrel{0}{0} \\
\stackrel{0}{0} \\
\infty\end{array}$ & $\frac{1}{ \pm}$ & $\begin{array}{l}0 \\
\frac{0}{0} \\
\stackrel{0}{0} \\
\infty\end{array}$ & $\frac{1}{\frac{1}{4}}$ & $\begin{array}{l}\frac{0}{0} \\
\frac{0}{0} \\
\infty\end{array}$ & & & $\frac{0}{\frac{0}{0}}$ & $\frac{1}{\frac{1}{4}}$ & $\begin{array}{l}\frac{0}{2} \\
\frac{0}{2} \\
\frac{\Phi}{0}\end{array}$ & $\frac{\bar{d}}{\frac{\pi}{\alpha}}$ & $\begin{array}{l}0 \\
\frac{0}{0} \\
\Phi \\
\Phi\end{array}$ & $\frac{1}{\frac{1}{4}}$ & $\frac{0}{\frac{0}{0}}$ & 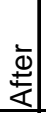 & $\begin{array}{l}\frac{0}{0} \\
\frac{0}{0} \\
\Phi\end{array}$ & 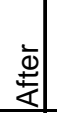 & $\begin{array}{l}0 \\
\frac{0}{0} \\
\stackrel{0}{\Phi} \\
\Phi\end{array}$ & $\frac{1}{\frac{1}{4}}$ \\
\hline 1 & 5 & 2 & 2 & 1 & 0 & 0 & 0 & 0 & 0 & 0 & 0 & & & 0 & 0 & 0 & 0 & 0 & 0 & 0 & 0 & 0 & 0 & 2 & \\
\hline 2 & 5 & 2 & 0 & 2 & 0 & 2 & 0 & 0 & 0 & 0 & 0 & & & 0 & 0 & $\overline{0}$ & 0 & 0 & 0 & 0 & 0 & 0 & 3 & 0 & \\
\hline 3 & 5 & 2 & 6 & 4 & 1 & 0 & 5 & 1 & 0 & 0 & 1 & & & 1 & 1 & 0 & 0 & 2 & 0 & 1 & 0 & 4 & 1 & 21 & 7 \\
\hline 4 & 1 & 5 & 0 & 11 & 0 & 0 & 0 & 0 & 0 & 1 & 0 & & & 3 & 5 & 0 & 0 & 0 & 0 & 0 & 0 & 0 & 3 & 3 & 20 \\
\hline 5 & 1 & 5 & 6 & 37 & 0 & 0 & 2 & 1 & 0 & 1 & 0 & & & 1 & 9 & 0 & 0 & 0 & 0 & 1 & 0 & 1 & 5 & 11 & 53 \\
\hline 6 & 1 & 5 & 4 & 22 & 0 & 1 & 0 & 1 & 0 & 0 & 0 & & & 5 & 3 & 0 & 0 & 0 & 1 & 0 & 0 & 0 & 4 & 9 & 33 \\
\hline 7 & 1 & 5 & 0 & 1 & 0 & 0 & 0 & 1 & 0 & 0 & 0 & & & 0 & 1 & 0 & 0 & 0 & 0 & 1 & 0 & 2 & 7 & 3 & \\
\hline 8 & 3 & 5 & 6 & 19 & 0 & 0 & 0 & 2 & 0 & 0 & 0 & & & 1 & 2 & 0 & 0 & 0 & 3 & 1 & 0 & 1 & 2 & 9 & 28 \\
\hline 9 & 4 & 4 & 9 & 6 & 1 & 1 & 1 & 0 & 0 & 0 & 0 & & & 10 & 10 & 0 & 1 & 1 & 7 & 2 & 0 & 4 & 3 & 28 & 29 \\
\hline 10 & 5 & 2 & 0 & 3 & 0 & 0 & 0 & 2 & 0 & 0 & 0 & & & 0 & 1 & 0 & 0 & 0 & 0 & 0 & 0 & 0 & 0 & 0 & \\
\hline 11 & 5 & 3 & 1 & 0 & 0 & 0 & 0 & 0 & 0 & 0 & 0 & & & 0 & 0 & 0 & 0 & 0 & 0 & 0 & 0 & 0 & 0 & 1 & 0 \\
\hline 12 & 5 & 3 & 3 & 2 & 0 & 0 & 0 & 0 & 0 & 0 & 0 & & & 2 & 3 & 0 & 0 & 1 & 2 & 0 & 0 & 0 & 0 & 6 & \\
\hline 13 & 1 & 5 & 0 & 2 & 0 & 0 & 0 & 0 & 0 & 0 & 0 & & & 0 & 0 & 0 & 0 & 0 & 0 & 0 & 0 & 0 & 6 & 0 & 9 \\
\hline 14 & 3 & 5 & 1 & 7 & 0 & 0 & 1 & 2 & 0 & 0 & 0 & & & 0 & 5 & 0 & 0 & 1 & 8 & 0 & 0 & 0 & 2 & 3 & 25 \\
\hline 15 & 4 & 4 & 7 & 3 & 0 & 2 & 0 & 0 & 2 & 0 & 0 & & & 6 & 2 & 0 & 0 & 3 & 2 & 0 & 0 & 9 & 23 & 27 & 32 \\
\hline 16 & 3 & 5 & 0 & 0 & 0 & 0 & 0 & 1 & 0 & 0 & 0 & & & 0 & 0 & 0 & 0 & 0 & 0 & 0 & 0 & 0 & 0 & 0 & \\
\hline 17 & 5 & 2 & 1 & 4 & 0 & 1 & 0 & 1 & 1 & 0 & 0 & & & 5 & 2 & 0 & 0 & 0 & 2 & 0 & 0 & 0 & 2 & 7 & \\
\hline 18 & 1 & 5 & 0 & 8 & 0 & 0 & 0 & 2 & 0 & 0 & 0 & & & 2 & 5 & 0 & 0 & 1 & 3 & 0 & 0 & 0 & 4 & 3 & 22 \\
\hline 19 & 5 & & 0 & 1 & 0 & 0 & 1 & 0 & 0 & 0 & 0 & & & 3 & 0 & 0 & 0 & 1 & 0 & 1 & 0 & 0 & 0 & 6 & \\
\hline Total & 63 & 72 & 46 & 133 & 2 & 7 & 10 & 14 & 3 & 2 & 1 & & & 39 & 49 & 0 & 1 & 10 & 28 & 7 & 0 & 21 & 65 & 139 & \\
\hline
\end{tabular}


Table 4-5: Summary Table for Severity of Crashes Within 500 feet of the intersection.

\begin{tabular}{|c|c|c|c|c|c|c|c|c|}
\hline \multirow{3}{*}{ 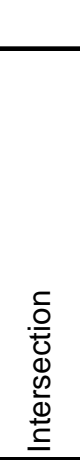 } & & & \multicolumn{6}{|c|}{ Severity of Crashes } \\
\hline & \multicolumn{2}{|r|}{$\begin{array}{l}\infty \\
\stackrel{\infty}{\mathbb{N}} \\
\stackrel{\mathbb{N}}{\succ}\end{array}$} & \multicolumn{2}{|r|}{ 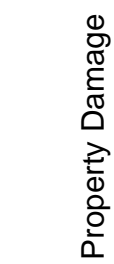 } & \multicolumn{2}{|c|}{ 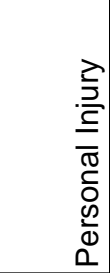 } & \multicolumn{2}{|c|}{ 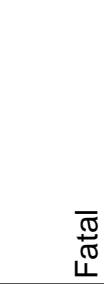 } \\
\hline & $\begin{array}{l}0 \\
\stackrel{0}{0} \\
\stackrel{0}{\emptyset} \\
\end{array}$ & 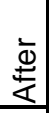 & 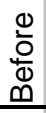 & $\frac{\bar{\Phi}}{\frac{1}{4}}$ & $\begin{array}{l}0 \\
\stackrel{0}{0} \\
\stackrel{0}{\emptyset} \\
\end{array}$ & $\frac{\bar{d}}{\frac{ \pm}{4}}$ & $\begin{array}{l}\frac{\Phi}{\vdots} \\
\frac{0}{\Phi} \\
\Phi\end{array}$ & $\underset{\frac{\Phi}{ \pm}}{\frac{\Phi}{4}}$ \\
\hline 1 & 5 & 2 & 1 & 0 & 1 & 1 & 0 & 0 \\
\hline 2 & 5 & 2 & 0 & 5 & 0 & 2 & 0 & 0 \\
\hline 3 & 5 & 2 & 17 & 6 & 4 & 1 & 0 & 0 \\
\hline 4 & 1 & 5 & 2 & 19 & 1 & 1 & 0 & 0 \\
\hline 5 & 1 & 5 & 11 & 47 & 0 & 6 & 0 & 0 \\
\hline 6 & 1 & 5 & 9 & 22 & 0 & 11 & 0 & 0 \\
\hline 7 & 1 & 5 & 3 & 7 & 0 & 3 & 0 & 0 \\
\hline 8 & 3 & 5 & 4 & 22 & 5 & 6 & 0 & 0 \\
\hline 9 & 4 & 4 & 19 & 24 & 9 & 5 & 0 & 0 \\
\hline 10 & 5 & 2 & 0 & 4 & 0 & 3 & 0 & 0 \\
\hline 11 & 5 & 3 & 0 & 0 & 1 & 0 & 0 & 0 \\
\hline 12 & 5 & 3 & 3 & 4 & 3 & 3 & 0 & 0 \\
\hline 13 & 1 & 5 & 0 & 6 & 0 & 3 & 0 & 0 \\
\hline 14 & 3 & 5 & 2 & 16 & 1 & 9 & 0 & 0 \\
\hline 15 & 4 & 4 & 18 & 21 & 9 & 11 & 0 & 0 \\
\hline 16 & 3 & 5 & 0 & 0 & 0 & 0 & 0 & 0 \\
\hline 17 & 5 & 2 & 3 & 9 & 4 & 3 & 0 & 0 \\
\hline 18 & 1 & 5 & 2 & 17 & 0 & 5 & 1 & 0 \\
\hline 19 & 5 & 3 & 4 & 1 & 1 & 0 & 1 & 0 \\
\hline Total & 63 & 72 & 98 & 230 & 39 & 73 & 2 & 0 \\
\hline
\end{tabular}

Table 4-6 summarizes the crash types for crashes within 1000 feet of the intersection and shows additional crashes with the larger study area. There is an increase of seven before crashes and six after crashes. 
Table 4-6: Summary Table for Crash Types Within 1000 feet of the Intersection.

\begin{tabular}{|c|c|c|c|c|c|c|c|c|c|c|c|c|c|c|c|c|c|c|c|c|c|c|c|c|c|c|}
\hline \multirow{3}{*}{ 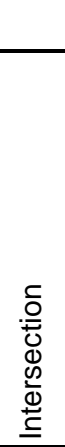 } & & & \multicolumn{24}{|c|}{ Counts by Crash Types } \\
\hline & \multirow{2}{*}{\multicolumn{2}{|c|}{ 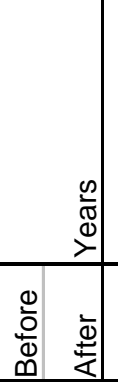 }} & \multicolumn{2}{|c|}{ 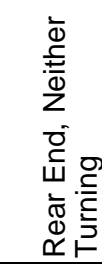 } & \multicolumn{2}{|c|}{ 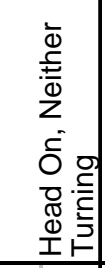 } & \multicolumn{2}{|c|}{ 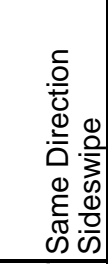 } & \multicolumn{2}{|c|}{ 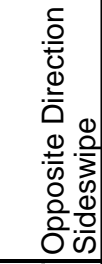 } & \multicolumn{3}{|c|}{ 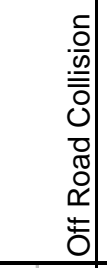 } & \multicolumn{2}{|r|}{$\begin{array}{l}\frac{0}{0} \\
\frac{1}{2} \\
\pm \\
\frac{1}{0} \\
\frac{0}{x}\end{array}$} & \multicolumn{3}{|c|}{ 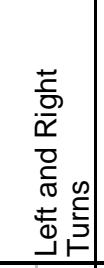 } & \multicolumn{2}{|r|}{ 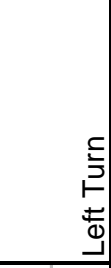 } & \multicolumn{2}{|r|}{ 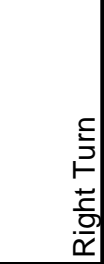 } & \multicolumn{2}{|r|}{ 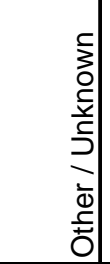 } & & $\begin{array}{l}\bar{\pi} \\
\text { 음 }\end{array}$ \\
\hline & & & $\begin{array}{l}0 \\
\frac{0}{0} \\
0 \\
0\end{array}$ & $\frac{\bar{\Phi}}{\frac{ \pm}{d}}$ & $\begin{array}{l}0 \\
\frac{0}{0} \\
\Phi \\
\infty\end{array}$ & $\frac{\bar{d}}{\frac{ \pm}{d}}$ & $\begin{array}{l}0 \\
\stackrel{0}{0} \\
\stackrel{0}{0} \\
\infty\end{array}$ & $\frac{1}{ \pm}$ & $\begin{array}{l}0 \\
\frac{0}{0} \\
\stackrel{0}{0} \\
\infty\end{array}$ & $\frac{1}{\frac{1}{4}}$ & $\begin{array}{l}\frac{0}{0} \\
\frac{0}{0} \\
\infty\end{array}$ & & & $\frac{0}{\frac{0}{0}}$ & $\frac{\bar{\Phi}}{\frac{1}{4}}$ & $\frac{\Phi}{\frac{0}{0}}$ & & & $\begin{array}{l}\frac{\Phi}{0} \\
\frac{0}{\Phi} \\
\Phi\end{array}$ & $\frac{\bar{d}}{\frac{ \pm}{4}}$ & $\begin{array}{l}\frac{0}{0} \\
\frac{0}{D} \\
\varpi\end{array}$ & 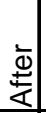 & $\begin{array}{l}\frac{0}{0} \\
\frac{0}{0} \\
\Phi\end{array}$ & 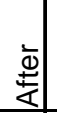 & $\begin{array}{l}\frac{\Phi}{\grave{0}} \\
\frac{0}{\Phi} \\
\Phi\end{array}$ & $\frac{1}{\frac{1}{4}}$ \\
\hline 1 & 5 & 2 & 2 & 1 & 0 & 0 & 0 & 0 & 0 & 0 & 0 & & & 0 & 0 & 0 & & & 0 & 0 & 0 & 0 & 0 & 0 & 2 & \\
\hline 2 & 5 & 2 & 0 & 2 & 0 & 2 & 0 & 0 & 0 & 0 & 0 & & & 0 & 0 & $\overline{0}$ & & & 0 & 0 & 0 & 0 & 0 & 3 & 0 & \\
\hline 3 & 5 & 2 & 6 & 4 & 1 & 0 & 5 & 1 & 0 & 0 & 1 & & & 1 & 1 & 0 & & & 2 & 0 & 1 & 0 & 4 & 1 & 21 & 7 \\
\hline 4 & 1 & 5 & 0 & 11 & 0 & 0 & 0 & 0 & 0 & 1 & 0 & & & 3 & 5 & 0 & & & 0 & 0 & 0 & & 0 & 3 & 3 & 20 \\
\hline 5 & 1 & 5 & 6 & 38 & 0 & 0 & 2 & 1 & 0 & 1 & $\overline{0}$ & & & 1 & 9 & 0 & & & 0 & 0 & 1 & 0 & 1 & 5 & 11 & 54 \\
\hline 6 & 1 & 5 & 4 & 22 & 0 & 1 & 0 & 1 & 0 & 0 & 0 & & & 5 & 3 & 0 & & & 0 & 1 & 0 & 0 & 0 & 4 & 9 & \\
\hline 7 & 1 & 5 & 0 & 1 & 0 & 0 & 0 & 1 & 0 & 0 & 0 & & & 0 & 1 & 0 & & & 0 & 0 & 1 & 0 & 2 & 7 & 3 & \\
\hline 8 & 3 & 5 & 6 & 19 & 0 & 0 & 0 & 2 & 0 & 0 & 0 & & & 1 & 2 & 0 & & & 0 & 3 & 1 & 0 & 1 & 2 & 9 & 28 \\
\hline 9 & 4 & 4 & 9 & 6 & 1 & 1 & 1 & 0 & 0 & 0 & 0 & & & 10 & 10 & 0 & & & 1 & 7 & 2 & 0 & 4 & 3 & 28 & 29 \\
\hline 10 & 5 & 2 & 0 & 3 & 0 & 0 & 0 & 2 & 0 & 0 & 0 & & & 0 & 1 & 0 & & & 0 & 0 & 0 & 0 & 0 & 0 & 0 & \\
\hline 11 & 5 & 3 & 1 & 0 & 0 & 0 & 0 & 0 & 0 & 0 & 0 & & & 0 & & 0 & & & 0 & 0 & 0 & 0 & 0 & 0 & 1 & \\
\hline 12 & 5 & 3 & 6 & 2 & 0 & 0 & 0 & 0 & 0 & 0 & 0 & & & 3 & & 0 & & & 1 & 2 & 0 & 0 & 0 & 0 & 10 & \\
\hline 13 & 1 & 5 & 0 & 2 & 0 & 0 & 0 & 0 & 0 & 0 & 0 & & & 0 & 0 & 0 & & & 0 & 0 & 0 & 0 & 0 & 6 & 0 & \\
\hline 14 & 3 & 5 & 1 & 7 & 0 & 0 & 1 & 2 & 0 & 0 & 0 & & & 0 & 5 & 0 & & & 1 & 8 & 0 & 0 & 0 & 2 & 3 & \\
\hline 15 & 4 & 4 & 8 & 4 & 0 & 2 & 0 & 0 & 2 & 0 & 0 & & & 6 & 2 & 0 & & & 3 & 2 & 0 & 0 & 9 & 23 & 28 & 33 \\
\hline 16 & 3 & 5 & 0 & 0 & 0 & 0 & 0 & 1 & 0 & 0 & 0 & & & 0 & & 0 & & & 0 & 0 & 0 & 0 & 0 & 0 & 0 & \\
\hline 17 & 5 & 2 & 1 & 4 & 0 & 1 & 0 & 1 & 1 & 0 & 0 & & & 5 & 2 & 0 & & & 0 & 2 & 0 & 0 & 0 & 2 & 7 & \\
\hline 18 & 1 & 5 & 1 & 8 & 1 & 0 & 0 & 3 & 0 & 0 & 0 & & & 2 & 5 & 0 & & & 1 & 3 & 0 & 0 & 0 & 5 & 5 & \\
\hline 19 & 5 & & 0 & 1 & 0 & 0 & 1 & 0 & 0 & 0 & 0 & & & 3 & 1 & 0 & & & 1 & 0 & 1 & 0 & 0 & 0 & 6 & \\
\hline Total & 63 & 72 & 51 & 135 & 3 & 7 & 10 & 15 & 3 & 2 & 1 & & & 40 & 51 & 0 & & & 10 & 28 & 7 & 0 & 21 & 66 & 146 & \\
\hline
\end{tabular}

Indicates one fatality 
Table 4-7: Summary Table for Severity of Crashes Within 1000 feet of the intersection.

\begin{tabular}{|c|c|c|c|c|c|c|c|c|}
\hline \multirow{3}{*}{ 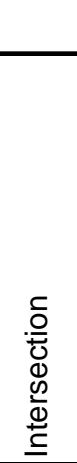 } & \multirow{2}{*}{\multicolumn{2}{|c|}{$\begin{array}{l}\stackrel{\infty}{\mathbb{\Phi}} \\
\stackrel{\mathbb{\infty}}{\succ} \\
\end{array}$}} & \multicolumn{6}{|c|}{ Severity of Crashes } \\
\hline & & & \multicolumn{2}{|r|}{ 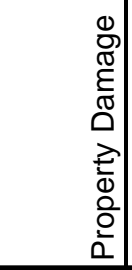 } & \multicolumn{2}{|r|}{ 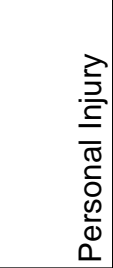 } & \multicolumn{2}{|r|}{$\begin{array}{l}\overline{\widetilde{\sigma}} \\
\underset{\mathbb{\sigma}}{\square} \\
\stackrel{1}{*}\end{array}$} \\
\hline & $\begin{array}{l}0 \\
\stackrel{0}{0} \\
\stackrel{0}{\Phi} \\
\infty\end{array}$ & 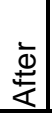 & $\begin{array}{l}\frac{\Phi}{0} \\
\frac{0}{\Phi} \\
\infty\end{array}$ & $\underset{\frac{1}{4}}{\frac{\Phi}{4}}$ & $\begin{array}{l}\frac{\Phi}{0} \\
\frac{0}{\Phi} \\
\infty\end{array}$ & 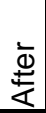 & 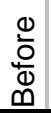 & 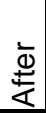 \\
\hline 1 & 5 & 2 & 1 & 0 & 1 & 1 & 0 & 0 \\
\hline 2 & 5 & 2 & 0 & 5 & 0 & 2 & 0 & 0 \\
\hline 3 & 5 & 2 & 17 & 6 & 4 & 1 & 0 & 0 \\
\hline 4 & 1 & 5 & 2 & 19 & 1 & 1 & 0 & 0 \\
\hline 5 & 1 & 5 & 11 & 48 & 0 & 6 & 0 & 0 \\
\hline 6 & 1 & 5 & 9 & 22 & 0 & 11 & 0 & 0 \\
\hline 7 & 1 & 5 & 3 & 7 & 0 & 3 & 0 & 0 \\
\hline 8 & 3 & 5 & 4 & 22 & 5 & 6 & 0 & 0 \\
\hline 9 & 4 & 4 & 19 & 24 & 9 & 5 & 0 & 0 \\
\hline 10 & 5 & 2 & 0 & 4 & 0 & 3 & 0 & 0 \\
\hline 11 & 5 & 3 & 0 & 0 & 1 & 0 & 0 & 0 \\
\hline 12 & 5 & 3 & 7 & 4 & 3 & 4 & 0 & 0 \\
\hline 13 & 1 & 5 & 0 & 6 & 0 & 3 & 0 & 0 \\
\hline 14 & 3 & 5 & 2 & 16 & 1 & 9 & 0 & 0 \\
\hline 15 & 4 & 4 & 19 & 22 & 9 & 11 & 0 & 0 \\
\hline 16 & 3 & 5 & 1 & 0 & 0 & 0 & 0 & 0 \\
\hline 17 & 5 & 2 & 3 & 9 & 4 & 3 & 0 & 0 \\
\hline 18 & 1 & 5 & 3 & 19 & 1 & 5 & 1 & 0 \\
\hline 19 & 5 & 3 & 4 & 2 & 1 & 0 & 1 & 0 \\
\hline Total & 63 & 72 & 105 & 235 & 40 & 74 & 2 & 0 \\
\hline
\end{tabular}

\section{5. $\quad$ School Zone Intersections}

From the previous list of intersections, seven intersections are located in school zones. Schools are located at a corner of each of these intersections. For this set of intersections, there are 32 years of before and 19 years of after installation data with 58 and 64 crashes respectively. Crash data is categorized by crash type and severity of crash. From the data, there are no 'Fatal' crashes that are reported for any of the school zone intersections. All of the crashes consist of 'Property Damage' or 'Personal Injury' crash severities. The data is also separated by distances 
from the intersection as seen in Table 4-8. Crashes are categorized by crash types and are limited to the crashes within 200 feet of the intersection. For this study area, there are a total of 50 crashes before and 59 crashes after signal installation. These crashes are then separated by severity as seen in Table 4-8. 
Table 4-8: Summary Table for Crash Types Within 200 feet of the School Zone Intersection.

\begin{tabular}{|c|c|c|c|c|c|c|c|c|c|c|c|c|c|c|c|c|c|c|c|c|c|c|c|c|c|}
\hline \multirow{3}{*}{ 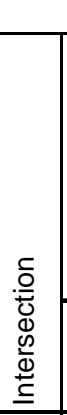 } & & & \multicolumn{23}{|c|}{ Counts by Crash Types } \\
\hline & & 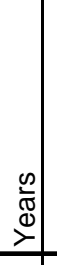 & & 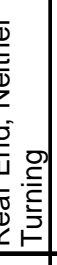 & & 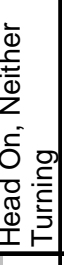 & & $\begin{array}{l}0 \\
\frac{1}{3} \\
0 \\
0 \\
0 \\
0 \\
0 \\
0\end{array}$ & & 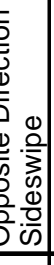 & & 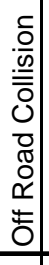 & & $\begin{array}{l}\frac{0}{0} \\
\frac{2}{\alpha} \\
\frac{1}{0} \\
\frac{0}{\square}\end{array}$ & & 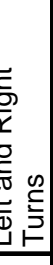 & & 言 & & & $\begin{array}{l}5 \\
\frac{5}{5} \\
\pm \\
\frac{ \pm}{0} \\
\frac{0}{\simeq}\end{array}$ & & 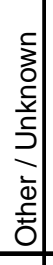 & & 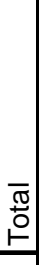 \\
\hline & 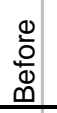 & $\frac{\bar{\Phi}}{\frac{\bar{d}}{\alpha}}$ & 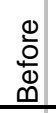 & $\frac{\bar{\Phi}}{\frac{\bar{d}}{\alpha}}$ & $\begin{array}{l}0 \\
\stackrel{0}{0} \\
\Phi \\
\Phi\end{array}$ & 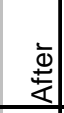 & $\begin{array}{l}0 \\
\frac{0}{0} \\
\stackrel{0}{0} \\
\oplus\end{array}$ & $\begin{array}{l}\frac{\bar{\Phi}}{\frac{1}{\alpha}} \\
\end{array}$ & $\begin{array}{l}0 \\
\stackrel{0}{0} \\
\stackrel{0}{\Phi} \\
\end{array}$ & $\begin{array}{l}\frac{\bar{\Phi}}{\bar{t}} \\
\end{array}$ & $\begin{array}{l}0 \\
\frac{0}{0} \\
\stackrel{D}{D} \\
\end{array}$ & $\begin{array}{l}\frac{\bar{\Phi}}{\frac{ \pm}{4}} \\
\end{array}$ & $\begin{array}{l}\stackrel{0}{0} \\
\frac{0}{\Phi} \\
\varrho\end{array}$ & $\begin{array}{c}\bar{\Phi} \\
\frac{\vec{\alpha}}{\alpha}\end{array}$ & $\begin{array}{l}0 \\
\frac{0}{0} \\
\stackrel{0}{0} \\
\end{array}$ & $\begin{array}{l}\frac{\bar{\Phi}}{\frac{1}{\alpha}} \\
\end{array}$ & 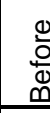 & 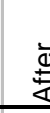 & & 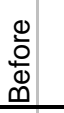 & $\begin{array}{c}\overline{\bar{\omega}} \\
\frac{\vec{\alpha}}{\mathrm{a}}\end{array}$ & $\begin{array}{l}\frac{0}{0} \\
\frac{0}{D} \\
\varrho\end{array}$ & $\begin{array}{c}\bar{\Phi} \\
\frac{1}{\alpha} \\
\end{array}$ & 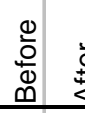 & 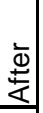 \\
\hline 1 & 5 & 2 & 1 & 0 & $\overline{0}$ & 0 & 0 & 0 & 0 & 0 & 0 & 0 & $\overline{0}$ & 0 & 0 & 0 & 0 & & & 0 & 0 & 0 & 0 & 1 & 0 \\
\hline 2 & 5 & 2 & $\overline{0}$ & 2 & 0 & 2 & 0 & 0 & $\overline{0}$ & 0 & $\overline{0}$ & 0 & 0 & 0 & 0 & 0 & $\bar{c}$ & 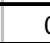 & of & 0 & 0 & 0 & 2 & 0 & 6 \\
\hline 3 & 5 & 2 & 6 & 4 & 0 & 0 & 5 & 1 & 0 & 0 & 1 & 0 & 1 & 1 & 0 & & 2 & 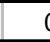 & 0 & 1 & 0 & 4 & 1 & 20 & \\
\hline 9 & 4 & 4 & 6 & 5 & 1 & 1 & 1 & 0 & 0 & 0 & 0 & 1 & 9 & 9 & 0 & 1 & & 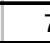 & 70 & 2 & 0 & 4 & 3 & $\begin{array}{ll}23 & 2 \\
\end{array}$ & 27 \\
\hline 10 & 5 & 2 & 0 & 3 & 0 & 0 & 0 & 2 & 0 & 0 & 0 & 0 & 0 & 1 & 0 & 0 & & 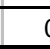 & of & 0 & 0 & 0 & 0 & 0 & 6 \\
\hline 16 & 3 & 5 & 0 & 0 & $\overline{0}$ & 0 & 0 & 1 & 0 & 0 & 0 & 0 & $\overline{0}$ & 0 & 0 & 0 & & 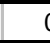 & 0 & 0 & 0 & 0 & 0 & 0 & \\
\hline 17 & 5 & 2 & 1 & 4 & 0 & 1 & 0 & 1 & 0 & 0 & 0 & 0 & 5 & 2 & 0 & $\overline{0}$ & & 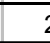 & 2 & 0 & 0 & 0 & 2 & 6 & 12 \\
\hline Total & 32 & \begin{tabular}{l|l|}
19 \\
\end{tabular} & 14 & 18 & 1 & 4 & 6 & 5 & 0 & 0 & 1 & 1 & 15 & 13 & 0 & 1 & 2 & 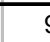 & 9 & 3 & 0 & 8 & 8 & \begin{tabular}{l|l}
50 & 5
\end{tabular} & 59 \\
\hline
\end{tabular}

Table 4-9: Summary Table for Severity of Crashes Within 200 feet of the School Zone Intersection.

\begin{tabular}{|c|c|c|c|c|c|c|c|c|}
\hline \multirow{3}{*}{ 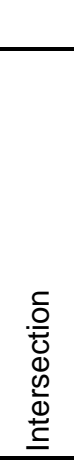 } & & & \multicolumn{6}{|c|}{ Severity of Crashes } \\
\hline & \multicolumn{2}{|r|}{$\begin{array}{l}\stackrel{\infty}{\delta} \\
\stackrel{0}{\delta}\end{array}$} & \multicolumn{2}{|c|}{ 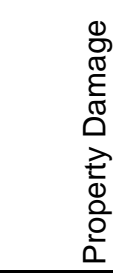 } & \multicolumn{2}{|r|}{ 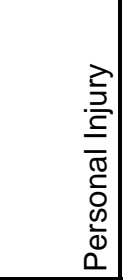 } & \multicolumn{2}{|r|}{ 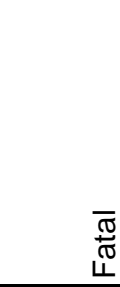 } \\
\hline & $\begin{array}{l}\stackrel{0}{0} \\
\stackrel{0}{\Phi} \\
\Phi\end{array}$ & $\frac{\dot{\Phi}}{\frac{1}{\alpha}}$ & $\begin{array}{l}\frac{0}{\grave{0}} \\
\frac{0}{\Phi} \\
\oplus\end{array}$ & $\frac{\bar{\Phi}}{\frac{1}{2}}$ & $\begin{array}{l}0 \\
\frac{0}{0} \\
\oplus \\
\oplus\end{array}$ & $\frac{\bar{\Phi}}{\frac{\bar{\alpha}}{\alpha}}$ & 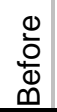 & $\frac{\bar{\Phi}}{\frac{1}{\alpha}}$ \\
\hline 1 & 5 & 2 & 1 & 0 & 0 & 0 & 0 & 0 \\
\hline 2 & 5 & 2 & 0 & 4 & 0 & 2 & 0 & 0 \\
\hline 3 & 5 & 2 & 17 & 6 & 3 & 1 & 0 & 0 \\
\hline 9 & 4 & 4 & 18 & 22 & 5 & 5 & 0 & 0 \\
\hline 10 & 5 & 2 & 0 & 4 & 0 & 2 & 0 & 0 \\
\hline 16 & 3 & 5 & 0 & 1 & 0 & 0 & 0 & 0 \\
\hline 17 & 5 & 2 & 2 & 9 & 4 & 3 & 0 & 0 \\
\hline Total & 32 & 19 & 38 & 46 & 12 & 13 & 0 & 0 \\
\hline
\end{tabular}


The following tables, Table 4-10 and Table 4-11, show results of crashes within 500 feet of school zone intersections. In this study area, there are 58 crashes before and 64 crashes after signal installation. This is an increase from the 200 feet study area. 
Table 4-10: Summary Table for Crash Types Within 500 feet of the School Zone Intersection.

\begin{tabular}{|c|c|c|c|c|c|c|c|c|c|c|c|c|c|c|c|c|c|c|c|c|c|c|c|c|c|}
\hline \multirow{3}{*}{ 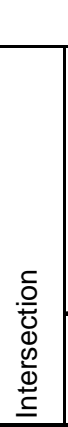 } & & & \multicolumn{23}{|c|}{ Counts by Crash Types } \\
\hline & \multicolumn{2}{|r|}{$\begin{array}{l}\infty \\
\stackrel{\infty}{\nabla} \\
\stackrel{D}{2} \\
\nu\end{array}$} & \multicolumn{2}{|c|}{ 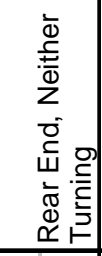 } & \multicolumn{2}{|c|}{ 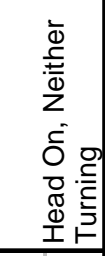 } & \multicolumn{2}{|c|}{ 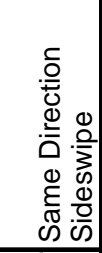 } & \multicolumn{2}{|c|}{ 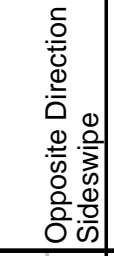 } & \multicolumn{3}{|c|}{ 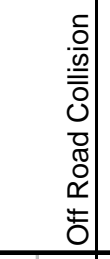 } & \multicolumn{2}{|r|}{$\begin{array}{l}\frac{0}{5} \\
\frac{2}{2} \\
\text { 늠 } \\
\frac{0}{0} \\
\end{array}$} & \multicolumn{2}{|c|}{ 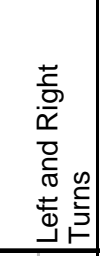 } & \multicolumn{2}{|r|}{ 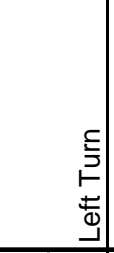 } & \multicolumn{2}{|r|}{ 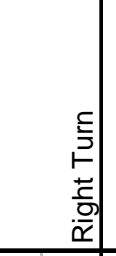 } & \multicolumn{2}{|r|}{ 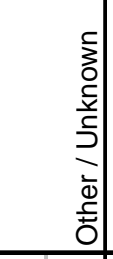 } & \multicolumn{2}{|r|}{$\begin{array}{l}\bar{\pi} \\
\stackrel{0}{0} \\
-\end{array}$} \\
\hline & $\begin{array}{l}\stackrel{0}{0} \\
\frac{0}{0} \\
\Phi\end{array}$ & $\begin{array}{l}\frac{1}{\alpha} \\
\frac{+}{\alpha}\end{array}$ & $\begin{array}{l}\frac{0}{0} \\
\frac{0}{0} \\
\Phi\end{array}$ & $\begin{array}{l}\frac{1}{ \pm} \\
\frac{ \pm}{4}\end{array}$ & $\begin{array}{l}\frac{0}{0} \\
\frac{0}{0} \\
\Phi\end{array}$ & $\frac{\bar{d}}{\frac{ \pm}{\alpha}}$ & $\begin{array}{l}\frac{\Phi}{2} \\
\frac{0}{\Phi} \\
\Phi\end{array}$ & $\begin{array}{c}\bar{\Phi} \\
\frac{ \pm}{2} \\
\end{array}$ & 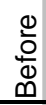 & 产 & & & $\frac{\grave{\Phi}}{\frac{1}{4}}$ & $\begin{array}{l}\frac{0}{0} \\
\frac{0}{0} \\
\Phi\end{array}$ & 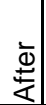 & $\frac{\stackrel{0}{0}}{\frac{0}{0}}$ & 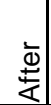 & $\begin{array}{l}\frac{\Phi}{0} \\
\frac{0}{\Phi} \\
\Phi\end{array}$ & 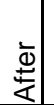 & 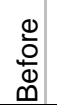 & $\begin{array}{l}\frac{\bar{d}}{\bar{d}} \\
\frac{+}{\alpha}\end{array}$ & $\frac{\frac{0}{0}}{\frac{0}{\Phi}}$ & $\begin{array}{l}\frac{1}{ \pm} \\
\frac{+}{\alpha}\end{array}$ & $\begin{array}{l}\frac{\Phi}{\grave{d}} \\
\frac{\Phi}{\Phi} \\
\Phi\end{array}$ & $\begin{array}{l}\frac{1}{ \pm} \\
\frac{ \pm}{\alpha}\end{array}$ \\
\hline 1 & 5 & 2 & 2 & 1 & 0 & 0 & 0 & 0 & 0 & 0 & & & 0 & 0 & 0 & 0 & 0 & 0 & 0 & 0 & 0 & 0 & 0 & 2 & 1 \\
\hline 2 & 5 & 2 & 0 & 2 & 0 & 2 & 0 & 0 & 0 & c & & & 0 & 0 & 0 & 0 & 0 & 0 & 0 & 0 & 0 & 0 & 3 & 0 & 7 \\
\hline 3 & 5 & 2 & 6 & 4 & 1 & 0 & 5 & 1 & 0 & $\mathrm{c}$ & & & 0 & 1 & 1 & 0 & 0 & 2 & 0 & 1 & 0 & 4 & 1 & 21 & 7 \\
\hline 9 & 4 & 4 & 9 & 6 & 1 & 1 & 1 & 0 & 0 & 0 & & & 1 & 10 & 10 & 0 & 1 & 1 & 7 & 2 & 0 & 4 & 3 & 28 & 29 \\
\hline 10 & 5 & 2 & 0 & 3 & 0 & 0 & 0 & 2 & 0 & c & & & 1 & 0 & 1 & 0 & 0 & 0 & 0 & 0 & 0 & 0 & 0 & 0 & 7 \\
\hline 16 & 3 & 5 & 0 & 0 & 0 & 0 & 0 & 1 & 0 & c & & & 0 & 0 & 0 & 0 & 0 & 0 & 0 & 0 & 0 & 0 & 0 & 0 & 1 \\
\hline 17 & 5 & 2 & 1 & 4 & 0 & 1 & 0 & 1 & 1 & c & & & 0 & 5 & 2 & 0 & 0 & 0 & 2 & 0 & 0 & 0 & 2 & 7 & 12 \\
\hline Total & 32 & 19 & 18 & 20 & 2 & 4 & 6 & 5 & 1 & c & & & 2 & 16 & 14 & 0 & 1 & 3 & 9 & 3 & 0 & 8 & 9 & 58 & 64 \\
\hline
\end{tabular}

Table 4-11: Summary Table for Severity of Crashes Within 500 feet of the School Zone Intersection.

\begin{tabular}{|c|c|c|c|c|c|c|c|c|}
\hline \multirow{3}{*}{ 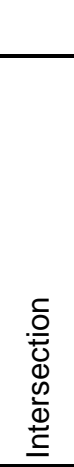 } & & & \multicolumn{6}{|c|}{ Severity of Crashes } \\
\hline & \multicolumn{2}{|r|}{$\begin{array}{l}\stackrel{\infty}{\bar{\varpi}} \\
\stackrel{\infty}{\nu}\end{array}$} & \multicolumn{2}{|c|}{ 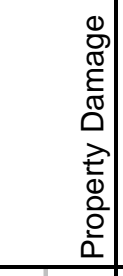 } & \multicolumn{2}{|r|}{ 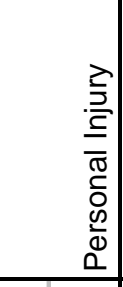 } & \multicolumn{2}{|r|}{$\begin{array}{l}\bar{\pi} \\
\stackrel{\tilde{\sigma}}{\leftarrow} \\
\end{array}$} \\
\hline & $\begin{array}{l}\frac{0}{0} \\
\frac{0}{0}\end{array}$ & $\frac{\bar{\Phi}}{\frac{1}{\alpha}}$ & $\begin{array}{l}\frac{\Phi}{0} \\
\frac{0}{\Phi} \\
\Phi\end{array}$ & $\begin{array}{l}\frac{\bar{d}}{\frac{1}{\alpha}} \\
\end{array}$ & $\begin{array}{l}\frac{\Phi}{0} \\
\frac{0}{\Phi} \\
\oplus\end{array}$ & $\begin{array}{c}\bar{\Phi} \\
\frac{1}{2}\end{array}$ & $\begin{array}{l}\frac{0}{0} \\
\frac{0}{0} \\
\infty\end{array}$ & $\frac{\bar{d}}{\frac{1}{\alpha}}$ \\
\hline 1 & 5 & 2 & 1 & 0 & 1 & 1 & 0 & 0 \\
\hline 2 & 5 & 2 & 0 & 5 & 0 & 2 & 0 & 0 \\
\hline 3 & 5 & 2 & 17 & 6 & 4 & 1 & 0 & 0 \\
\hline 9 & 4 & 4 & 19 & 24 & 9 & 5 & 0 & 0 \\
\hline 10 & 5 & 2 & 0 & 4 & 0 & 3 & 0 & $\overline{0}$ \\
\hline 16 & 3 & 5 & 0 & 0 & 0 & 0 & 0 & 0 \\
\hline 17 & 5 & 2 & 3 & 9 & 4 & 3 & 0 & 0 \\
\hline Total & 32 & 19 & 40 & 48 & 18 & 15 & 0 & 0 \\
\hline
\end{tabular}


Table 4-12: Summary Table for Crash Types Within 1000 feet of the School Zone Intersection.

\begin{tabular}{|c|c|c|c|c|c|c|c|c|c|c|c|c|c|c|c|c|c|c|c|c|c|c|c|c|c|}
\hline \multirow{3}{*}{ 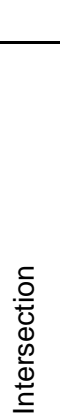 } & & & \multicolumn{23}{|c|}{ Counts by Crash Types } \\
\hline & & 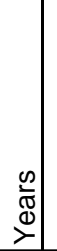 & & 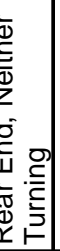 & 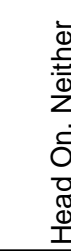 & 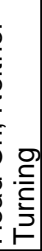 & & 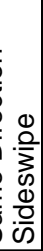 & & 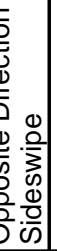 & & 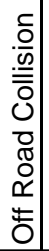 & & $\begin{array}{l}\frac{0}{0} \\
\frac{1}{x} \\
\frac{1}{0} \\
\frac{0}{\tilde{c}}\end{array}$ & & 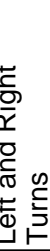 & & & $\begin{array}{l}5 \\
5 \\
\frac{5}{0} \\
\end{array}$ & & 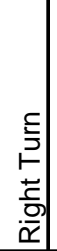 & & 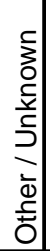 & & 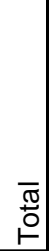 \\
\hline & $\frac{0}{\frac{0}{0}}$ & $\frac{\bar{\omega}}{\frac{\Phi}{d}}$ & $\frac{0}{\frac{0}{0}}$ & $\begin{array}{c}\bar{\Phi} \\
\frac{\Phi}{\alpha}\end{array}$ & $\frac{0}{\frac{0}{0}}$ & $\stackrel{\bar{\Phi}}{\frac{\Phi}{4}}$ & $\frac{0}{\frac{0}{0}}$ & $\begin{array}{l}\bar{\Phi} \\
\frac{\bar{t}}{女}\end{array}$ & $\frac{0}{\frac{0}{0}}$ & $\begin{array}{l}\grave{\Phi} \\
\frac{1}{2}\end{array}$ & $\frac{0}{0}$ & $\begin{array}{l}\frac{1}{\Phi} \\
\frac{\vec{t}}{2}\end{array}$ & 童 & $\begin{array}{l}\bar{\Phi} \\
\frac{ \pm}{d}\end{array}$ & 产 & $\stackrel{\bar{\Phi}}{\frac{\Phi}{4}}$ & $\frac{d}{d}$ & & $\begin{array}{l} \\
\\
\frac{1}{4} \\
\end{array}$ & $\frac{0}{\frac{0}{0}}$ & $\begin{array}{l}\bar{\Phi} \\
\frac{\vec{t}}{\alpha}\end{array}$ & $\frac{0}{0}$ & $\begin{array}{c}\bar{\Phi} \\
\frac{ \pm}{d}\end{array}$ & $\frac{\stackrel{0}{0}}{\frac{0}{0}}$ & $\underset{\frac{\Phi}{2}}{\frac{1}{2}}$ \\
\hline 1 & 5 & 2 & 2 & 1 & 0 & 0 & 0 & 0 & 0 & 0 & 0 & 0 & 0 & 0 & 0 & 0 & & 0 & 0 & 0 & 0 & 0 & 0 & 2 & 1 \\
\hline 2 & 5 & 2 & 0 & 2 & 0 & 2 & 0 & 0 & $\overline{0}$ & 0 & $\overline{0}$ & 0 & $\overline{0}$ & 0 & $\overline{0}$ & 0 & & 0 & 0 & 0 & 0 & 0 & 3 & $\overline{0}$ & 7 \\
\hline 3 & 5 & 2 & 6 & 4 & 1 & 0 & 5 & 1 & 0 & 0 & 1 & 0 & 1 & 1 & 0 & 0 & & 2 & 0 & 1 & 0 & 4 & 1 & 21 & 7 \\
\hline 9 & 4 & 4 & 9 & 6 & $\overline{1}$ & 1 & 1 & 0 & 0 & 0 & 0 & 1 & 10 & 10 & 0 & 1 & & 1 & 7 & 2 & 0 & 4 & 3 & 28 & 29 \\
\hline 10 & 5 & 2 & 0 & 3 & 0 & 0 & 0 & 2 & 0 & 0 & 0 & 1 & 0 & 1 & 0 & & & 0 & 0 & 0 & 0 & 0 & 0 & 0 & 7 \\
\hline 16 & 3 & 5 & $\overline{0}$ & 0 & $\overline{0}$ & 0 & $\overline{0}$ & 1 & $\overline{0}$ & 0 & $\overline{0}$ & 0 & $\overline{0}$ & 0 & $\overline{0}$ & $\overline{0}$ & & 0 & 0 & $\overline{0}$ & 0 & 0 & 0 & $\overline{0}$ & 1 \\
\hline 17 & 5 & 2 & 1 & 4 & 0 & 1 & 0 & 1 & 1 & 0 & 0 & 0 & 5 & 2 & 0 & $\overline{0}$ & & 0 & 2 & 0 & 0 & 0 & 2 & 7 & 12 \\
\hline Total & 32 & \begin{tabular}{|l|}
19 \\
\end{tabular} & 18 & 20 & 2 & 4 & 6 & 5 & 1 & 0 & 1 & 2 & 16 & 14 & 0 & & & 3 & 9 & 3 & 0 & 8 & 9 & 58 & 64 \\
\hline
\end{tabular}

Table 4-13: Summary Table for Severity of Crashes Within 1000 feet of the School Zone Intersection.

\begin{tabular}{|c|c|c|c|c|c|c|c|c|}
\hline \multirow{3}{*}{ 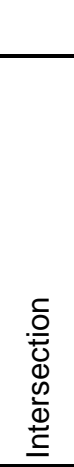 } & & & \multicolumn{6}{|c|}{ Severity of Crashes } \\
\hline & \multicolumn{2}{|r|}{$\begin{array}{l}\infty \\
\stackrel{\infty}{\mathbb{D}} \\
\stackrel{\Phi}{>} \\
\end{array}$} & \multicolumn{2}{|c|}{ 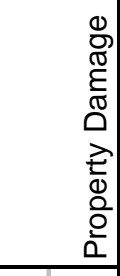 } & \multicolumn{2}{|r|}{ 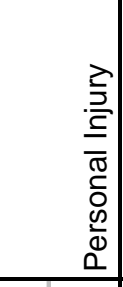 } & \multicolumn{2}{|r|}{$\begin{array}{l}\bar{\pi} \\
\tilde{\sigma}\end{array}$} \\
\hline & $\begin{array}{l}\frac{0}{0} \\
\frac{0}{0} \\
\infty\end{array}$ & $\begin{array}{c}\bar{\Phi} \\
\frac{\vec{\alpha}}{\alpha}\end{array}$ & $\begin{array}{l}\frac{\Phi}{\grave{0}} \\
\frac{0}{\Phi}\end{array}$ & $\frac{\bar{\phi}}{\frac{1}{\alpha}}$ & $\begin{array}{l}\frac{\Phi}{0} \\
\frac{0}{\Phi} \\
\infty\end{array}$ & $\begin{array}{c}\bar{\Phi} \\
\frac{1}{2}\end{array}$ & $\begin{array}{l}\frac{1}{0} \\
\frac{0}{0} \\
\infty\end{array}$ & $\frac{\bar{d}}{\frac{1}{4}}$ \\
\hline 1 & 5 & 2 & 1 & 0 & 1 & 1 & 0 & 0 \\
\hline 2 & 5 & 2 & 0 & 5 & 0 & 2 & 0 & 0 \\
\hline 3 & 5 & 2 & 17 & 6 & 4 & 1 & 0 & 0 \\
\hline 9 & 4 & 4 & 19 & 24 & 9 & 5 & 0 & 0 \\
\hline 10 & 5 & 2 & 0 & $\overline{4}$ & 0 & 3 & 0 & 0 \\
\hline 16 & 3 & 5 & 1 & 0 & 0 & 0 & 0 & $\overline{0}$ \\
\hline 17 & 5 & 2 & 3 & 9 & 4 & 3 & 0 & 0 \\
\hline Total & 32 & 19 & 41 & 48 & 18 & 15 & 0 & 0 \\
\hline
\end{tabular}


The last study area includes crashes within 1000 feet of the intersection. From Table 4-12, the total amount of crashes does not change from 500 feet. There is also no change in crash severity as seen in Table 4-13. 


\section{CHAPTER 5. STATISTICAL ANALYSIS}

The following section describes statistical analysis of the data tabulated in Chapter 4 . The statistical tests compares the before and after crash counts. Statistic tests are performed to determine if improvement or degradation in safety are statistically significant. The tests use a $10 \%$ significance level and the negative binomial distribution. This analysis is described through an example procedure using data from Intersection 8.

These tests are performed for each intersection at three different distances, 200, 500, and 1000 feet. The analysis procedure documented in this chapter is with data from 500 feet from the intersection. Results are then presented for 200 feet and 1000 feet distances.

\section{1. $\quad$ Negative Binomial Distribution Test}

The negative binomial distribution is used for the prediction of crashes at these intersections. This distribution is a generalization of the Poisson distribution. The Poisson distribution is not a correct assumption when randomness of crashes is higher than those caused by purely random chance. The negative binomial distribution allows for the higher dispersion of crash counts. The critical values for $10 \%$ significant level are determined using the negative binomial distribution. Observed crashes are then compared to these critical values to determine significant changes as a result of the treatment.

\section{2. $\quad$ Summary of Data}

Shown in Table 5-1 are the listings of each intersection with categorized crashes within 500 feet, which are separated by crashes before and after signal installation. There are a total of 63 before 
years and 71 after years. These years are not equal due to limitations of data availability. Along with a categorization by crash types, each crash is also classified by severity in Table 5-2. Based on the collected data, each crash is a 'Property Damage', 'Personal Injury', or 'Fatal'.

Table 5-1: Summary Table of Crash Type Within 500 feet of the Intersection.

\begin{tabular}{|c|c|c|c|c|c|c|c|c|c|c|c|c|c|c|c|c|c|c|c|c|c|c|c|c|}
\hline \multirow{3}{*}{ 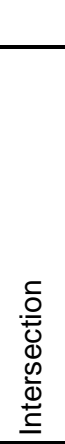 } & & & \multicolumn{22}{|c|}{ Counts by Crash Types } \\
\hline & & 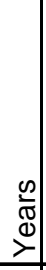 & & 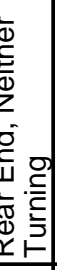 & & 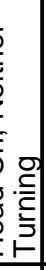 & & $\begin{array}{l}0 \\
0 \\
3 \\
0 \\
0 \\
0 \\
0 \\
0 \\
0 \\
0\end{array}$ & & 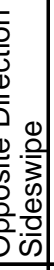 & & 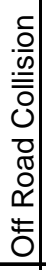 & & $\begin{array}{l}\frac{0}{0} \\
\text { 둔 } \\
\pm \\
\text { 흠 } \\
\text { 음 }\end{array}$ & \multicolumn{2}{|c|}{ 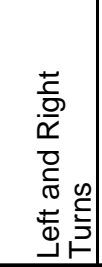 } & \multicolumn{2}{|r|}{ 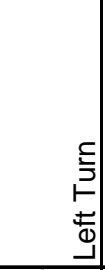 } & \multicolumn{4}{|r|}{ 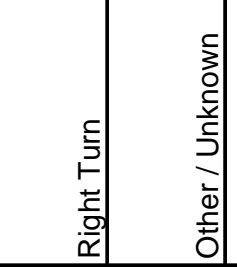 } & \multicolumn{2}{|c|}{$\begin{array}{l}\bar{\pi} \\
\stackrel{0}{0}\end{array}$} \\
\hline & $\begin{array}{l}\frac{\Phi}{\grave{0}} \\
\frac{0}{\Phi} \\
\oplus\end{array}$ & $\frac{\bar{d}}{\frac{1}{4}}$ & $\begin{array}{l}\frac{0}{0} \\
\frac{0}{0} \\
\infty\end{array}$ & $\begin{array}{l}\bar{\Phi} \\
\frac{ \pm}{4} \\
\end{array}$ & $\begin{array}{l}\frac{\Phi}{0} \\
\frac{0}{\Phi} \\
\oplus\end{array}$ & $\frac{\bar{d}}{\frac{1}{4}}$ & $\begin{array}{l}0 \\
\stackrel{0}{0} \\
\stackrel{0}{D} \\
\oplus\end{array}$ & $\frac{\bar{d}}{\frac{1}{4}}$ & $\begin{array}{l}\frac{0}{0} \\
\frac{0}{0} \\
\oplus\end{array}$ & $\begin{array}{l}\bar{\Phi} \\
\frac{ \pm}{4}\end{array}$ & $\begin{array}{l}\frac{\Phi}{0} \\
\frac{0}{\Phi} \\
\oplus\end{array}$ & $\frac{\bar{\Phi}}{\frac{1}{4}}$ & $\begin{array}{l}0 \\
\frac{0}{0} \\
\stackrel{0}{0} \\
\end{array}$ & $\frac{1}{\frac{1}{4}}$ & $\begin{array}{l}0 \\
\frac{0}{0} \\
0 \\
\end{array}$ & $\frac{\bar{d}}{\frac{1}{4}}$ & $\begin{array}{l}\frac{0}{0} \\
\frac{0}{\Phi} \\
\infty\end{array}$ & $\frac{\bar{d}}{\frac{ \pm}{4}}$ & $\begin{array}{l}\frac{\Phi}{0} \\
\frac{0}{\Phi} \\
\oplus\end{array}$ & $\underset{\frac{\bar{d}}{4}}{\frac{ \pm}{4}}$ & 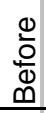 & $\underset{\frac{\Phi}{ \pm}}{\stackrel{ \pm}{ \pm}}$ & $\begin{array}{l}\frac{\Phi}{\square} \\
\frac{0}{\Phi} \\
\oplus\end{array}$ & $\frac{\bar{d}}{\frac{1}{4}}$ \\
\hline 1 & 5 & 2 & 2 & 1 & 0 & 0 & 0 & 0 & 0 & 0 & 0 & 0 & 0 & 0 & 0 & 0 & 0 & 0 & 0 & 0 & 0 & 0 & 2 & 1 \\
\hline 2 & 5 & 2 & 0 & 2 & 0 & 2 & 0 & 0 & 0 & 0 & 0 & 0 & 0 & 0 & 0 & 0 & 0 & 0 & 0 & 0 & 0 & 3 & 0 & 7 \\
\hline 3 & 5 & 2 & 6 & 4 & 1 & 0 & 5 & 1 & 0 & 0 & 1 & 0 & 1 & 1 & 0 & 0 & 2 & & & 0 & 4 & 1 & 21 & \\
\hline 4 & 1 & 5 & 0 & 11 & 0 & 0 & 0 & 0 & 0 & 1 & 0 & 0 & 3 & 5 & 0 & 0 & 0 & 0 & 0 & 0 & 0 & 3 & 3 & 20 \\
\hline 5 & 1 & 5 & 6 & 37 & 0 & 0 & 2 & 1 & 0 & 1 & 0 & 0 & 1 & 9 & 0 & 0 & 0 & 0 & 1 & 0 & 1 & 5 & 11 & 53 \\
\hline 6 & 1 & 5 & 4 & 22 & 0 & 1 & 0 & 1 & 0 & 0 & 0 & 1 & 5 & 3 & 0 & 0 & 0 & 1 & 0 & 0 & 0 & 4 & 9 & 33 \\
\hline 7 & 1 & 5 & 0 & 1 & 0 & 0 & 0 & 1 & 0 & 0 & 0 & 0 & 0 & 1 & 0 & 0 & 0 & 0 & 1 & 0 & 2 & 7 & 3 & \\
\hline 8 & 3 & 5 & 6 & 19 & 0 & 0 & 0 & 2 & 0 & 0 & 0 & 0 & 1 & 2 & 0 & 0 & 0 & 3 & 1 & 0 & 1 & 2 & 9 & 28 \\
\hline 9 & 4 & 4 & 9 & 6 & 1 & 1 & 1 & 0 & 0 & 0 & 0 & 1 & 10 & 10 & 0 & 1 & 1 & 7 & 2 & 0 & 4 & 3 & 28 & 29 \\
\hline 10 & 5 & 2 & 0 & 3 & 0 & 0 & 0 & 2 & 0 & 0 & 0 & 1 & 0 & 1 & 0 & 0 & 0 & 0 & 0 & 0 & 0 & 0 & 0 & \\
\hline 11 & 5 & 3 & 1 & 0 & 0 & 0 & 0 & 0 & 0 & 0 & 0 & 0 & 0 & 0 & 0 & 0 & 0 & 0 & 0 & 0 & 0 & 0 & 1 & 0 \\
\hline 12 & 5 & 3 & 3 & 2 & 0 & 0 & 0 & 0 & 0 & 0 & 0 & 0 & 2 & 3 & 0 & 0 & 1 & 2 & 0 & 0 & 0 & 0 & 6 & \\
\hline 13 & 1 & 5 & 0 & 2 & 0 & 0 & 0 & 0 & 0 & 0 & 0 & 1 & 0 & 0 & 0 & 0 & 0 & 0 & 0 & 0 & 0 & 6 & 0 & \\
\hline 14 & 3 & 5 & 1 & 7 & 0 & 0 & 1 & 2 & 0 & 0 & 0 & 1 & 0 & 5 & 0 & 0 & 1 & 8 & 0 & 0 & 0 & 2 & 3 & 25 \\
\hline 15 & 4 & 4 & 7 & 3 & 0 & 2 & 0 & 0 & 2 & 0 & 0 & 0 & 6 & 2 & 0 & 0 & 3 & 2 & 0 & 0 & 9 & 23 & 27 & 32 \\
\hline 16 & 3 & 5 & 0 & 0 & 0 & 0 & 0 & 1 & 0 & 0 & 0 & 0 & 0 & 0 & 0 & 0 & 0 & 0 & 0 & 0 & 0 & 0 & 0 & \\
\hline 17 & 5 & 2 & 1 & 4 & 0 & 1 & 0 & 1 & 1 & 0 & 0 & 0 & 5 & 2 & 0 & 0 & 0 & 2 & 0 & 0 & 0 & 2 & 7 & \\
\hline 18 & 1 & & 0 & 8 & 0 & 0 & 0 & 2 & 0 & 0 & 0 & 0 & 2 & 5 & 0 & 0 & 1 & 3 & 0 & 0 & 0 & 4 & 3 & \\
\hline 19 & 5 & 3 & 0 & 1 & 0 & 0 & 1 & 0 & 0 & 0 & 0 & 0 & 3 & 0 & 0 & 0 & 1 & 0 & 1 & 0 & 0 & 0 & 6 & \\
\hline otal & 63 & 72 & 46 & 133 & 2 & 7 & 10 & 14 & 3 & 2 & 1 & 5 & 39 & 49 & 0 & 1 & 10 & 28 & 7 & 0 & 21 & 65 & 139 & \\
\hline
\end{tabular}


Table 5-2: Summary Table of Severity of Crashes Within 500 feet of the Intersection.

\begin{tabular}{|c|c|c|c|c|c|c|c|c|}
\hline \multirow{3}{*}{ 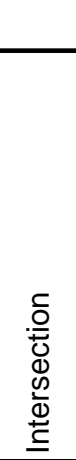 } & & & \multicolumn{6}{|c|}{ Severity of Crashes } \\
\hline & \multicolumn{2}{|r|}{ 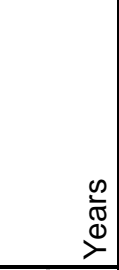 } & \multicolumn{2}{|r|}{ 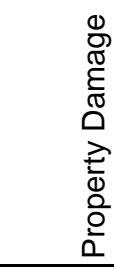 } & \multicolumn{2}{|c|}{ 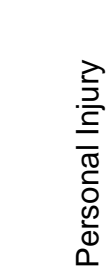 } & \multicolumn{2}{|r|}{$\begin{array}{l}\bar{\pi} \\
\stackrel{\pi}{\pi} \\
\stackrel{4}{0}\end{array}$} \\
\hline & $\begin{array}{l}0 \\
\stackrel{0}{0} \\
\stackrel{0}{\Perp} \\
\infty\end{array}$ & $\frac{\bar{\Phi}}{\frac{ \pm}{4}}$ & $\begin{array}{l}0 \\
\stackrel{0}{0} \\
\stackrel{0}{\Phi} \\
\Phi\end{array}$ & $\frac{\frac{1}{d}}{\frac{4}{4}}$ & 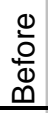 & 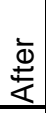 & 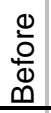 & $\frac{\bar{d}}{\frac{1}{4}}$ \\
\hline 1 & 5 & 2 & 1 & 0 & 1 & 1 & 0 & 0 \\
\hline 2 & 5 & 2 & 0 & 5 & 0 & 2 & 0 & 0 \\
\hline 3 & 5 & 2 & 17 & 6 & 4 & 1 & 0 & 0 \\
\hline 4 & 1 & 5 & 2 & 19 & 1 & 1 & 0 & 0 \\
\hline 5 & 1 & 5 & 11 & 47 & 0 & 6 & 0 & 0 \\
\hline 6 & 1 & 5 & 9 & 22 & 0 & 11 & 0 & 0 \\
\hline 7 & 1 & 5 & 3 & 7 & 0 & 3 & 0 & 0 \\
\hline 8 & 3 & 5 & 4 & 22 & 5 & 6 & 0 & 0 \\
\hline 9 & 4 & 4 & 19 & 24 & 9 & 5 & 0 & 0 \\
\hline 10 & 5 & 2 & 0 & 4 & 0 & 3 & 0 & 0 \\
\hline 11 & 5 & 3 & 0 & 0 & 1 & 0 & 0 & 0 \\
\hline 12 & 5 & 3 & 3 & 4 & 3 & 3 & 0 & 0 \\
\hline 13 & 1 & 5 & 0 & 6 & 0 & 3 & 0 & 0 \\
\hline 14 & 3 & 5 & 2 & 16 & 1 & 9 & 0 & 0 \\
\hline 15 & 4 & 4 & 18 & 21 & 9 & 11 & 0 & 0 \\
\hline 16 & 3 & 5 & 0 & 0 & 0 & 0 & 0 & 0 \\
\hline 17 & 5 & 2 & 3 & 9 & 4 & 3 & 0 & 0 \\
\hline 18 & 1 & 5 & 2 & 17 & 0 & 5 & 1 & 0 \\
\hline 19 & 5 & 3 & 4 & 1 & 1 & 0 & 1 & 0 \\
\hline Total & 63 & 72 & 98 & 230 & 39 & 73 & 2 & 0 \\
\hline
\end{tabular}

\section{3. $\quad$ Predicted Number of Crashes}

The following section describes the test procedure. Each intersection is represented with number of years, number of crashes, and Annual Average Daily Traffic (AADT) for the periods before and after the treatment. This data is obtained for each of the types and severity of crashes to calculate a predicted crash value if the treatment had not been installed. Variability of the mean estimate is also calculated. After each intersection is analyzed, an aggregate sum of crashes is 
calculated. The differences between aggregate sums of occurred and predicted crashes are then tested by comparing the critical values and the reported actual crashes after signal installation.

Data for each intersection is adjusted for changes in the overall exposure to risk. Changes in the exposure to risk is the product of a ratio of number of years before and after signal installation $\left(\mathrm{Y}_{A} / \mathrm{Y}_{B}\right)$ and the ratio of $A A D T\left(A A D T_{A} / A A D T_{B}\right)$ during the same time periods. AADTs for the midpoint years of before and after periods are used. For some of the intersections, AADT data is not available for the desired years. In such a case, growth rates are determined for these intersections and the desired year AADT is calculated. An exposure to risk factor of 1.0 relates to similar conditions before and after signal installation. Complete calculations of the exposure to risk factor $\left(\left(\mathrm{Y}_{A} / \mathrm{Y}_{B}\right)^{*}\left(A A D T_{A} / A A D T_{B}\right)\right)$ are shown in Table 5-3.

Intersection 8 is used as an example to describe the analysis procedure. Three years of before crash data and five years of after crash data were collected for this intersection where a traffic signal was installed in 1994.

- The ratio of years is calculated by dividing the five after years by the three before years. The resulting ratio years of crash data $\left(\mathrm{Y}_{A} / \mathrm{Y}_{B}\right)$ is 1.67.

- For the ratio of $A A D T\left(A A D T_{A} / A A D T_{B}\right)$, traffic data for the intersection was available for 1991 and 1996. The AADT during 1991 was 16,940 vehicles and for 1996, the volume was 16,560 vehicles. The ratio of traffic growth factor, $\left(A A D T_{A} / A A D T_{B}\right)$, is 0.98 . Note for this case, the value is slightly less than 1.0 because of the decline in AADT.

These ratios are then multiplied calculating the overall adjustment for exposure to risk. The resulting adjustment for exposure to risk for Intersection 8 is 1.63 . For clarity, this value is repeated in the second column of Table 5-4. 
Table 5-3: Summary Table of Change in Exposure to Risk.

\begin{tabular}{|c|c|c|c|c|c|c|c|c|c|c|c|c|c|}
\hline \multirow[b]{2}{*}{ 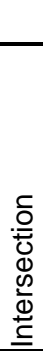 } & \multicolumn{4}{|c|}{ Years } & \multicolumn{8}{|c|}{ Annual Average Daily Traffic } & \multirow[b]{2}{*}{ 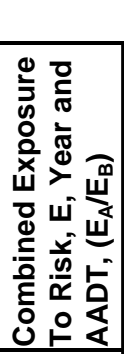 } \\
\hline & 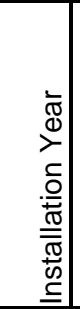 & 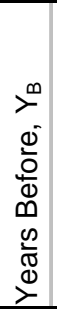 & 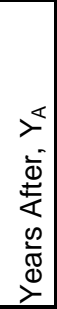 & 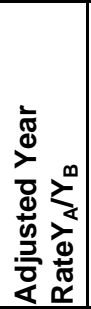 & $\begin{array}{l}\overline{\mathbb{J}} \\
\stackrel{\mathbb{1}}{\succ}\end{array}$ & 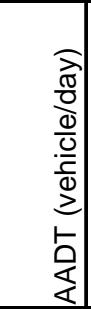 & $\begin{array}{l}\overline{\mathbb{J}} \\
\stackrel{0}{\nu}\end{array}$ & 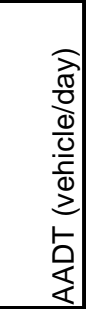 & $\begin{array}{l}0 \\
\frac{1}{\pi} \\
\frac{1}{5} \\
\frac{1}{3} \\
0 \\
0 \\
0\end{array}$ & 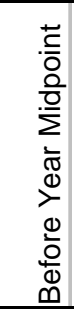 & 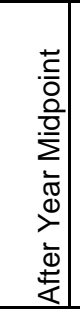 & 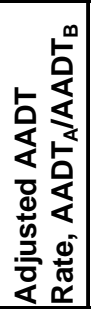 & \\
\hline 1 & 1997 & 5 & 2 & 0.40 & 1995 & 12560 & 1999 & 13190 & 1.012 & 1994 & 1998 & 1.05 & 0.42 \\
\hline 2 & 1997 & 5 & 2 & 0.40 & 1995 & 9490 & 1999 & 9030 & 0.988 & 1994 & 1998 & 0.95 & 0.38 \\
\hline 3 & 1997 & 5 & 2 & 0.40 & 1995 & 6930 & 2000 & 9110 & 1.056 & 1994 & 1998 & 1.24 & 0.50 \\
\hline 4 & 1992 & 1 & 5 & 5.00 & 1995 & 26040 & 2000 & 28380 & 1.017 & 1991 & 1995 & 1.07 & 5.36 \\
\hline 5 & 1992 & 1 & 5 & 5.00 & 1995 & 26040 & 2000 & 28380 & 1.017 & 1991 & 1995 & 1.07 & 5.36 \\
\hline 6 & 1992 & 1 & 5 & 5.00 & 1995 & 19860 & 2000 & 17530 & 0.975 & 1991 & 1995 & 0.90 & 4.52 \\
\hline 7 & 1992 & 1 & 5 & 5.00 & 1995 & 3970 & 1999 & 7410 & 1.169 & 1991 & 1995 & 1.87 & 9.33 \\
\hline 8 & 1994 & 3 & 5 & 1.67 & 1991 & 16940 & 1996 & 16560 & 0.995 & 1992 & 1997 & 0.98 & 1.63 \\
\hline 9 & 1995 & 4 & 4 & 1.00 & 1995 & 8720 & 1999 & 9930 & 1.033 & 1992 & 1997 & 1.18 & 1.18 \\
\hline 10 & 1997 & 5 & 2 & 0.40 & 1990 & 14010 & 1996 & 19420 & 1.056 & 1994 & 1998 & 1.24 & 0.50 \\
\hline 11 & 1996 & 5 & 3 & 0.60 & 1993 & 23800 & 1998 & 28030 & 1.033 & 1993 & 1998 & 1.18 & 0.71 \\
\hline 12 & 1996 & 5 & 3 & 0.60 & 1990 & 13200 & 1996 & 14880 & 1.020 & 1993 & 1998 & 1.10 & 0.66 \\
\hline 13 & 1992 & 1 & 5 & 5.00 & 1995 & 6130 & 1999 & 5920 & 0.991 & 1991 & 1995 & 0.97 & 4.83 \\
\hline 14 & 1994 & 3 & 5 & 1.67 & 1991 & 18050 & 1997 & 22030 & 1.034 & 1992 & 1997 & 1.18 & 1.97 \\
\hline 15 & 1995 & 4 & 4 & 1.00 & 1993 & 9970 & 1998 & 11150 & 1.023 & 1992 & 1997 & 1.12 & 1.12 \\
\hline 16 & 1994 & 3 & 5 & 1.67 & 1992 & 24420 & 1996 & 27820 & 1.033 & 1992 & 1997 & 1.18 & 1.96 \\
\hline 17 & 1997 & 5 & 2 & 0.40 & 1993 & 38090 & 1998 & 40620 & 1.013 & 1994 & 1998 & 1.05 & 0.42 \\
\hline 18 & 1992 & 1 & 5 & 5.00 & 1995 & 18690 & 1999 & 14990 & 0.946 & 1991 & 1995 & 0.80 & 4.01 \\
\hline 19 & 1996 & 5 & 3 & 0.60 & 1995 & 16630 & 1999 & 14810 & 0.971 & 1993 & 1998 & 0.87 & 0.52 \\
\hline
\end{tabular}

The combined exposure to risk factors change is multiplied with the actual number of crashes before installation to calculate the predicted value of crashes if the traffic signal is not installed. This procedure is performed for each of the intersections for type and severity of crashes. Aggregate sums of each type and severity are calculated for the predicted value of crashes and the actual values of before and after crashes as shown in the following tables. 
Table 5-4: Summary Calculations for 'Rear End, Neither Turning', 'Head On, Neither Turning', and 'Same Direction Sideswipe' at a Distance of 500 feet.

\begin{tabular}{|c|c|c|c|c|c|c|c|c|c|c|}
\hline \multirow[b]{2}{*}{ 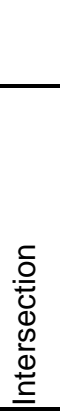 } & \multirow[b]{2}{*}{ 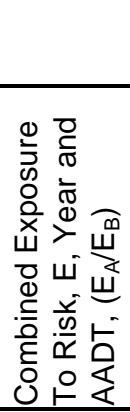 } & \multicolumn{3}{|c|}{$\begin{array}{l}\text { Rear End, Neither } \\
\text { Turning }\end{array}$} & \multicolumn{3}{|c|}{$\begin{array}{c}\text { Head On, Neither } \\
\text { Turning }\end{array}$} & \multicolumn{3}{|c|}{$\begin{array}{l}\text { Same Direction } \\
\text { Sideswipe }\end{array}$} \\
\hline & & $\begin{array}{l}0 \\
\frac{0}{0} \\
0 \\
\infty \\
0 \\
\frac{0}{0} \\
\frac{0}{0} \\
.0 \\
\frac{0}{\alpha}\end{array}$ & 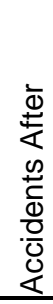 & 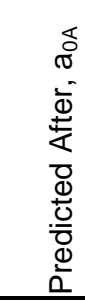 & $\begin{array}{l}0 \\
\frac{0}{0} \\
\infty \\
0 \\
\pm 0 \\
\frac{0}{0} \\
\frac{0}{0} \\
0\end{array}$ & $\begin{array}{l}\bar{\Phi} \\
\frac{1}{4} \\
\frac{0}{0} \\
\frac{0}{0} \\
\frac{0}{0} \\
\frac{0}{4}\end{array}$ & 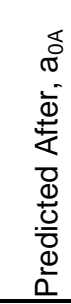 & 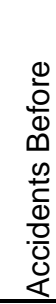 & $\begin{array}{l}\overline{0} \\
\frac{1}{4} \\
0 \\
\stackrel{0}{0} \\
\frac{0}{0} \\
\frac{0}{0} \\
\frac{0}{4}\end{array}$ & 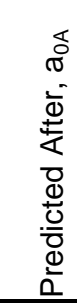 \\
\hline 1 & 0.42 & 2 & 1 & 0.84 & 0 & 0 & 0.00 & 0 & 0 & 0.00 \\
\hline 2 & 0.38 & 0 & 2 & 0.00 & 0 & 2 & 0.00 & 0 & 0 & 0.00 \\
\hline 3 & 0.50 & 6 & 4 & 2.99 & 1 & 0 & 0.50 & 5 & 1 & 2.49 \\
\hline 4 & 5.36 & $\overline{0}$ & 11 & 0.00 & 0 & 0 & 0.00 & 0 & 0 & 0.00 \\
\hline 5 & 5.36 & $\overline{6}$ & 37 & 32.14 & 0 & 0 & 0.00 & 2 & 1 & 10.71 \\
\hline 6 & 4.52 & 4 & 22 & 18.10 & 0 & 1 & 0.00 & 0 & 1 & 0.00 \\
\hline 7 & 9.33 & 0 & 1 & 0.00 & 0 & 0 & 0.00 & 0 & 1 & 0.00 \\
\hline 8 & 1.63 & 6 & 19 & 9.78 & 0 & 0 & 0.00 & 0 & 2 & 0.00 \\
\hline 9 & 1.18 & 9 & 6 & 10.59 & 1 & 1 & 1.18 & 1 & 0 & 1.18 \\
\hline 10 & 0.50 & 0 & 3 & 0.00 & 0 & 0 & 0.00 & 0 & 2 & 0.00 \\
\hline 11 & 0.71 & 1 & 0 & 0.71 & 0 & 0 & 0.00 & 0 & 0 & 0.00 \\
\hline 12 & 0.66 & 3 & 2 & 1.99 & 0 & 0 & 0.00 & 0 & 0 & 0.00 \\
\hline 13 & 4.83 & 0 & 2 & 0.00 & 0 & 0 & 0.00 & 0 & 0 & 0.00 \\
\hline 14 & 1.97 & 1 & 7 & 1.97 & 0 & 0 & 0.00 & 1 & 2 & 1.97 \\
\hline 15 & 1.12 & 7 & 3 & 7.83 & 0 & 2 & 0.00 & 0 & 0 & 0.00 \\
\hline 16 & 1.96 & 0 & 0 & 0.00 & 0 & 0 & 0.00 & 0 & 1 & 0.00 \\
\hline$\overline{17}$ & 0.42 & 1 & 4 & 0.42 & 0 & 1 & 0.00 & 0 & $\overline{1}$ & 0.00 \\
\hline 18 & 4.01 & 0 & 8 & 0.00 & 0 & 0 & 0.00 & 0 & 2 & 0.00 \\
\hline 19 & 0.52 & 0 & $\overline{1}$ & 0.00 & 0 & $\overline{0}$ & 0.00 & 1 & $\mathrm{c}$ & 0.52 \\
\hline Total & & 46 & 133 & 87.34 & 2 & 7 & 1.67 & 10 & 14 & 16.87 \\
\hline
\end{tabular}

For each crash type in Table 5-4, the observed before crashes are multiplied by the exposure to risk factor, $E_{A} / E_{B}$, (Table 5-3) to calculate a predicted after crash value. For example, at Intersection 8, the adjustment factor 1.63 is multiplied by the number of 'Rear End, Neither Turning' crash type (6). A predicted crash value $\left(a_{0 A}\right)$ of 9.78 is calculated. This value is then added together with the other predicted values for the other 18 intersections to calculate an aggregate sum of predicted after crash values of 87.34 . 
Table 5-5: Summary Calculations for 'Opposite Direction Sideswipe', 'Off Road Collision', and 'Right Angle' at a Distance of 500 feet.

\begin{tabular}{|c|c|c|c|c|c|c|c|c|c|c|}
\hline \multirow[b]{2}{*}{ 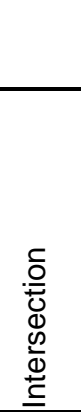 } & \multirow[b]{2}{*}{ 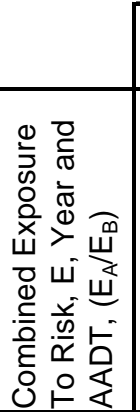 } & \multicolumn{3}{|c|}{$\begin{array}{l}\text { Opposite Direction } \\
\text { Sideswipe }\end{array}$} & \multicolumn{3}{|c|}{ Off Road Collision } & \multicolumn{3}{|c|}{ Right Angle } \\
\hline & & $\begin{array}{l}0 \\
\frac{0}{0} \\
0 \\
\infty \\
0 \\
\frac{0}{0} \\
\frac{0}{0} \\
\frac{0}{0} \\
0\end{array}$ & $\begin{array}{l}\bar{\Phi} \\
\frac{1}{4} \\
\frac{0}{2} \\
\frac{1}{0} \\
\frac{0}{0} \\
\frac{0}{2}\end{array}$ & 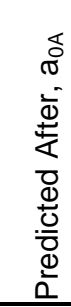 & $\begin{array}{l}0 \\
\frac{0}{0} \\
\frac{0}{0} \\
0 \\
\frac{0}{ \pm} \\
\frac{0}{0} \\
.0 \\
\frac{0}{\alpha}\end{array}$ & 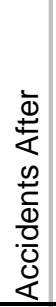 & 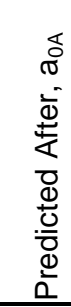 & $\begin{array}{l}0 \\
\frac{0}{0} \\
\frac{0}{0} \\
0 \\
\frac{0}{ \pm} \\
\frac{0}{0} \\
.0 \\
\frac{0}{\alpha}\end{array}$ & $\begin{array}{l}\bar{\Phi} \\
\frac{1}{4} \\
\frac{0}{1} \\
\frac{1}{0} \\
\frac{0}{0} \\
\frac{0}{\alpha}\end{array}$ & 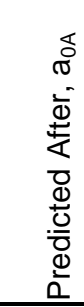 \\
\hline 1 & 0.42 & 0 & 0 & 0.00 & 0 & 0 & 0.00 & 0 & 0 & 0.00 \\
\hline 2 & 0.38 & $\overline{0}$ & 0 & 0.00 & $\overline{0}$ & 0 & 0.00 & $\overline{0}$ & 0 & 0.00 \\
\hline 3 & 0.50 & $\overline{0}$ & 0 & 0.00 & 1 & $\overline{0}$ & 0.50 & 1 & 1 & 0.50 \\
\hline 4 & 5.36 & 0 & 1 & 0.00 & 0 & 0 & 0.00 & 3 & 5 & 16.07 \\
\hline 5 & 5.36 & $\overline{0}$ & 1 & 0.00 & $\overline{0}$ & 0 & 0.00 & 1 & 9 & 5.36 \\
\hline 6 & 4.52 & 0 & 0 & 0.00 & 0 & 1 & 0.00 & 5 & 3 & 22.62 \\
\hline 7 & 9.33 & 0 & 0 & 0.00 & 0 & 0 & 0.00 & 0 & 1 & 0.00 \\
\hline 8 & 1.63 & 0 & 0 & 0.00 & 0 & 0 & 0.00 & 1 & 2 & 1.63 \\
\hline 9 & 1.18 & 0 & 0 & 0.00 & 0 & 1 & 0.00 & 10 & 10 & 11.76 \\
\hline 10 & 0.50 & 0 & 0 & 0.00 & 0 & 1 & 0.00 & 0 & 1 & 0.00 \\
\hline 11 & 0.71 & 0 & 0 & 0.00 & 0 & 0 & 0.00 & 0 & 0 & 0.00 \\
\hline 12 & 0.66 & 0 & 0 & 0.00 & 0 & 0 & 0.00 & 2 & 3 & 1.33 \\
\hline 13 & 4.83 & 0 & 0 & 0.00 & 0 & 1 & 0.00 & 0 & 0 & 0.00 \\
\hline 14 & 1.97 & $\overline{0}$ & 0 & 0.00 & $\overline{0}$ & 1 & 0.00 & 0 & 5 & 0.00 \\
\hline 15 & 1.12 & 2 & 0 & 2.24 & $\overline{0}$ & 0 & 0.00 & $\overline{6}$ & 2 & 6.71 \\
\hline 16 & 1.96 & 0 & 0 & 0.00 & 0 & 0 & 0.00 & 0 & 0 & 0.00 \\
\hline 17 & 0.42 & 1 & 0 & 0.42 & 0 & 0 & 0.00 & 5 & 2 & 2.11 \\
\hline 18 & 4.01 & 0 & 0 & 0.00 & 0 & 0 & 0.00 & 2 & 5 & 8.02 \\
\hline 19 & 0.52 & $\overline{0}$ & 0 & 0.00 & 0 & 0 & 0.00 & 3 & 0 & 1.56 \\
\hline Total & & 3 & 2 & 2.66 & 1 & 5 & 0.50 & 39 & 49 & 77.66 \\
\hline
\end{tabular}

Similar calculations are followed for 'Rear End, Neither Turning', 'Head On, Neither Turning', and 'Same Direction Sideswipe'. Table 5-5 shows the calculations for 'Opposite Direction Sideswipe', 'Off Road Collision', and 'Right Angle' at a distance of 500 feet from the intersection. Table 5-6 shows calculations of 'Left and Right Turns', 'Left Turn', and 'Right Turn' crashes within 500 feet from the intersection. 
Table 5-6: Summary Calculations for 'Left and Right Turns', 'Left Turns', and 'Right Turn' at a Distance of 500 feet.

\begin{tabular}{|c|c|c|c|c|c|c|c|c|c|c|}
\hline \multirow[b]{2}{*}{ 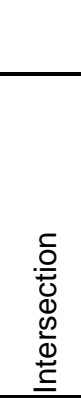 } & \multirow[b]{2}{*}{ 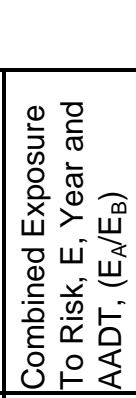 } & \multicolumn{3}{|c|}{ Left and Right Turns } & \multicolumn{3}{|c|}{ Left Turn } & \multicolumn{3}{|c|}{ Right Turn } \\
\hline & & 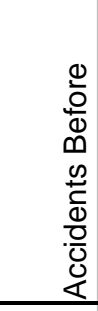 & $\begin{array}{l}\overline{0} \\
\frac{1}{4} \\
0 \\
\frac{0}{0} \\
\frac{0}{0} \\
.0 \\
0 \\
\frac{0}{2}\end{array}$ & 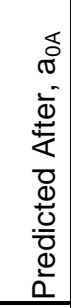 & 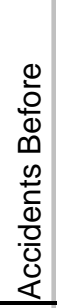 & $\begin{array}{l}\overline{0} \\
\frac{1}{4} \\
0 \\
0 \\
\frac{1}{0} \\
.0 \\
.0 \\
0 \\
\frac{0}{2}\end{array}$ & 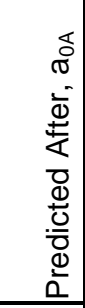 & $\begin{array}{l}0 \\
\frac{0}{0} \\
0 \\
\infty \\
0 \\
\frac{0}{0} \\
\frac{0}{0} \\
0 \\
0\end{array}$ & $\begin{array}{l}\bar{y} \\
\frac{10}{4} \\
\frac{0}{0} \\
\frac{0}{0} \\
\frac{0}{0} \\
0 \\
\end{array}$ & 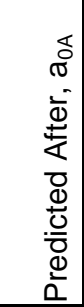 \\
\hline 1 & 0.42 & 0 & 0 & 0.00 & 0 & 0 & 0.00 & 0 & 0 & 0.00 \\
\hline 2 & 0.38 & 0 & 0 & 0.00 & 0 & 0 & 0.00 & 0 & c & 0.00 \\
\hline 3 & 0.50 & 0 & 0 & 0.00 & 2 & 0 & 1.00 & 1 & 0 & 0.50 \\
\hline 4 & 5.36 & 0 & 0 & 0.00 & 0 & 0 & 0.00 & 0 & c & 0.00 \\
\hline 5 & 5.36 & 0 & 0 & 0.00 & 0 & 0 & 0.00 & 1 & 0 & 5.36 \\
\hline 6 & 4.52 & $\overline{0}$ & 0 & 0.00 & 0 & 1 & 0.00 & $\overline{0}$ & $\bar{c}$ & 0.00 \\
\hline 7 & 9.33 & 0 & 0 & 0.00 & 0 & 0 & 0.00 & 1 & 0 & 9.33 \\
\hline 8 & 1.63 & 0 & 0 & 0.00 & 0 & 3 & 0.00 & 1 & c & 1.63 \\
\hline 9 & 1.18 & 0 & 1 & 0.00 & 1 & 7 & 1.18 & 2 & c & 2.35 \\
\hline 10 & 0.50 & 0 & 0 & 0.00 & 0 & 0 & 0.00 & 0 & 0 & 0.00 \\
\hline 11 & 0.71 & 0 & 0 & 0.00 & 0 & 0 & 0.00 & 0 & $\mathrm{c}$ & 0.00 \\
\hline 12 & 0.66 & 0 & 0 & 0.00 & 1 & 2 & 0.66 & 0 & $\mathrm{c}$ & 0.00 \\
\hline 13 & 4.83 & $\overline{0}$ & 0 & 0.00 & 0 & 0 & 0.00 & 0 & 0 & 0.00 \\
\hline 14 & 1.97 & 0 & 0 & 0.00 & 1 & 8 & 1.97 & 0 & c & 0.00 \\
\hline 15 & 1.12 & 0 & 0 & 0.00 & 3 & 2 & 3.36 & 0 & 0 & 0.00 \\
\hline 16 & 1.96 & 0 & 0 & 0.00 & 0 & $\overline{0}$ & 0.00 & 0 & $\bar{c}$ & 0.00 \\
\hline 17 & 0.42 & 0 & 0 & 0.00 & 0 & 2 & 0.00 & 0 & c & 0.00 \\
\hline 18 & 4.01 & 0 & 0 & 0.00 & 1 & 3 & 4.01 & 0 & 0 & 0.00 \\
\hline 19 & 0.52 & $\overline{0}$ & 0 & 0.00 & 1 & $\overline{0}$ & 0.52 & 1 & 0 & 0.52 \\
\hline Total & & 0 & 1 & 0.00 & 10 & 28 & 12.69 & 7 & 0 & 19.69 \\
\hline
\end{tabular}


Table 5-7: Summary Calculations for 'Other / Unknown', and 'Total' at a Distance of 500 feet.

\begin{tabular}{|c|c|c|c|c|c|c|c|}
\hline \multirow[b]{2}{*}{ 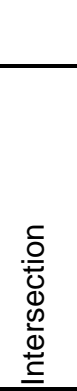 } & \multirow[b]{2}{*}{ 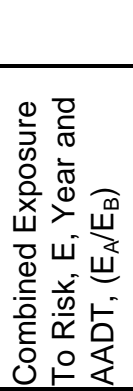 } & \multicolumn{3}{|c|}{ Other / Unknown } & \multicolumn{3}{|c|}{ Total } \\
\hline & & $\begin{array}{l}0 \\
\frac{0}{0} \\
\frac{0}{0} \\
\infty \\
\frac{0}{2} \\
\frac{1}{0} \\
\frac{0}{0} \\
\frac{0}{4}\end{array}$ & 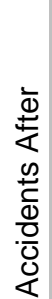 & 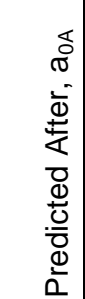 & $\begin{array}{l}0 \\
\frac{0}{0} \\
\frac{0}{0} \\
0 \\
0 \\
\frac{0}{0} \\
\frac{0}{0} \\
\frac{0}{4}\end{array}$ & $\begin{array}{l}\frac{\bar{d}}{0} \\
\frac{1}{4} \\
0 \\
\frac{0}{c} \\
\frac{0}{0} \\
\frac{0}{0} \\
0\end{array}$ & 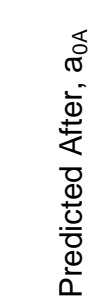 \\
\hline 1 & 0.42 & 0 & 0 & 0.00 & 2 & 1 & 0.84 \\
\hline 2 & 0.38 & 0 & 3 & 0.00 & 0 & 7 & 0.00 \\
\hline 3 & 0.50 & 4 & 1 & 1.99 & 21 & 7 & 10.45 \\
\hline 4 & 5.36 & 0 & 3 & 0.00 & 3 & 20 & 16.07 \\
\hline 5 & 5.36 & 1 & 5 & 5.36 & 11 & 53 & 58.92 \\
\hline 6 & 4.52 & 0 & 4 & 0.00 & 9 & 33 & 40.72 \\
\hline 7 & 9.33 & 2 & 7 & 18.66 & 3 & 10 & 28.00 \\
\hline 8 & 1.63 & 1 & 2 & 1.63 & 9 & 28 & 14.66 \\
\hline 9 & 1.18 & 4 & 3 & 4.71 & 28 & 29 & 32.94 \\
\hline 10 & 0.50 & 0 & 0 & 0.00 & 0 & 7 & 0.00 \\
\hline 11 & 0.71 & 0 & 0 & 0.00 & 1 & 0 & 0.71 \\
\hline 12 & 0.66 & 0 & 0 & 0.00 & 6 & 7 & 3.98 \\
\hline 13 & 4.83 & 0 & 6 & 0.00 & 0 & 9 & 0.00 \\
\hline 14 & 1.97 & 0 & 2 & 0.00 & 3 & 25 & 5.90 \\
\hline 15 & 1.12 & 9 & 23 & 10.07 & 27 & 32 & 30.20 \\
\hline 16 & 1.96 & 0 & 0 & 0.00 & 0 & 1 & 0.00 \\
\hline 17 & 0.42 & 0 & 2 & 0.00 & 7 & 12 & 2.95 \\
\hline 18 & 4.01 & 0 & 4 & 0.00 & 3 & 22 & 12.03 \\
\hline 19 & 0.52 & 0 & 0 & 0.00 & 6 & 1 & 3.11 \\
\hline Total & & 21 & 65 & 42.41 & 139 & 304 & 261.48 \\
\hline
\end{tabular}


Table 5-7 shows the calculations of the crash type 'Other/Unknown' and 'Total'. The total values are the sum of each crash type for the before and after periods. At Intersection 8, there were nine crashes before signal installation and 28 after installation. The nine observed crashes are multiplied by the exposure to risk factor for a predicted value of 28.00 .

Along with crash types, severity of crashes is also analyzed. The change in exposure to risk factor is also applied to the number of crash severities, shown in Table 5-8. Predicted values for 'Property Damage', 'Personal Injury', and 'Fatal' are calculated. For Intersection 8, the 1.63 exposure to risk factor is multiplied to the four observed 'Property Damage' crashes to calculate 6.52 predicted 'Property Damage' crashes and the five observed 'Personal Injury' crashes for an 8.15 predicted 'Personal Injury' crashes. These predicted values are then added together for an aggregate sum. 
Table 5-8: Summary Calculations for 'Property Damage', 'Personal Injury', and 'Fatal' at a Distance of 500 feet.

\begin{tabular}{|c|c|c|c|c|c|c|c|c|c|c|}
\hline \multirow[b]{2}{*}{ 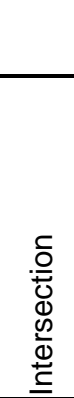 } & \multirow[b]{2}{*}{ 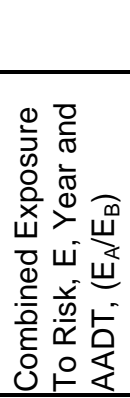 } & \multicolumn{3}{|c|}{ Property Damage } & \multicolumn{3}{|c|}{ Personal Injury } & \multicolumn{3}{|c|}{ Fatal } \\
\hline & & 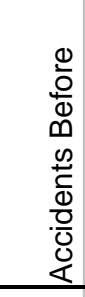 & 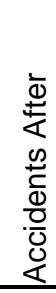 & 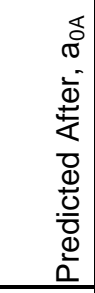 & $\begin{array}{l}0 \\
\frac{0}{0} \\
0 \\
0 \\
\frac{0}{0} \\
\frac{0}{0} \\
\frac{0}{0} \\
0\end{array}$ & $\begin{array}{l}\bar{\Phi} \\
\frac{1}{4} \\
0 \\
\frac{0}{0} \\
\frac{0}{0} \\
\frac{0}{0} \\
\frac{0}{4}\end{array}$ & 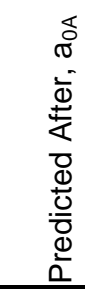 & 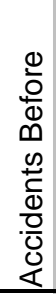 & 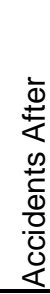 & 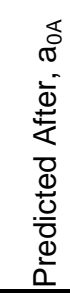 \\
\hline 1 & 0.42 & 1 & 0 & 0.42 & 1 & 1 & 0.42 & 0 & 0 & 0.00 \\
\hline 2 & 0.38 & 0 & 5 & 0.00 & 0 & 2 & 0.00 & 0 & 0 & 0.00 \\
\hline 3 & 0.50 & 17 & 6 & 8.46 & 4 & 1 & 1.99 & 0 & 0 & 0.00 \\
\hline 4 & 5.36 & 2 & 19 & 10.71 & 1 & 1 & 5.36 & 0 & 0 & 0.00 \\
\hline 5 & 5.36 & 11 & 47 & 58.92 & 0 & 6 & 0.00 & 0 & 0 & 0.00 \\
\hline 6 & 4.52 & 9 & 22 & 40.72 & 0 & 11 & 0.00 & $\overline{0}$ & 0 & 0.00 \\
\hline 7 & 9.33 & 3 & 7 & 28.00 & 0 & 3 & 0.00 & 0 & 0 & 0.00 \\
\hline 8 & 1.63 & 4 & 22 & 6.52 & 5 & 6 & 8.15 & 0 & 0 & 0.00 \\
\hline 9 & 1.18 & 19 & 24 & 22.35 & 9 & 5 & 10.59 & 0 & 0 & 0.00 \\
\hline 10 & 0.50 & 0 & 4 & 0.00 & 0 & 3 & 0.00 & 0 & 0 & 0.00 \\
\hline 11 & 0.71 & 0 & 0 & 0.00 & 1 & 0 & 0.71 & 0 & 0 & 0.00 \\
\hline 12 & 0.66 & 3 & 4 & 1.99 & 3 & 3 & 1.99 & 0 & 0 & 0.00 \\
\hline 13 & 4.83 & 0 & $\overline{6}$ & 0.00 & 0 & 3 & 0.00 & 0 & 0 & 0.00 \\
\hline 14 & 1.97 & 2 & 16 & 3.94 & 1 & 9 & 1.97 & $\overline{0}$ & 0 & 0.00 \\
\hline 15 & 1.12 & 18 & 21 & 20.13 & 9 & 11 & 10.07 & 0 & 0 & 0.00 \\
\hline 16 & 1.96 & 0 & 0 & 0.00 & 0 & 0 & 0.00 & 0 & 0 & 0.00 \\
\hline 17 & 0.42 & 3 & $\overline{9}$ & 1.26 & 4 & 3 & 1.68 & $\overline{0}$ & 0 & 0.00 \\
\hline 18 & 4.01 & 2 & 17 & 8.02 & 0 & 5 & 0.00 & 1 & 0 & 4.01 \\
\hline 19 & 0.52 & 4 & 1 & 2.08 & 1 & 0 & 0.52 & 1 & 0 & 0.52 \\
\hline Total & & 98 & 230 & 213.52 & 39 & 73 & 43.43 & 2 & 0 & 4.53 \\
\hline
\end{tabular}

\section{4. $\quad$ Negative Binomial Test}

With the aggregate sums of number of crashes, actual and predicted, a negative binomial distribution test is performed. From the test, two critical values are determined for each of the following two tests at $10 \%$ significant levels. Two tests are used for each type and severity of crashes. For each test, the critical values are compared to the actual number of crashes after installation. 
- Test 1 evaluates if there is a statistically significant reduction in crashes after the installation of a traffic signal. For this test, a decrease in crashes is significant if the observed number of crashes is less than the critical value.

- Test 2 evaluates if there is a statistically significant increase in observed crashes after the signal is installed. An increase in crashes is significant if the observed number of crashes is greater than the critical value.

\section{5. $\quad \underline{\text { Results }}$}

Test 1 and Test 2 are performed on each crash type, shown in Table 5-9, and severity of crashes, Table 5-10. For example, the category 'Rear End, Neither Turning' had 133 crashes, but only 87.34 were predicted. Based upon the negative binomial model, the critical value for determining if there was a statistically significant increase was 163 crashes. Consequently there was statistically significant evidence to support the hypothesis that there was an increase of crashes in this category after the signal installation. The results from Test 1 for crashes within 500 feet show that there is significant decrease of crashes for 'Right Angle', and 'Right Turn'. Results from Test 2 for the same data set show that there is significant increase of crashes for 'Rear End, Neither Turning', 'Head On, Neither Turning', 'Off Road Collision' 'Left Turn', 'Other/Unknown', and 'Personal Injury'. 'Left and Right Turns' did not have sufficient data to perform either test since there is only one reported crash of this type. Table 5-11 shows the summary of statistical calculations for the negative binomial test. 
Table 5-9: Results Table for Crash Types Within 500 feet of All Intersections.

\begin{tabular}{|c|c|c|c|c|c|c|}
\hline Type of Crashes & $\begin{array}{c}\text { Actual Value, } \\
\qquad a_{A}\end{array}$ & $\begin{array}{l}\text { Predicted } \\
\text { Value, } a_{0 A}\end{array}$ & $\begin{array}{c}\text { Low Critical } \\
\text { Value @ 10\% }\end{array}$ & $\begin{array}{c}\text { Test 1, Test if } \\
\text { Significant } \\
\text { Improvement }\end{array}$ & $\begin{array}{c}\text { High Critical } \\
\text { Value @ } 10 \%\end{array}$ & $\begin{array}{l}\text { Test 2, Test if } \\
\text { Significant } \\
\text { Degradation }\end{array}$ \\
\hline $\begin{array}{c}\text { Rear End, Neither } \\
\text { Turning }\end{array}$ & 133 & 87.34 & 63 & $\mathrm{NO}$ & 113 & YES \\
\hline $\begin{array}{l}\text { Head On, Neither } \\
\text { Turning }\end{array}$ & 7 & 1.67 & 0 & $\mathrm{NO}$ & 4 & YES \\
\hline $\begin{array}{l}\text { Same Direction } \\
\text { Sideswipe }\end{array}$ & 14 & 16.87 & 7 & $\mathrm{NO}$ & 29 & $\mathrm{NO}$ \\
\hline $\begin{array}{l}\text { Opposite Direction } \\
\text { Sideswipe }\end{array}$ & 2 & 2.66 & 0 & $\mathrm{NO}$ & 6 & $\mathrm{NO}$ \\
\hline Off Road Collision & 5 & 0.50 & 0 & $\mathrm{NO}$ & 2 & YES \\
\hline Right Angle & 49 & 77.66 & 55 & YES & 102 & $\mathrm{NO}$ \\
\hline $\begin{array}{l}\text { Left and Right } \\
\text { Turns }\end{array}$ & 1 & 0.00 & \multicolumn{4}{|c|}{ INSUFFICIENT DATA } \\
\hline Left Turn & 28 & 12.69 & 5 & $\mathrm{NO}$ & 21 & YES \\
\hline Right Turn & 0 & 19.69 & 7 & YES & 36 & $\mathrm{NO}$ \\
\hline Other / Unknown & 65 & 42.41 & 23 & $\mathrm{NO}$ & 64 & YES \\
\hline Total & 304 & 261.48 & 216 & $\mathrm{NO}$ & 308 & NO \\
\hline
\end{tabular}

Table 5-10: Results Table for Severity of Crashes Within 500 feet of All Intersections.

\begin{tabular}{|c|r|r|r|r|r|r|}
\hline Severity of Crashes & \multicolumn{1}{|c|}{$\begin{array}{c}\text { Actual Value, } \\
\mathrm{a}_{\mathrm{A}}\end{array}$} & $\begin{array}{c}\text { Predicted } \\
\text { Value, } \mathrm{a}_{\mathrm{OA}}\end{array}$ & $\begin{array}{c}\text { Low Critical } \\
\text { Value @ 10\% }\end{array}$ & $\begin{array}{c}\text { Test 1, Test if } \\
\text { Significant } \\
\text { Improvement }\end{array}$ & $\begin{array}{c}\text { High Critical } \\
\text { Value @ 10\% }\end{array}$ & $\begin{array}{c}\text { Test 2, Test if } \\
\text { Significant } \\
\text { Degradation }\end{array}$ \\
\hline Property Damage & 230 & 213.52 & 171 & $\mathrm{NO}$ & 257 & NO \\
\hline Personal Injury & 73 & 43.43 & 30 & $\mathrm{NO}$ & 58 & YES \\
\hline Fatal & 0 & 4.53 & 0 & $\mathrm{NO}$ & 11 & NO \\
\hline
\end{tabular}


Table 5-11: Summary Statistical Calculations for Crashes Within 500 feet of All Intersections.

\begin{tabular}{|c|c|c|c|c|c|}
\hline & $\begin{array}{c}\text { Predicted Value, } \\
\sum \mathrm{a}_{\mathrm{OA}}\end{array}$ & $\begin{array}{c}\text { Predicted Variance, } \\
\sum \text { var } \mathrm{a}_{0 \mathrm{~A}}\end{array}$ & Variability, $\alpha$ & $s=1 / \alpha$ & $p=1 /\left(1+\alpha^{*} \Sigma a_{0 A}\right)$ \\
\hline $\begin{array}{l}\text { Rear End, Neither } \\
\text { Turning }\end{array}$ & 87.34 & 298.89 & 0.039 & 25.52 & 0.226 \\
\hline $\begin{array}{l}\text { Head On, Neither } \\
\text { Turning }\end{array}$ & 1.67 & 1.63 & 0.582 & 1.72 & 0.506 \\
\hline $\begin{array}{l}\text { Same Direction } \\
\text { Sideswipe }\end{array}$ & 16.87 & 64.14 & 0.226 & 4.43 & 0.208 \\
\hline $\begin{array}{c}\text { Opposite Direction } \\
\text { Sideswipe }\end{array}$ & 2.66 & 2.68 & 0.379 & 2.64 & 0.498 \\
\hline Off Road Collision & 0.50 & 0.25 & 1.000 & 1.00 & 0.668 \\
\hline Right Angle & 77.66 & 276.12 & 0.046 & 21.84 & 0.220 \\
\hline $\begin{array}{l}\text { Left and Right } \\
\text { Turns }\end{array}$ & 0.00 & 0.00 & \multicolumn{3}{|c|}{ INSUFFICIENT DATA } \\
\hline Left Turn & 12.69 & 26.29 & 0.163 & 6.12 & 0.325 \\
\hline Right Turn & 19.69 & 121.73 & 0.314 & 3.18 & 0.139 \\
\hline Other / Unknown & 42.41 & 223.32 & 0.124 & 8.05 & 0.160 \\
\hline Total & 261.48 & 1015.04 & 0.015 & 67.36 & 0.205 \\
\hline Property Damage & 213.52 & 925.18 & 0.020 & 49.28 & 0.188 \\
\hline Personal Injury & 43.43 & 73.51 & 0.039 & 25.66 & 0.371 \\
\hline Fatal & 4.53 & 16.35 & 0.797 & 1.25 & 0.217 \\
\hline
\end{tabular}

Each test was also performed for 200 feet and 1000 feet data sets. Table 5-12 and Table 5-13 show the results of the tests for crashes within 200 feet of the intersections. At this distance, 'Right Angle' and 'Right Turn' are statistically significant for improvement after traffic signal installation. 'Rear End, Neither Turning', 'Head On, Neither Turning', 'Off Road Collision', and 'Left Turn' are statistically significant for degradation after signal installation. Results of these tests for crash types are in Table 5-12. The tests on severity of crashes, in Table 5-13, show that 'Personal Injury' passes Test 2 and there is significant degradation after signal installation. 
Table 5-12: Results Table for Crash Types Within 200 feet of All Intersections.

\begin{tabular}{|c|r|r|r|r|r|r|}
\hline Type of Crashes & $\begin{array}{c}\text { Actual Value, } \\
a_{\mathrm{A}}\end{array}$ & $\begin{array}{c}\text { Predicted } \\
\text { Value, } \mathrm{a}_{0 \mathrm{~A}}\end{array}$ & $\begin{array}{c}\text { Low Critical } \\
\text { Value @ 10\% }\end{array}$ & $\begin{array}{c}\text { Test 1, Test if } \\
\text { Significant } \\
\text { Improvement }\end{array}$ & $\begin{array}{c}\text { High Critical } \\
\text { Value @ 10\% }\end{array}$ & $\begin{array}{c}\text { Test 2, Test if } \\
\text { Significant } \\
\text { Degradation }\end{array}$ \\
\hline $\begin{array}{c}\text { Rear End, Neither } \\
\text { Turning }\end{array}$ & 129 & 82.07 & 58 & NO & 108 & YES \\
\hline $\begin{array}{c}\text { Head On, Neither } \\
\text { Turning }\end{array}$ & 7 & 1.18 & 0 & NO & 3 & YES \\
\hline $\begin{array}{c}\text { Same Direction } \\
\text { Sideswipe }\end{array}$ & 11 & 16.87 & 7 & NO & 29 & NO \\
\hline $\begin{array}{c}\text { Opposite Direction } \\
\text { Sideswipe }\end{array}$ & 2 & 2.24 & 0 & NO & 5 & NO \\
\hline $\begin{array}{c}\text { Off Road Collision } \\
\text { Right Angle }\end{array}$ & 4 & 0.50 & 0 & NO & 101 & NES \\
\hline Left and Right \\
Turns
\end{tabular}

Table 5-13: Results Table for Severity of Crashes Within 200 feet of All Intersections.

\begin{tabular}{|c|r|r|r|r|r|r|}
\hline Severity of Crashes & \multicolumn{1}{|c|}{$\begin{array}{c}\text { Actual Value, } \\
a_{\mathrm{A}}\end{array}$} & $\begin{array}{r}\text { Predicted } \\
\text { Value, } \mathrm{a}_{\mathrm{OA}}\end{array}$ & $\begin{array}{c}\text { Low Critical } \\
\text { Value @ 10\% }\end{array}$ & $\begin{array}{c}\text { Test 1, Test if } \\
\text { Significant } \\
\text { Improvement }\end{array}$ & $\begin{array}{c}\text { High Critical } \\
\text { Value @ 10\% }\end{array}$ & $\begin{array}{c}\text { Test 2, Test if } \\
\text { Significant } \\
\text { Degradation }\end{array}$ \\
\hline Property Damage & 224 & 210.74 & 168 & $\mathrm{NO}$ & 255 & NO \\
\hline Personal Injury & 67 & 37.15 & 25 & $\mathrm{NO}$ & 51 & YES \\
\hline Fatal & 0 & 4.53 & 0 & $\mathrm{NO}$ & 11 & NO \\
\hline
\end{tabular}


Table 5-14 and Table 5-15 are summary tables for tests performed on crashes within 1000 feet of the intersection. For Test 1, 'Right Angle' and 'Right Turn' are statistically significant for improvement after traffic signal installation. 'Rear End, Neither Turning', 'Off Road Collision', Left Turn', and 'Other/Unknown' are statistically significant for degradation after signal installation. The same tests are performed on these crashes for severity of crashes at 1000 feet from the intersection and 'Personal Injury' is significant for degradation after signal installation.

Table 5-14: Results Table for Crash Types Within 1000 feet of All Intersections.

\begin{tabular}{|c|r|r|r|r|r|r|}
\hline Type of Crashes & \multicolumn{1}{|c|}{$\begin{array}{c}\text { Actual Value, } \\
a_{A}\end{array}$} & $\begin{array}{c}\text { Predicted } \\
\text { Value, } \mathrm{a}_{0 \mathrm{~A}}\end{array}$ & $\begin{array}{r}\text { Low Critical } \\
\text { Value @ 10\% }\end{array}$ & $\begin{array}{c}\text { Test 1, Test if } \\
\text { Significant } \\
\text { Improvement }\end{array}$ & $\begin{array}{c}\text { High Critical } \\
\text { Value @ 10\% }\end{array}$ & $\begin{array}{c}\text { Test 2, Test if } \\
\text { Significant } \\
\text { Degradation }\end{array}$ \\
\hline $\begin{array}{c}\text { Rear End, Neither } \\
\text { Turning }\end{array}$ & 135 & 94.46 & 69 & NO & 121 & YES \\
\hline $\begin{array}{c}\text { Head On, Neither } \\
\text { Turning }\end{array}$ & 7 & 5.68 & 1 & NO & 12 & NO \\
\hline $\begin{array}{c}\text { Same Direction } \\
\text { Sideswipe }\end{array}$ & 15 & 16.87 & 7 & NO & 29 & NO \\
\hline $\begin{array}{c}\text { Opposite Direction } \\
\text { Sideswipe }\end{array}$ & 2 & 2.66 & 0 & NO & 6 & NO \\
\hline $\begin{array}{c}\text { Off Road Collision } \\
\text { Right Angle }\end{array}$ & 5 & 0.50 & 0 & NO & 103 & NO \\
\hline Left and Right \\
Turns
\end{tabular}


Table 5-15: Results Table for Severity of Crashes Within 1000 feet of All Intersections.

\begin{tabular}{|c|r|r|r|r|r|r|}
\hline Severity of Crashes & \multicolumn{1}{|c|}{$\begin{array}{c}\text { Actual Value, } \\
a_{\mathrm{A}}\end{array}$} & $\begin{array}{c}\text { Predicted } \\
\text { Value, } \mathrm{a}_{0 \mathrm{~A}}\end{array}$ & $\begin{array}{c}\text { Low Critical } \\
\text { Value @ 10\% }\end{array}$ & $\begin{array}{c}\text { Test 1, Test if } \\
\text { Significant } \\
\text { Improvement }\end{array}$ & $\begin{array}{c}\text { High Critical } \\
\text { Value @ 10\% }\end{array}$ & $\begin{array}{c}\text { Test 2, Test if } \\
\text { Significant } \\
\text { Degradation }\end{array}$ \\
\hline Property Damage & 235 & 223.26 & 180 & $\mathrm{NO}$ & 268 & NO \\
\hline Personal Injury & 74 & 47.44 & 33 & $\mathrm{NO}$ & 63 & YES \\
\hline Fatal & 0 & 4.53 & 0 & $\mathrm{NO}$ & 11 & NO \\
\hline
\end{tabular}

Crashes at each intersection were tested at three distances, 200, 500, and 1000 feet from the intersection. The two tests show if there is any significant improvement or degradation after a traffic signal installation. Table $5-16$ is a summary table of results for each test at each distance. From the results, 'Right Angle' and 'Right Turn' are consistently significant for improvement after signal installation at each distance. As for being statistically significant for degradation, 'Rear End, Neither Turning', 'Off Road Collision', 'Left Turn' and 'Personal Injury' are significant at each distance. 'Head On, Neither Turning' is significant for degradation at distances 200 feet and 500 feet from the intersection. 'Other/Unknown' is statistically significant for degradation at 500 feet and 1000 feet. 
Table 5-16: Summary Table of Results for Test 1 and Test 2 for Distances 200 feet, 500 feet, and 1000 feet from All Intersections.

\begin{tabular}{|c|c|c|c|c|c|c|}
\hline & \multirow{2}{*}{\multicolumn{3}{|c|}{$\begin{array}{c}\text { Significant Safety Improvement } \\
\text { with Signal Installation } \\
\text { Distance From Intersection }\end{array}$}} & \multirow{2}{*}{\multicolumn{3}{|c|}{$\begin{array}{c}\text { Significant Safety Degradation } \\
\text { with Signal Installation } \\
\text { Distance From Intersection }\end{array}$}} \\
\hline & & & & & & \\
\hline & 200 feet & 500 feet & 1000 feet & 200 feet & 500 feet & 1000 feet \\
\hline $\begin{array}{l}\text { Rear End, Neither } \\
\text { Turning }\end{array}$ & & & & $\checkmark$ & $\checkmark$ & $\checkmark$ \\
\hline $\begin{array}{c}\text { Head On, Neither } \\
\text { Turning }\end{array}$ & & & & $\checkmark$ & $\checkmark$ & \\
\hline \multicolumn{7}{|l|}{$\begin{array}{l}\text { Same Direction } \\
\text { Sideswipe }\end{array}$} \\
\hline \multicolumn{7}{|l|}{$\begin{array}{c}\text { Opposite Direction } \\
\text { Sideswipe } \\
\end{array}$} \\
\hline Off Road Collision & & & & $\checkmark$ & $\checkmark$ & $\checkmark$ \\
\hline Right Angle & $\checkmark$ & $\checkmark$ & $\checkmark$ & & & \\
\hline \multicolumn{7}{|l|}{$\begin{array}{l}\text { Left and Right } \\
\text { Turns } \\
\end{array}$} \\
\hline Left Turn & & & & $\checkmark$ & $\checkmark$ & $\checkmark$ \\
\hline Right Turn & $\checkmark$ & $\checkmark$ & $\checkmark$ & & & \\
\hline Other / Unknown & & & & & $\checkmark$ & $\checkmark$ \\
\hline Total & & & & & & \\
\hline \multicolumn{7}{|l|}{ Property Damage } \\
\hline Personal Injury & & & & $\checkmark$ & $\checkmark$ & $\checkmark$ \\
\hline Fatal & & & & & & \\
\hline
\end{tabular}

\section{6. $\quad$ School Zone Intersection Analysis}

The results of an analysis on intersections located at school zones are shown in the following section. The same analysis testing procedure described previously in this section was applied to this data subset (Only intersections 1, 2, 3, 9, 10, 16, 17). Counts for crash types at these 
intersections are given in Table 5-17. The sample size is smaller than the previous analysis with 58 before installation crashes and 64 after installation crashes. From the smaller sample size, the crashes are also categorized in severity of crashes in Table 5-18.

Table 5-17: Summary Table of Crash Type Counts at School Zone Intersections Within 500 feet of the Intersection.

\begin{tabular}{|c|c|c|c|c|c|c|c|c|c|c|c|c|c|c|c|c|c|c|c|c|c|c|c|c|}
\hline \multirow{3}{*}{ 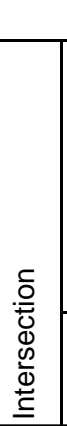 } & & & \multicolumn{22}{|c|}{ Counts by Crash Types } \\
\hline & & 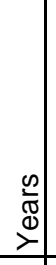 & 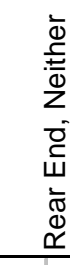 & 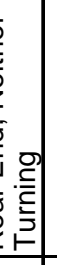 & $\begin{array}{l}\frac{1}{2} \\
\frac{ \pm}{ \pm} \\
\frac{1}{z} \\
0\end{array}$ & 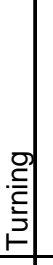 & & $\begin{array}{l}0 \\
\vdots \\
0 \\
0 \\
0 \\
0 \\
0\end{array}$ & $\begin{array}{l}\text { o } \\
\stackrel{0}{0} \\
\stackrel{0}{0}\end{array}$ & 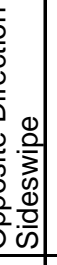 & & 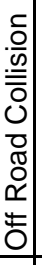 & & $\begin{array}{l}\frac{0}{0} \\
\frac{1}{2} \\
\pm \\
\frac{0}{0} \\
\end{array}$ & 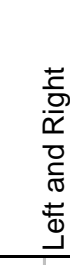 & 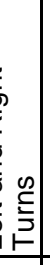 & & $\begin{array}{l}5 \\
5 \\
5 \\
5 \\
\\
\end{array}$ & & $\begin{array}{l}5 \\
5 \\
1 \\
\pm \\
\frac{5}{0} \\
\frac{0}{0} \\
\end{array}$ & & 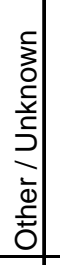 & & \\
\hline & $\begin{array}{l}\frac{0}{0} \\
\frac{0}{0} \\
\Phi \\
\end{array}$ & $\frac{\bar{d}}{\frac{\bar{t}}{\alpha}}$ & $\begin{array}{l}0 \\
\frac{0}{0} \\
\square \\
\end{array}$ & 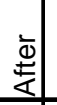 & $\begin{array}{l}\frac{\Phi}{0} \\
\frac{0}{0} \\
\oplus\end{array}$ & 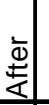 & $\begin{array}{l}0 \\
\frac{0}{0} \\
\stackrel{0}{0} \\
\end{array}$ & 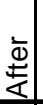 & $\begin{array}{l}\frac{0}{0} \\
\frac{0}{0} \\
\Phi\end{array}$ & $\begin{array}{l}\overline{\bar{\omega}} \\
\frac{\vec{\alpha}}{2}\end{array}$ & $\begin{array}{l}\frac{0}{0} \\
\frac{0}{D} \\
\Phi\end{array}$ & $\begin{array}{l}\frac{1}{\bar{d}} \\
\frac{\vec{t}}{2}\end{array}$ & $\begin{array}{l}\frac{\Phi}{0} \\
\frac{0}{0} \\
\oplus\end{array}$ & $\begin{array}{c}\frac{\bar{\omega}}{\bar{\alpha}} \\
\end{array}$ & $\begin{array}{l}0 \\
\frac{0}{0} \\
\Phi \\
\oplus\end{array}$ & 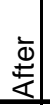 & $\begin{array}{l}\frac{\Phi}{0} \\
\frac{0}{\mathscr{D}} \\
\oplus\end{array}$ & $\begin{array}{c}\overline{\bar{m}} \\
\frac{\vec{k}}{\mathbf{2}}\end{array}$ & $\begin{array}{l}\frac{0}{0} \\
\frac{0}{0} \\
\Phi\end{array}$ & $\begin{array}{c}\overline{\bar{d}} \\
\frac{\vec{\alpha}}{\alpha}\end{array}$ & 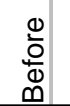 & $\begin{array}{c}\overline{\bar{\omega}} \\
\frac{\vec{k}}{2}\end{array}$ & $\frac{\Phi}{\frac{\Phi}{\Phi}}$ & $\frac{\bar{q}}{\frac{9}{\alpha}}$ \\
\hline 1 & 5 & 2 & 2 & 1 & 0 & 0 & 0 & 0 & 0 & 0 & 0 & 0 & 0 & 0 & 0 & 0 & 0 & 0 & 0 & 0 & 0 & 0 & 2 & \\
\hline 2 & 5 & 2 & 0 & 2 & 0 & 2 & 0 & 0 & 0 & 0 & 0 & 0 & 0 & 0 & 0 & 0 & 0 & 0 & 0 & 0 & 0 & 3 & 0 & \\
\hline 3 & 5 & 2 & 6 & 4 & 1 & 0 & 5 & 1 & 0 & 0 & 1 & 0 & 1 & 1 & 0 & 0 & 2 & 0 & 1 & 0 & 4 & 1 & 21 & \\
\hline 9 & 4 & 4 & 9 & 6 & 1 & 1 & 1 & 0 & 0 & 0 & 0 & 1 & 10 & 10 & 0 & 1 & 1 & 7 & 2 & 0 & 4 & 3 & $\begin{array}{ll}28 & 25 \\
\end{array}$ & \\
\hline 10 & 5 & 2 & 0 & 3 & 0 & 0 & 0 & 2 & 0 & 0 & 0 & 1 & 0 & 1 & 0 & 0 & 0 & 0 & 0 & 0 & 0 & 0 & 0 & \\
\hline 16 & 3 & 5 & 0 & 0 & 0 & 0 & 0 & 1 & $\overline{0}$ & 0 & 0 & 0 & 0 & 0 & 0 & 0 & 0 & 0 & 0 & 0 & 0 & 0 & 0 & \\
\hline 17 & 5 & 2 & 1 & 4 & 0 & 1 & 0 & 1 & 1 & 0 & 0 & 0 & 5 & 2 & 0 & 0 & 0 & 2) & 0 & 0 & 0 & 2 & \begin{tabular}{l|l|}
7 & 11
\end{tabular} & \\
\hline Total & 32 & 19 & $\begin{array}{ll}18 \\
\end{array}$ & 20 & 2 & 4 & 6 & 5 & 1 & 0 & 1 & 2 & 16 & 14 & 0 & 1 & 3 & 9 & 3 & 0 & 8 & & $\begin{array}{ll}58 & 6\end{array}$ & \\
\hline
\end{tabular}


Table 5-18: Summary Table of Severity of Crashes at School Zone Intersections Within 500 feet of the Intersection.

\begin{tabular}{|c|c|c|c|c|c|c|c|c|}
\hline \multirow{3}{*}{ 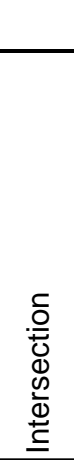 } & & & \multicolumn{6}{|c|}{ Severity of Crashes } \\
\hline & \multicolumn{2}{|r|}{$\begin{array}{l}\stackrel{\infty}{\bar{\sigma}} \\
\stackrel{\infty}{\nu}\end{array}$} & \multicolumn{2}{|c|}{ 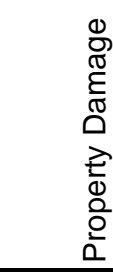 } & \multicolumn{2}{|r|}{ 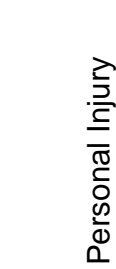 } & \multicolumn{2}{|r|}{$\begin{array}{l}\overline{\widetilde{\pi}} \\
\widetilde{\omega}\end{array}$} \\
\hline & 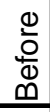 & 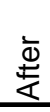 & $\begin{array}{l}0 \\
\frac{0}{0} \\
\Phi \\
\end{array}$ & $\frac{\bar{\Phi}}{\frac{\Phi}{\alpha}}$ & $\begin{array}{l}0 \\
\stackrel{0}{0} \\
\Phi \\
\Phi\end{array}$ & 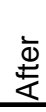 & $\begin{array}{l}0 \\
\stackrel{0}{0} \\
\Phi \\
\Phi \\
\end{array}$ & $\frac{\bar{d}}{\frac{1}{4}}$ \\
\hline 1 & 5 & 2 & 1 & 0 & 1 & 1 & 0 & 0 \\
\hline 2 & 5 & 2 & 0 & 5 & 0 & 2 & 0 & 0 \\
\hline 3 & 5 & 2 & 17 & 6 & 4 & 1 & 0 & 0 \\
\hline 9 & 4 & 4 & 19 & 24 & 9 & 5 & 0 & 0 \\
\hline 10 & 5 & 2 & 0 & 4 & 0 & 3 & 0 & 0 \\
\hline 16 & 3 & 5 & 0 & 0 & 0 & 0 & 0 & 0 \\
\hline 17 & 5 & 2 & 3 & 9 & 4 & 3 & 0 & 0 \\
\hline Total & 32 & 19 & 40 & 48 & 18 & 15 & 0 & 0 \\
\hline
\end{tabular}

Along with the same categorization of crashes, a new change in exposure to risk is calculated. Again, the adjustment to exposure is the product of ratio of years and ratio of AADT. The resulting change in exposure to risk is calculated in Table 5-19. 
Table 5-19: Summary Table of Change in Exposure to Risk for School Zone Intersections.

\begin{tabular}{|c|c|c|c|c|c|c|c|c|c|c|c|c|c|}
\hline & \multicolumn{4}{|c|}{ Years } & \multicolumn{8}{|c|}{ Annual Average Daily Traffic } & \multirow[b]{2}{*}{ 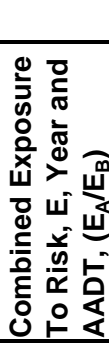 } \\
\hline 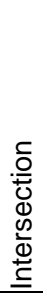 & 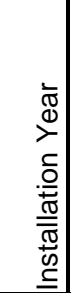 & 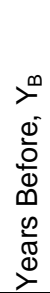 & 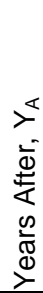 & 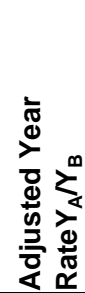 & $\stackrel{\bar{D}}{\nu}$ & $\begin{array}{l}\frac{\pi}{0} \\
\frac{0}{0} \\
\frac{0}{0} \\
\frac{0}{0} \\
2 \\
5 \\
\frac{0}{2}\end{array}$ & $\stackrel{\bar{D}}{\nu}$ & $\begin{array}{l}\frac{\pi}{0} \\
\frac{0}{0} \\
\frac{0}{0} \\
\frac{0}{0} \\
2 \\
\circ \\
\end{array}$ & $\begin{array}{l}\frac{0}{0} \\
\frac{\pi}{0} \\
\frac{7}{3} \\
\frac{0}{0} \\
0\end{array}$ & 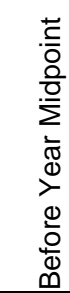 & 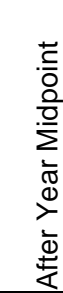 & 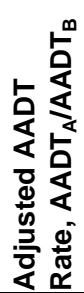 & \\
\hline 1 & 1997 & 5 & 2 & 0.40 & 1995 & 12560 & 1999 & 13190 & 1.012 & 1994 & 1998 & 1.05 & 0.42 \\
\hline 2 & 1997 & 5 & 2 & 0.40 & 1995 & 9490 & 1999 & 9030 & 0.988 & 1994 & 1998 & 0.95 & 0.38 \\
\hline 3 & 1997 & 5 & 2 & 0.40 & 1995 & 6930 & 2000 & 9110 & 1.056 & 1994 & 1998 & 1.24 & 0.50 \\
\hline 9 & 1995 & 4 & 4 & 1.00 & 1995 & 8720 & 1999 & 9930 & 1.033 & 1992 & 1997 & 1.18 & 1.18 \\
\hline 10 & 1997 & 5 & 2 & 0.40 & 1990 & 14010 & 1996 & $1942 C$ & 1.056 & 1994 & 1998 & 1.24 & 0.50 \\
\hline 16 & 1994 & 3 & 5 & 1.67 & 1992 & 24420 & 1996 & $2782 C$ & 1.033 & 1992 & 1997 & 1.18 & 1.96 \\
\hline 17 & 1997 & 5 & 2 & 0.40 & 1993 & 38090 & 1998 & 40620 & 1.013 & 1994 & 1998 & 1.05 & 0.42 \\
\hline
\end{tabular}

The same calculations are used to determine the aggregate predicted after crash values. The change of exposure to risk was multiplied to the observed before crashes and then totaled for the aggregate sum. This procedure is applied to each crash type and severity. The aggregate predicted values are then compared to critical values calculated from the negative binomial distribution. Test 1 and Test 2 are used to compare these values.

The results of these tests on crash types within 500 feet of the intersection are in Table 5-20. 'Head On, Neither Turning', 'Off Road Collision', 'Left Turn' and 'Total' are statistically significant for degradation after the signal installation. There are no statistically significant improvements for any crash types at 500 feet. 
Table 5-20: Results Table for Crash Types Within 500 feet of School Zone Intersections.

\begin{tabular}{|c|r|r|r|r|r|r|}
\hline Type of Crashes & \multicolumn{1}{|c|}{$\begin{array}{c}\text { Actual Value, } \\
a_{\mathrm{A}}\end{array}$} & $\begin{array}{c}\text { Predicted } \\
\text { Value, } \mathrm{a}_{0 \mathrm{~A}}\end{array}$ & $\begin{array}{c}\text { Low Critical } \\
\text { Value @ 10\% }\end{array}$ & $\begin{array}{c}\text { Test 1, Test if } \\
\text { Significant } \\
\text { Improvement }\end{array}$ & $\begin{array}{c}\text { High Critical } \\
\text { Value @ 10\% }\end{array}$ & $\begin{array}{c}\text { Test 2, Test if } \\
\text { Significant } \\
\text { Degradation }\end{array}$ \\
\hline $\begin{array}{c}\text { Rear End, Neither } \\
\text { Turning }\end{array}$ & 20 & 14.84 & 8 & NO & 22 & NO \\
\hline $\begin{array}{c}\text { Head On, Neither } \\
\text { Turning }\end{array}$ & 4 & 1.67 & 0 & NO & 4 & YES \\
\hline $\begin{array}{c}\text { Same Direction } \\
\text { Sideswipe }\end{array}$ & 5 & 3.67 & 1 & NO & 7 & NO \\
\hline $\begin{array}{c}\text { Opposite Direction } \\
\text { Sideswipe }\end{array}$ & 0 & 0.42 & 0 & NO & NO \\
\hline $\begin{array}{c}\text { Off Road Collision } \\
\text { Right Angle }\end{array}$ & 14 & 14.37 & 8 & NO & 22 & YES \\
\hline Left and Right \\
Turns
\end{tabular}

Table 5-21 shows the results of the same tests on severity of crashes within 500 feet. Degradation for 'Property Damage' is statistically significant. For this data set, 'Fatal' and 'Left and Right Turns' do not have sufficient data to determine and significant changes of safety. 
Table 5-21: Results Table for Severity of Crashes Within 500 feet of School Zone Intersections.

\begin{tabular}{|c|r|r|r|r|r|r|}
\hline Severity of Crashes & \multicolumn{1}{|c|}{$\begin{array}{c}\text { Actual Value, } \\
\mathrm{a}_{\mathrm{A}}\end{array}$} & $\begin{array}{c}\text { Predicted } \\
\text { Value, } \mathrm{a}_{\mathrm{OA}}\end{array}$ & $\begin{array}{c}\text { Low Critical } \\
\text { Value @ 10\% }\end{array}$ & $\begin{array}{c}\text { Test 1, Test if } \\
\text { Significant } \\
\text { Improvement }\end{array}$ & $\begin{array}{c}\text { High Critical } \\
\text { Value @ 10\% }\end{array}$ & $\begin{array}{c}\text { Test 2, Test if } \\
\text { Significant } \\
\text { Degradation }\end{array}$ \\
\hline Property Damage & 48 & 32.50 & 23 & $\mathrm{NO}$ & 43 & YES \\
\hline Personal Injury & 15 & 14.68 & 8 & $\mathrm{NO}$ & 22 & NO \\
\hline Fatal & 0 & 0.00 & \multicolumn{4}{|c|}{ INSUFFICIENT DATA } \\
\hline
\end{tabular}

The tests are also applied to crashes at school zone intersections for 200 feet and 1000 feet from the intersection. In Table 5-22, results from the tests on crash types for crashes within 200 feet show that 'Rear End, Neither Turning', 'Head On, Neither Turning', 'Left Turn', and 'Total' are statistically significant for safety degradation after signal installation. At this distance, there is insufficient data for 'Off Road Collision', along with 'Left and Right Turns'. Table 5-23 is a table of results for the tests on severity of crashes at 200 feet. Again, 'Fatal' does not have sufficient data for a test, while 'Property Damage' is found to be significant for degradation. 
Table 5-22: Results Table for Crash Types Within 200 feet of School Zone Intersections.

\begin{tabular}{|c|c|c|c|c|c|c|}
\hline Type of Crashes & $\begin{array}{c}\text { Actual Value, } \\
a_{\mathrm{A}}\end{array}$ & $\begin{array}{l}\text { Predicted } \\
\text { Value, } a_{0 A}\end{array}$ & $\begin{array}{l}\text { Low Critical } \\
\text { Value @ 10\% }\end{array}$ & $\begin{array}{l}\text { Test 1, Test if } \\
\text { Significant } \\
\text { Improvement }\end{array}$ & $\begin{array}{c}\text { High Critical } \\
\text { Value @ } 10 \%\end{array}$ & $\begin{array}{l}\text { Test 2, Test if } \\
\text { Significant } \\
\text { Degradation }\end{array}$ \\
\hline $\begin{array}{c}\text { Rear End, Neither } \\
\text { Turning }\end{array}$ & 18 & 10.89 & 5 & $\mathrm{NO}$ & 17 & YES \\
\hline $\begin{array}{l}\text { Head On, Neither } \\
\text { Turning }\end{array}$ & 4 & 1.18 & 0 & $\mathrm{NO}$ & 3 & YES \\
\hline $\begin{array}{l}\text { Same Direction } \\
\text { Sideswipe }\end{array}$ & 5 & 3.67 & 1 & $\mathrm{NO}$ & 7 & NO \\
\hline $\begin{array}{c}\text { Opposite Direction } \\
\text { Sideswipe }\end{array}$ & 0 & 0.00 & \multicolumn{4}{|c|}{ INSUFFICIENT DATA } \\
\hline Off Road Collision & 1 & 0.50 & 0 & $\mathrm{NO}$ & 2 & NO \\
\hline Right Angle & 13 & 13.19 & 7 & $\mathrm{NO}$ & 20 & $\mathrm{NO}$ \\
\hline $\begin{array}{l}\text { Left and Right } \\
\text { Turns } \\
\end{array}$ & 1 & 0.00 & \multicolumn{4}{|c|}{ INSUFFICIENT DATA } \\
\hline Left Turn & 9 & 1.00 & 0 & $\mathrm{NO}$ & 3 & YES \\
\hline Right Turn & 0 & 2.85 & 0 & $\mathrm{NO}$ & 6 & $\mathrm{NO}$ \\
\hline Other / Unknown & 8 & 6.70 & 2 & $\mathrm{NO}$ & 12 & NO \\
\hline Total & 59 & 39.96 & 29 & $\mathrm{NO}$ & 52 & YES \\
\hline
\end{tabular}

Table 5-23: Results Table for Severity of Crashes Within 200 feet of School Zone Intersections.

\begin{tabular}{|c|r|r|r|r|r|r|}
\hline Severity of Crashes & $\begin{array}{c}\text { Actual Value, } \\
a_{\mathrm{A}}\end{array}$ & $\begin{array}{c}\text { Predicted } \\
\text { Value, } a_{0 \mathrm{~A}}\end{array}$ & $\begin{array}{c}\text { Low Critical } \\
\text { Value @ 10\% }\end{array}$ & $\begin{array}{c}\text { Test 1, Test if } \\
\text { Significant } \\
\text { Improvement }\end{array}$ & $\begin{array}{c}\text { High Critical } \\
\text { Value @ 10\% }\end{array}$ & $\begin{array}{c}\text { Test 2, Test if } \\
\text { Significant } \\
\text { Degradation }\end{array}$ \\
\hline Property Damage & 46 & 30.90 & 21 & NO & 41 & YES \\
\hline Personal Injury & 13 & 9.06 & 4 & NO & 14 & NO \\
\hline Fatal & 0 & 0.00 & \multicolumn{4}{|c|}{ INSUFFICIENT DATA } \\
\hline
\end{tabular}


Crashes at school zones intersection within 1000 feet were then tested for significant changes after traffic signal installation. Table 5-24 is a results table for crash types at this distance. These results are similar to the one at 500 feet. 'Head On, Neither Turning', 'Off Road Collision', 'Left Turn', and 'Total' are found to be statistically significant for degradation. Again, there are no statistically significant improvements at this distance at school zone intersection.

Table 5-24: Results Table for Crash Types Within 1000 feet of School Zone Intersections.

\begin{tabular}{|c|c|c|c|c|c|c|}
\hline Type of Crashes & $\begin{array}{c}\text { Actual Value, } \\
a_{\mathrm{A}}\end{array}$ & $\begin{array}{l}\text { Predicted } \\
\text { Value, } a_{0 A}\end{array}$ & $\begin{array}{c}\text { Low Critical } \\
\text { Value @ 10\% }\end{array}$ & $\begin{array}{c}\text { Test } 1 \text {, Test if } \\
\text { Significant } \\
\text { Improvement }\end{array}$ & $\begin{array}{c}\text { High Critical } \\
\text { Value @10\% }\end{array}$ & $\begin{array}{c}\text { Test 2, Test if } \\
\text { Significant } \\
\text { Degradation }\end{array}$ \\
\hline $\begin{array}{l}\text { Rear End, Neither } \\
\text { Turning }\end{array}$ & 20 & 14.84 & 8 & $\mathrm{NO}$ & 22 & $\mathrm{NO}$ \\
\hline $\begin{array}{c}\text { Head On, Neither } \\
\text { Turning }\end{array}$ & 4 & 1.67 & 0 & $\mathrm{NO}$ & 4 & YES \\
\hline $\begin{array}{l}\text { Same Direction } \\
\text { Sideswipe }\end{array}$ & 5 & 3.67 & 1 & $\mathrm{NO}$ & 7 & $\mathrm{NO}$ \\
\hline $\begin{array}{l}\text { Opposite Direction } \\
\text { Sideswipe }\end{array}$ & 0 & 0.42 & 0 & $\mathrm{NO}$ & 1 & $\mathrm{NO}$ \\
\hline Off Road Collision & 2 & 0.50 & 0 & $\mathrm{NO}$ & 2 & YES \\
\hline Right Angle & 14 & 14.37 & 8 & $\mathrm{NO}$ & 22 & $\mathrm{NO}$ \\
\hline $\begin{array}{l}\text { Left and Right } \\
\text { Turns }\end{array}$ & 1 & 0.00 & \multicolumn{4}{|c|}{ INSUFFICIENT DATA } \\
\hline Left Turn & 9 & 2.17 & 0 & $\mathrm{NO}$ & 5 & YES \\
\hline Right Turn & 0 & 2.85 & 0 & $\mathrm{NO}$ & 6 & $\mathrm{NO}$ \\
\hline Other / Unknown & 9 & 6.70 & 2 & $\mathrm{NO}$ & 12 & NO \\
\hline Total & 64 & 47.18 & 35 & $\mathrm{NO}$ & 60 & YES \\
\hline
\end{tabular}

Results for severity of crashes within 1000 feet of school zone intersection are similar to previous results for crash severity at school zone intersections. Table 5-25 shows the results of the two tests on severity of crashes. 'Property Damage' is found to be statistically significant for 
degradation after the traffic signal installation. Results for 'Fatal' are not able to be calculated due to insufficient data.

Table 5-25: Results Table for Severity of Crashes Within 1000 feet of School Zone Intersections.

\begin{tabular}{|c|r|r|r|r|r|r|}
\hline Severity of Crashes & $\begin{array}{c}\text { Actual Value, } \\
a_{A}\end{array}$ & $\begin{array}{c}\text { Predicted } \\
\text { Value, } \mathrm{a}_{0 \mathrm{~A}}\end{array}$ & $\begin{array}{r}\text { Low Critical } \\
\text { Value @ 10\% }\end{array}$ & $\begin{array}{c}\text { Test 1, Test if } \\
\text { Significant } \\
\text { Improvement }\end{array}$ & $\begin{array}{c}\text { High Critical } \\
\text { Value @ 10\% }\end{array}$ & $\begin{array}{c}\text { Test 2, Test if } \\
\text { Significant } \\
\text { Degradation }\end{array}$ \\
\hline Property Damage & 48 & 34.46 & 24 & $\mathrm{NO}$ & 45 & YES \\
\hline Personal Injury & 15 & 14.68 & 8 & $\mathrm{NO}$ & 22 & NO \\
\hline Fatal & 0 & 0.00 & \multicolumn{5}{|c|}{ INSUFFICIENT DATA } \\
\hline
\end{tabular}

School zone intersections were tested for any statistical significant changes due to a traffic signal intersection for crashes within 200, 500, and 1000 feet from the intersection. Table 5-26 summarizes the results from these tests. For these intersections, there are no significant safety improvements due to signal installation. Crash types; 'Head On, Neither Turning' 'Left and Right Turns' and 'Total' are statistically significant for degradation at each distance. Crash severity 'Property Damage' degrades significantly also at these distances. 'Rear End, Neither Turning' is significant for degradation for crashes within 200 feet of the intersection. 'Off Road Collision" is found to be statistically degrading for distances of 500 and 1000 feet from school zone intersections. 
Table 5-26: Summary Table of Results for Test 1 and Test 2 on School Zone Intersection for Distances 200 feet, 500 feet, and 1000 feet from the Intersection.

\begin{tabular}{|c|c|c|c|c|c|c|}
\hline & \multirow{2}{*}{\multicolumn{3}{|c|}{$\begin{array}{c}\text { Significant Safety Improvement } \\
\text { with Signal Installation }\end{array}$}} & \multirow{2}{*}{\multicolumn{3}{|c|}{$\begin{array}{c}\begin{array}{c}\text { Significant Safety Degradation } \\
\text { with Signal Installation }\end{array} \\
\text { Distance From Intersection }\end{array}$}} \\
\hline & & & & & & \\
\hline & 200 feet & 500 feet & 1000 feet & 200 feet & 500 feet & 1000 feet \\
\hline $\begin{array}{l}\text { Rear End, Neither } \\
\text { Turning }\end{array}$ & & & & $\checkmark$ & & \\
\hline $\begin{array}{l}\text { Head On, Neither } \\
\text { Turning }\end{array}$ & & & & $\sqrt{ }$ & $\checkmark$ & $\checkmark$ \\
\hline \multicolumn{7}{|l|}{$\begin{array}{l}\text { Same Direction } \\
\text { Sideswipe }\end{array}$} \\
\hline \multicolumn{7}{|l|}{$\begin{array}{c}\text { Opposite Direction } \\
\text { Sideswipe } \\
\end{array}$} \\
\hline Off Road Collision & & & & & $\checkmark$ & $\checkmark$ \\
\hline \multicolumn{7}{|l|}{ Right Angle } \\
\hline \multicolumn{7}{|l|}{$\begin{array}{l}\text { Left and Right } \\
\text { Turns } \\
\end{array}$} \\
\hline Left Turn & & & & $\checkmark$ & $\checkmark$ & $\checkmark$ \\
\hline \multicolumn{7}{|l|}{ Right Turn } \\
\hline \multicolumn{7}{|l|}{ Other / Unknown } \\
\hline Total & & & & $\checkmark$ & $\checkmark$ & $\checkmark$ \\
\hline Property Damage & & & & $\checkmark$ & $\checkmark$ & $\checkmark$ \\
\hline \multicolumn{7}{|l|}{ Personal Injury } \\
\hline Fatal & & & & & & \\
\hline
\end{tabular}




\section{CHAPTER 6. CONCLUSIONS AND RECOMMENDATIONS}

\section{1. $\quad$ Summary of Results}

A total of 19 intersections were selected and analyzed to show the effects of minimally warranted signal installation. Of these 19 intersections, seven signals are located adjacent to school zones. For each intersection, crash data was obtained for up to five years before and five years after signal installation. Installation year was not included in the analysis so that any crashes associated with the construction work zone would not bias the data. This data was adjusted for Exposure to Risk to account for changes in average daily traffic and the varying number of before and after data years. Data was evaluated at three different study areas, 200 feet, 500 feet, and 1000 feet from the intersections. Crash data was also categorized by type and severity. From this data, negative binomial tests were used to determine if there were any significant changes due to signal installation. The first test was used to evaluate any significant safety improvements while the second test evaluated significant safety degradation. These tests were used for each of the 19 intersections and then only for the seven school zone intersections.

Results of the tests on all of the 19 intersections show that there was a significant safety improvement for the crash types 'Right Angle' and 'Right Turn'. There was also significant safety degradation for the crash types 'Rear End, Neither Turning', 'Head On, Neither Turning' (for 200 feet and 500 feet only), 'Off Road Collision', 'Left Turn', and 'Other/Unknown' (for 500 feet and 1000 feet only). Crash severity 'Personal Injury' was also found to be significant for degradation.

Tests on the seven intersections at school zones resulted in no significant safety improvements. 'Head On, Neither Turning', 'Left Turn', 'Total', and 'Property Damage' were found to have significant safety degradation. 'Rear End, Neither Turning' was found to be significant for degradation at 200 feet and 'Off Road Collision' was found to be significant for degradation at distances of 500 feet and 1000 feet.

These results do not indicate that it is beneficial to install traffic signals in school zones when the warrants defined by the Manual on Uniform Traffic Control Devices have not been met. In fact, 
they suggest that for intersections not meeting the warrants, traffic signals should not be installed. Based upon these findings, it is recommended that the Indiana Department of Transportation continue following nationally prescribed warrants for determining when a traffic signal should be installed.

\section{2. $\quad$ Traffic Signal Alternatives}

During the research, three school zones were identified for further study. The following schools have requested signal installation at adjacent intersections.

- Kanakakee Valley High School in Wheatfield, Indiana,

- Northview High School in Brazil, Indiana,

- Delphi Community High School in Delphi, Indiana

\subsubsection{Kankakee Valley High School}

Kankakee Valley High School is located in Wheatfield, Indiana at the intersection of SR-10 and CR-400W. This intersection is two-way stop controlled with a flashing beacon. There are approximately 1800 students and 200 faculty and staff. Of the 1800 students, there are an estimated number of 150 student drivers. Along with the student and staff drivers, there are 2030 school buses that service the high school and adjacent middle school.

As noted in Chapter 2, the intersection at Kankakee Valley High School did not meet any of minimum requirements of the traffic warrants. After multiple requests for signal installation, INDOT had recommended alternative methods of traffic control. This included the use of an 'Advance School Flasher' warning signs at the school's expense. The school corporation has implemented these alternatives. 


\subsubsection{Northview High School}

This school is located in Brazil, Indiana at the intersection of SR-340 and Kennedy's Crossing Road. The intersection is controlled with a one-way stop on Kennedy's Crossing Rd. The school currently has approximately 1,300 staff and students. There is also a middle school next to the high school which is connected by an interior road, seen in Figure 6-1. For these two schools, there are 28 school buses servicing the students. Along with school buses, there are approximately 400 student drivers.

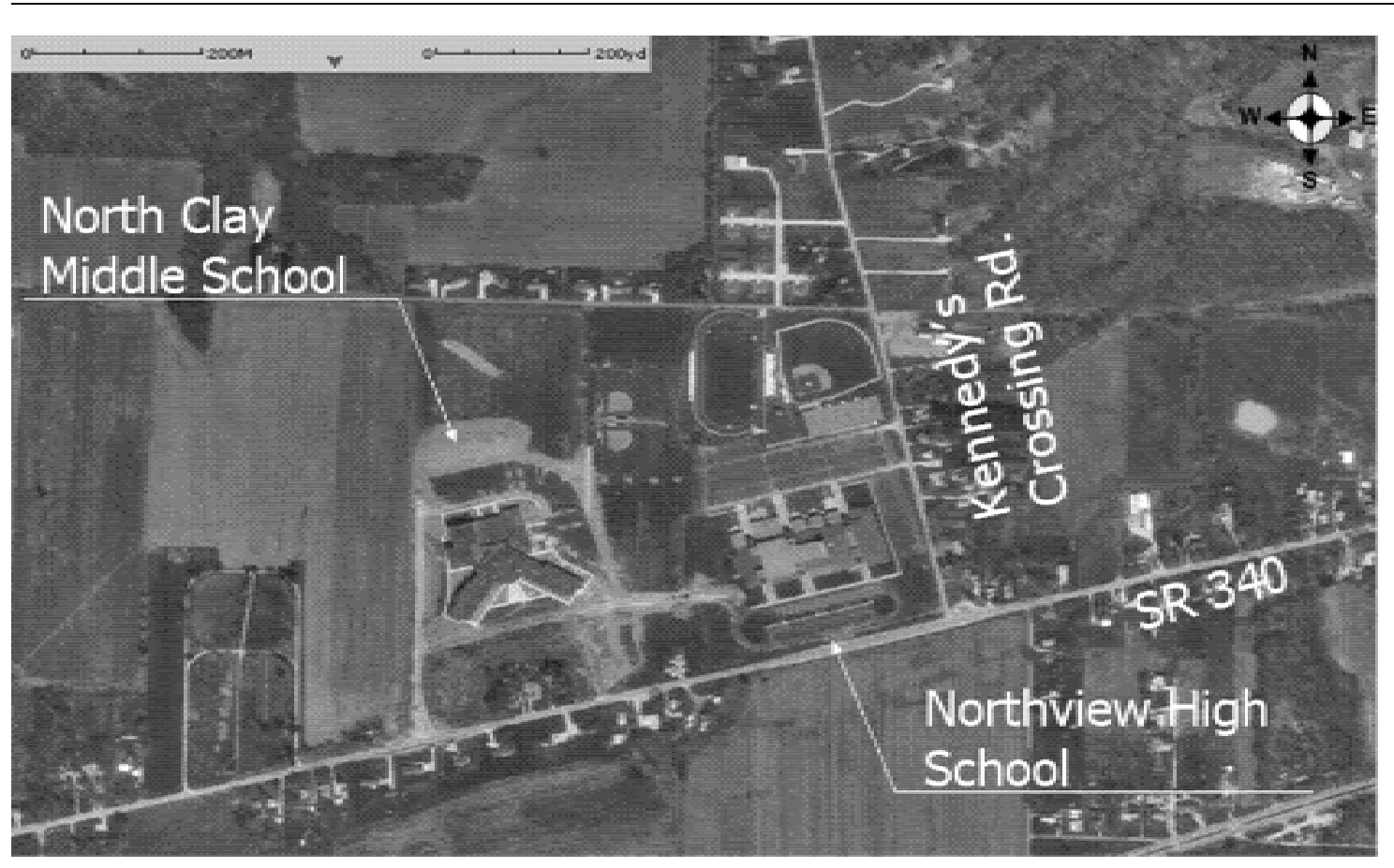

Figure 6-1: Aerial view of Clay County schools in Brazil, Indiana.

Northview High School has also requested and been denied for signal installation at the adjacent intersection. At the time of dismissal, there is an increase of vehicular volume. Since INDOT did not install a traffic signal, the Transportation Department for Clay County Schools began in April 2000 to use a reserve police officer to direct traffic flows. It has been documented that there had been seven crashes in 1998, six crashes in 1999, and three crashes in 2000 . Since the police officer began directing traffic, there have not been any reported crashes at the intersection. There is an officer at the intersection each school day and when he is not able to be there, the Director of Transportation for Clay County Schools, Frank Misner has substituted. Currently, the 
school corporation pays for the officer's salary of $\$ 10,000$ per year, but is concerned that there will not be sufficient funds to continue the use of the reserve police officer. The school corporation continues to request signal installation.

\subsubsection{Delphi Community High School}

Delphi Community High School is located in Delphi, Indiana at the intersection of US-421 and Armory Road. The intersection is controlled by a two-way stop sign and a flashing beacon as seen in Figure 6-2. Approach speeds are posted at $35 \mathrm{mph}$ with no school zone warning signs. Current enrollment is $\mathbf{5 0 0}$ students with 70 faculty and staff. Traffic volumes include approximately 20 school buses and 150 student drivers.

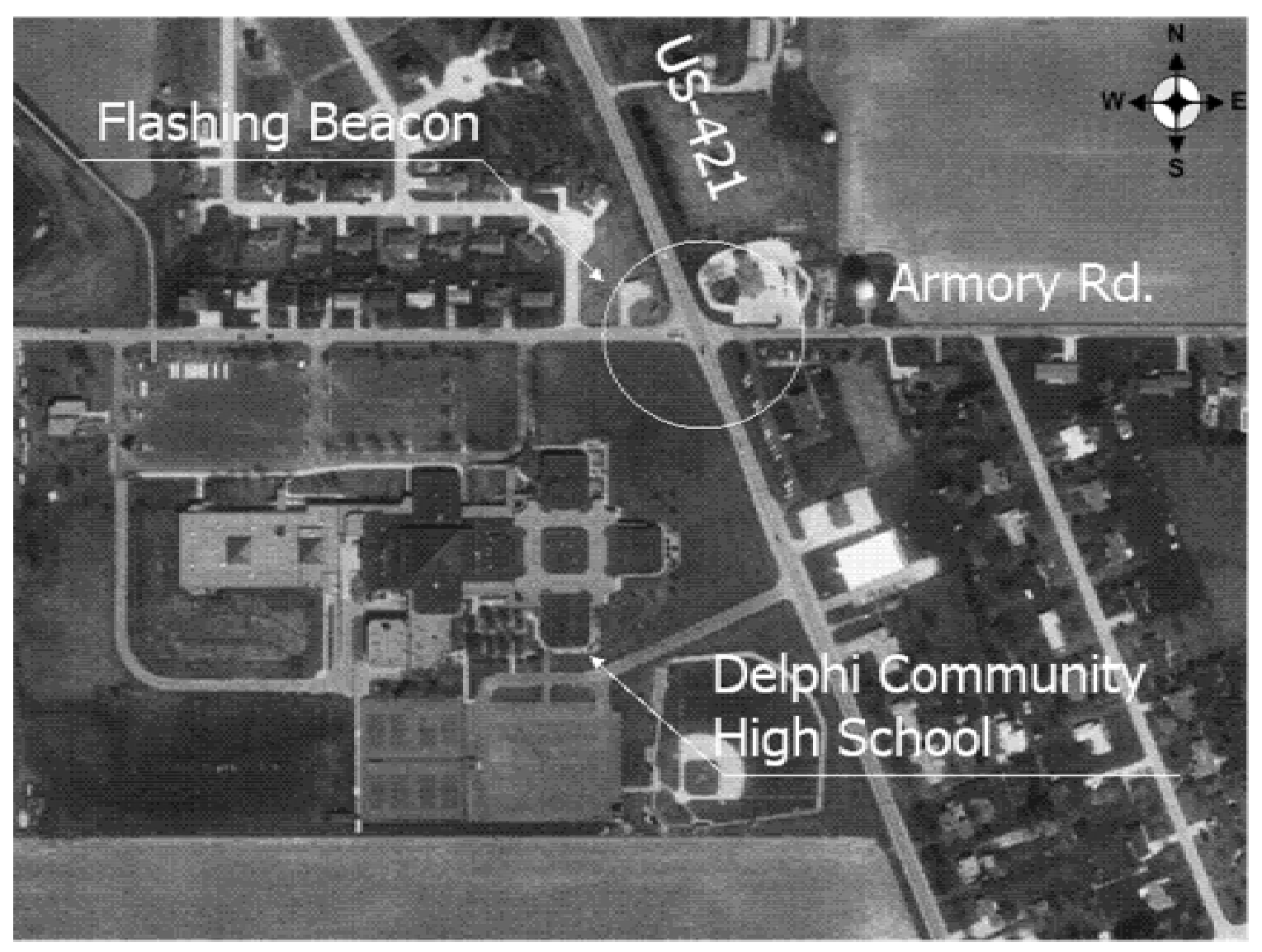

Figure 6-2: Aerial view of Delphi Community High School in Delphi, Indiana. 
Over the past ten years, there have been multiple requests for signal installation at the intersection. INDOT has denied their requests, citing that the vehicular volume does not meet minimum requirements for traffic signal warrants. In response to these denials, city and county police officers have volunteered to direct traffic at the intersection. Observations show that there is a staggered time when the students and school buses leave. The students leave shortly after dismissal and the school buses wait until the police officer comes and directs traffic. This began in 1999 with city police officers coming to the intersection during afternoon dismissal. At first, police participation was low, but increased when the county police office took control of the responsibility. Currently the Carroll County Sheriff, Denny Randle, arrives during the afternoon dismissal time and directs traffic. According to the Delphi Community High School principal, Bob Handlin, there has been an officer at the intersection close to $99 \%$ of the time. The only times when there no officer directing traffic is during early dismissal times and when the officer is called away on police duty. The police department did not want school employees to direct traffic if an officer does not arrive at the intersection. This duty is on a volunteer basis and officers are not paid with incentives. When an officer is not present, bus drivers use an alternative route taking them away from US-421 and utilizing local streets. The school corporation continues to request for signal installation.

\section{3. $\quad$ Future Work}

Although this study found that the installation of traffic signals at minimally warranted signals would not improve safety, there is still a need to find other methods of traffic control. Based upon anecdotal reports, one of the most effect procedures appears to be the use of law enforcement personnel to direct traffic during peak periods. Further work should be undertaken defining procedures, policies, and funding alternatives for school districts to follow should they choose to have traffic manually controlled during peak periods. 


\section{LIST OF REFERENCES}

Aggarawal, G.C., Mortensen, S.L. "Do Advance School Flashers Reduce Speed?" ITE Journal. October, 1993: 24-30.

Dobersek, M.M. "Validity of Peak-Hour Traffic Signal Warrants". Marquette University, 1992.

Hawkins, H.G., Carlson, P.J. "Evaluation of Potential Traffic Signal Warrant Considerations".

Report Number 3991-1, Texas Transportation Institute, The Texas A\&M University System, 1998.

Hawkins, H.G., Carlson, P.J. "Traffic Signal Warrants, Guidelines for Conducting a Traffic Signal Warrant Analysis". Report Number 3991-2, Texas Transportation Institute, The Texas A\&M University System, 1998.

Grote, J. "Phoenix Plans for Walking to School" City of Phoenix Street Transportation Department, Purdue University Road School March 2002

Henry, R.D., Calhoun, J.H.L., Pfefer, R.C., Seyfried, R.K. "Peak-Hour Traffic Signal Warrant". NCHRP Report, September, 1982.

Institute of Transportation Engineers. Design and Safety of Pedestrian Facilities. Washington D.C. 1998.

"Manual on Uniform Traffic Control Devices" (MUTCD), Federal Highway Administration, U.S. Department of Transportation, 2000 edition

McCoy, P.T., Heimann, J.E. "School Speed Limits and Speeds in School Zones". Transportation Research Record. 1254. 1990: 1-7.

Reiss, M.L., Robertson, H.D. "Driver Perception of School Traffic Control Devices".

Transportation Research Record. 600. 1976: 36-39.

Robertson, H.D. "The Application of Pedestrian Signals at Traffic Signalized Intersections". Public Roads, December, 1984: 81-87.

Rosenbaum, M.J., Young, P., Byington, S.R., Basham, W. "Speed Control in Rural School Zones". Transportation Research Record. 541. 1975: 12-25.

Rust, L. "Traffic Signal Warrants in the 1982 Indiana Manual". Engineering Bulletin of Purdue University, 1982: 145-147.

Saibel, C., Salzberg, P., Doane, R., Moffat, J. "Vehicle Speeds in School Zones”. ITE Journal. November, 1999: 38-42.

Schrader, M.H. "Study of Effectiveness of Selected School Zone Traffic Control Devices". Transportation Research Record. 1692. 1999: 24-29. 
Texas Department of Transportation. "Precious Cargo”. Brochure 1999.

Todd, K. "Traffic Signal Warrants: The Controversy That Never Ends". American City and County, December, 1982: 25-27.

Trinkaus, J. "Compliance With a School Zone Speed Limit: Another Look". Perceptual and Motor Skills, October, 1998: 673-674.

Turner, S.M., Carlson, P.J. "Pedestrian Crossing Guidelines for Texas". Report Number 2136-2, Texas Transportation Institute, The Texas A\&M University System, 2000.

Williams, J.C., Ardekan, S.A. "Impacts of Traffic Signal Installation at Marginally Warranted Intersection". Report Number 1350-1F, Texas Department of Transportation, 1996. 
APPENDIX 


\section{APPENDIX A. CRASH TYPE DEFINITIONS}

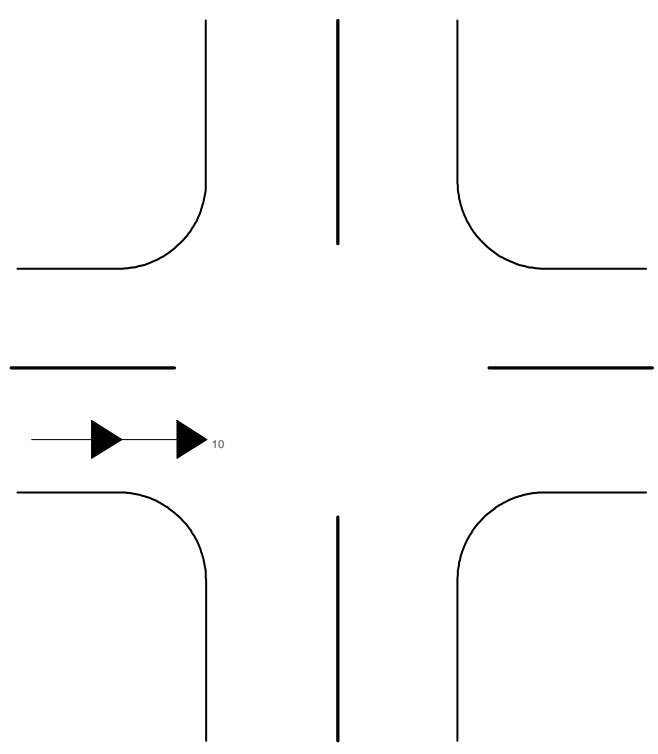

Figure A-1:

'Rear End, Neither Turning' - These crashes are characterized when one vehicle collides with another from behind as seen. 


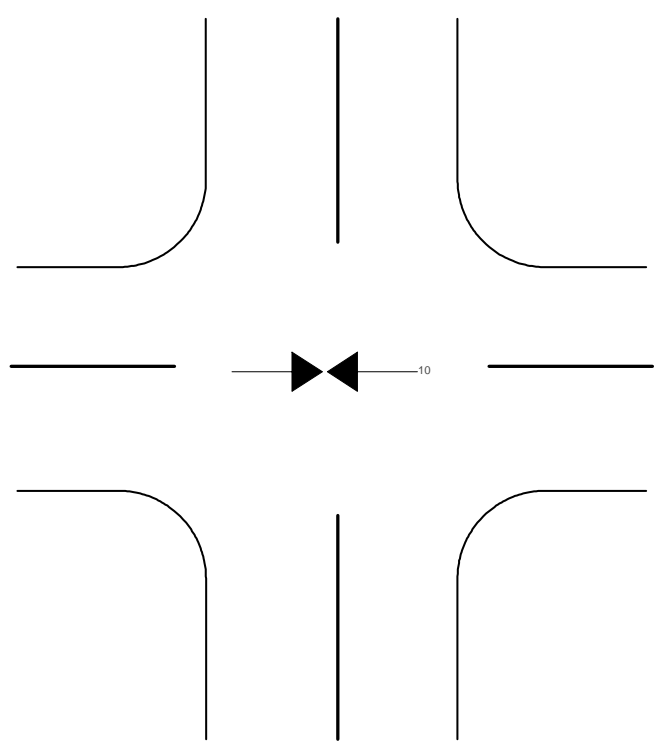

Figure A-2:

'Head On, Neither Turning' - These crashes involve vehicles traveling in opposite directions and colliding with each other head on. This crash occurs when one vehicle crosses the median into the other lane.

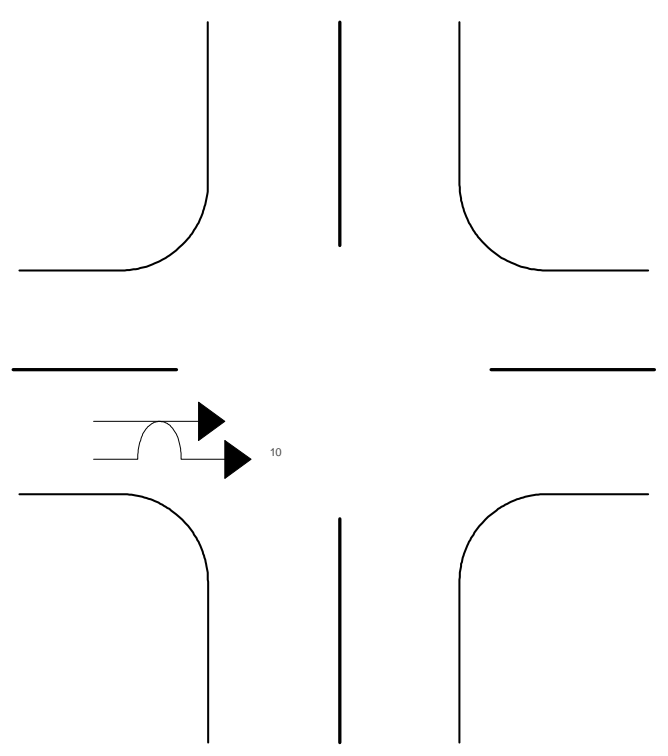

Figure A-3:

'Same Direction Sideswipe' - These crashes occur when a vehicle attempts to pass another vehicle. There are two typical situations, when a vehicle tries to pass a turning vehicle, or when a vehicle crosses into the adjacent lane. 


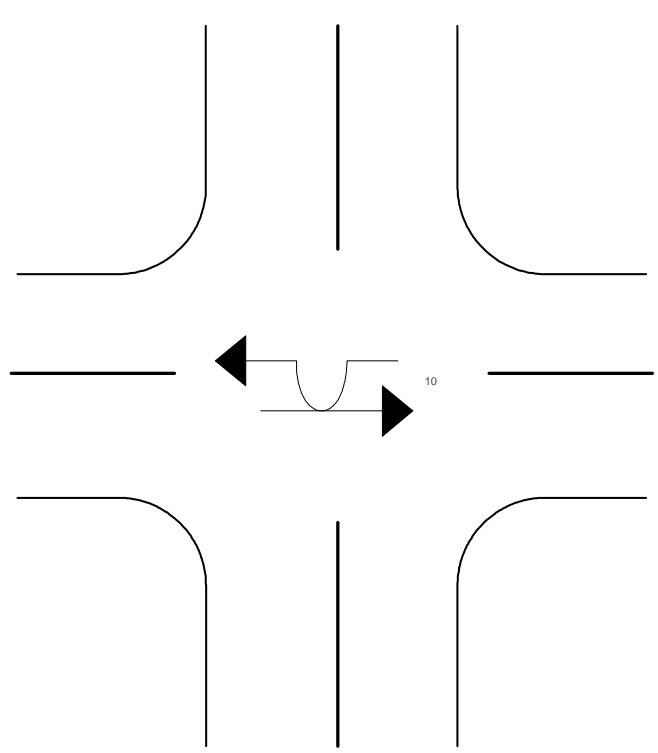

Figure A-4:

'Opposite Direction Sideswipe' - Crashes are categorized as 'Opposite Direction Sideswipe' when a vehicles traveling in opposite directions collide. These crashes are similar to 'Head On, Neither Turning', but the collision point is different.

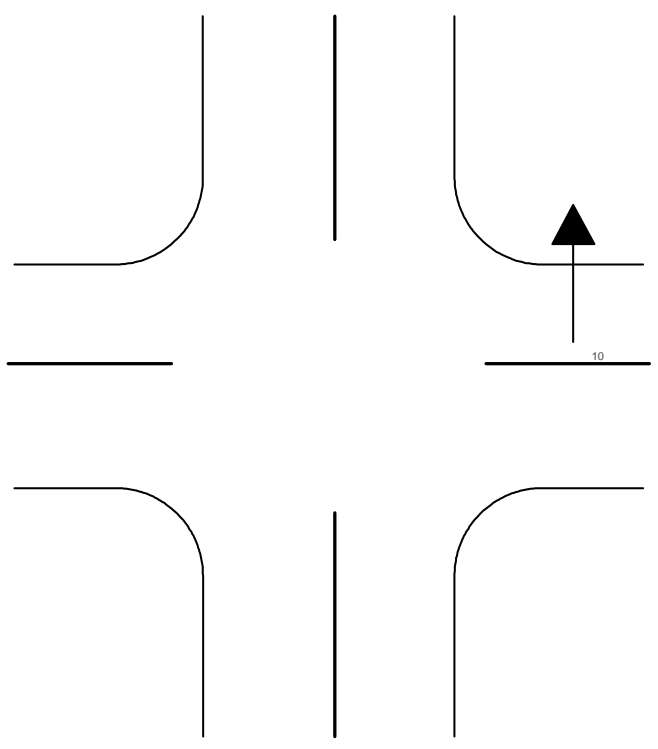

Figure A-5:

'Off Road Collision' -These crashes occur when a vehicle is avoiding something on the roadway, or the driver loses control of the vehicle. 


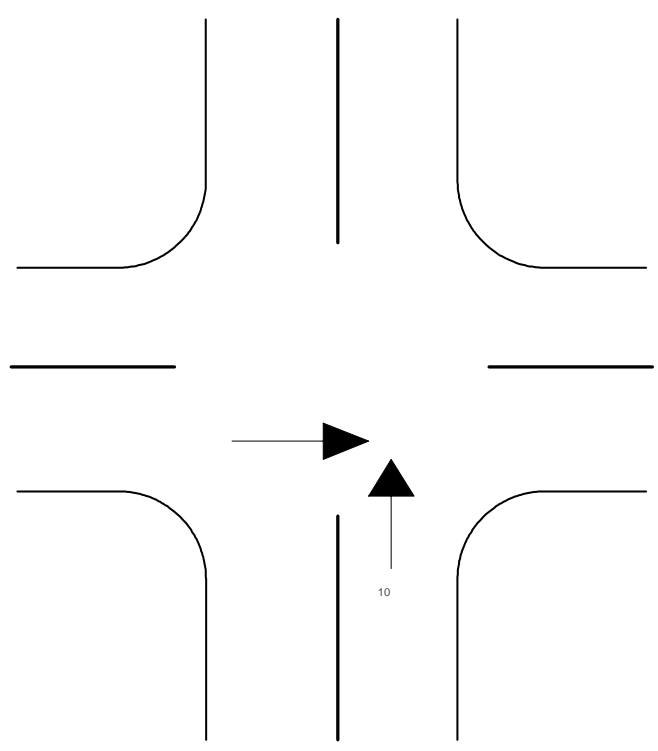

Figure A-6:

'Right Angle' - This category involves accidents where vehicles are typically crossing a roadway, but does not judge the gap correctly and is hit by the oncoming vehicle. 


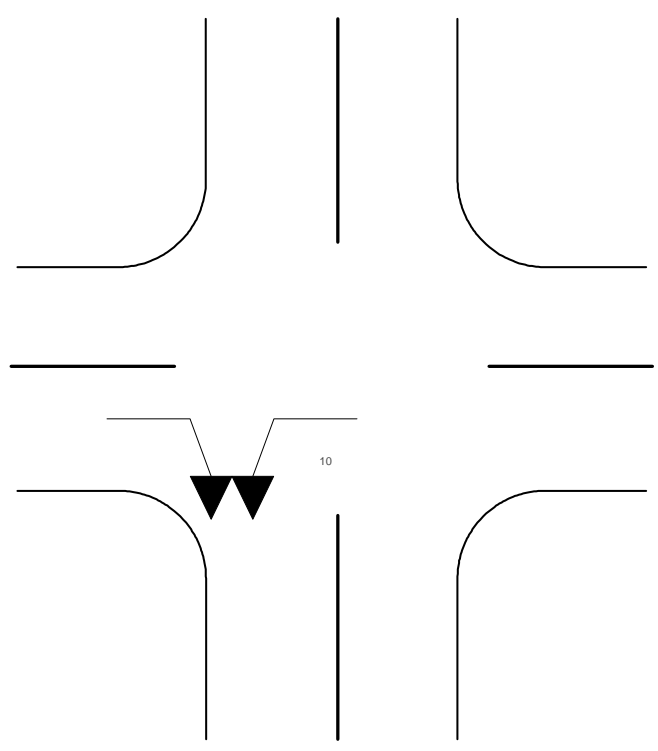

Figure A-7:

'Left and Right Turns' - These crashes occur when a vehicle is turning right and another vehicle turning left. This can occur if either vehicle becomes hasty and does not allow for enough distance for the vehicle to complete their turn.

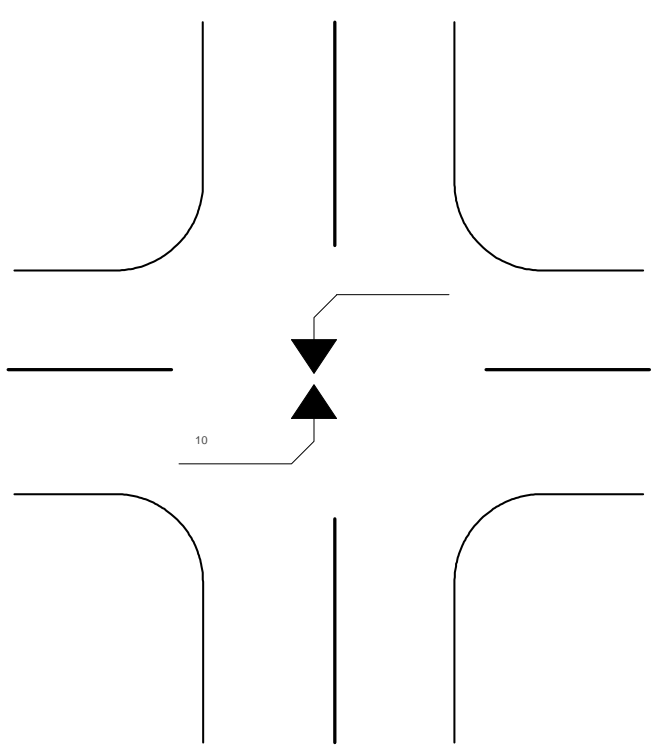

Figure A-8:

'Left Turn' - This is a crash diagram of one example of a 'Left Turn' that shows a crash with two vehicles that are turning left at the same time. 


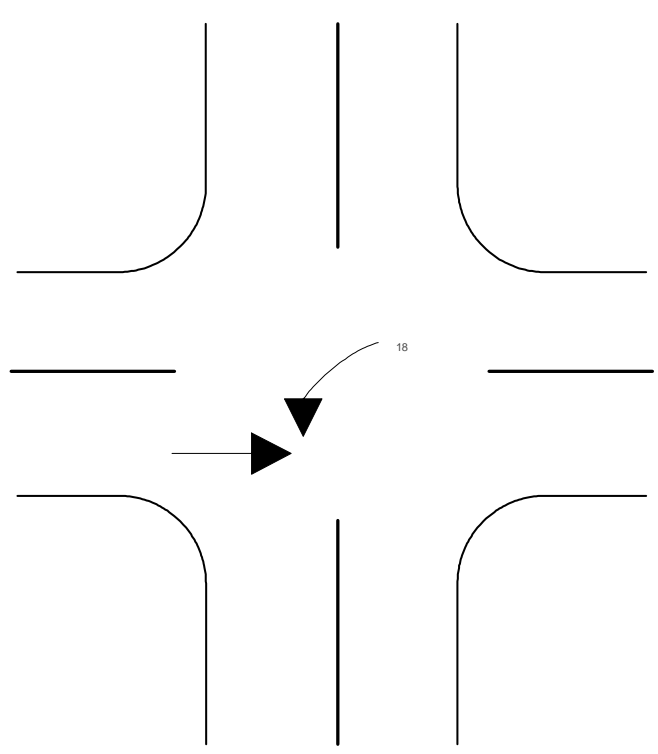

Figure A-9:

'Left Turn' - This is a crash diagram of another example of a 'Left Turn' that occurs when a vehicle turns left in front of an oncoming vehicle. 


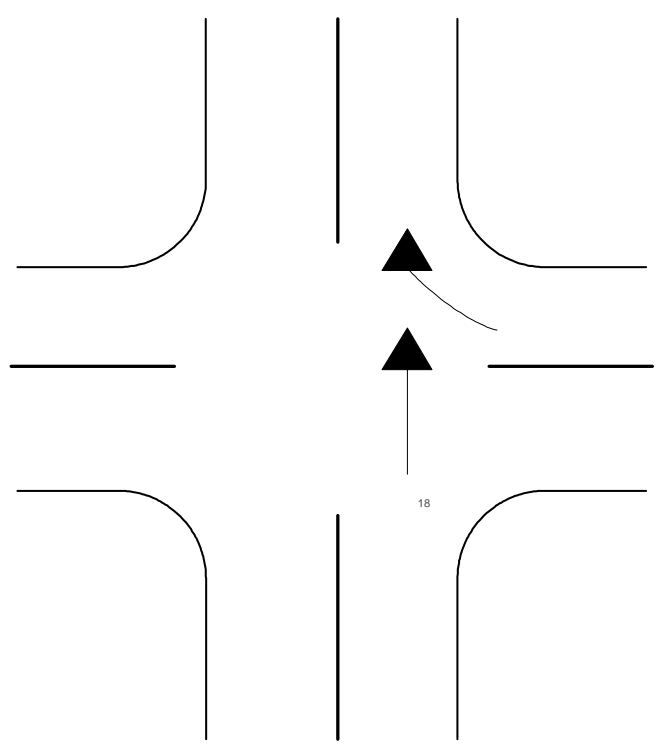

Figure A-10:

'Right Turn' - Crashes are categorized 'Right Turn' when the cause of the crash is a result of one of the vehicles is turning right. A typical scenario for this type of crash occurs when a vehicle turns right in front of an oncoming vehicle. Another typical situation for this type of crash is when a vehicle slows down to turn right and the vehicle behind it collides into the vehicle ahead.

'Other/Unknown' - These crashes are due to the lack of information within police crash reports. A crash could be put into this category if a police officer does not provide the information, or if there are external reasons causing the crash. 